Prepared in cooperation with Colorado State University and the National Park Service

\title{
Development of an Aerial Population Survey Method for Elk (Cervus elaphus) in Rocky Mountain National Park, Colorado
}

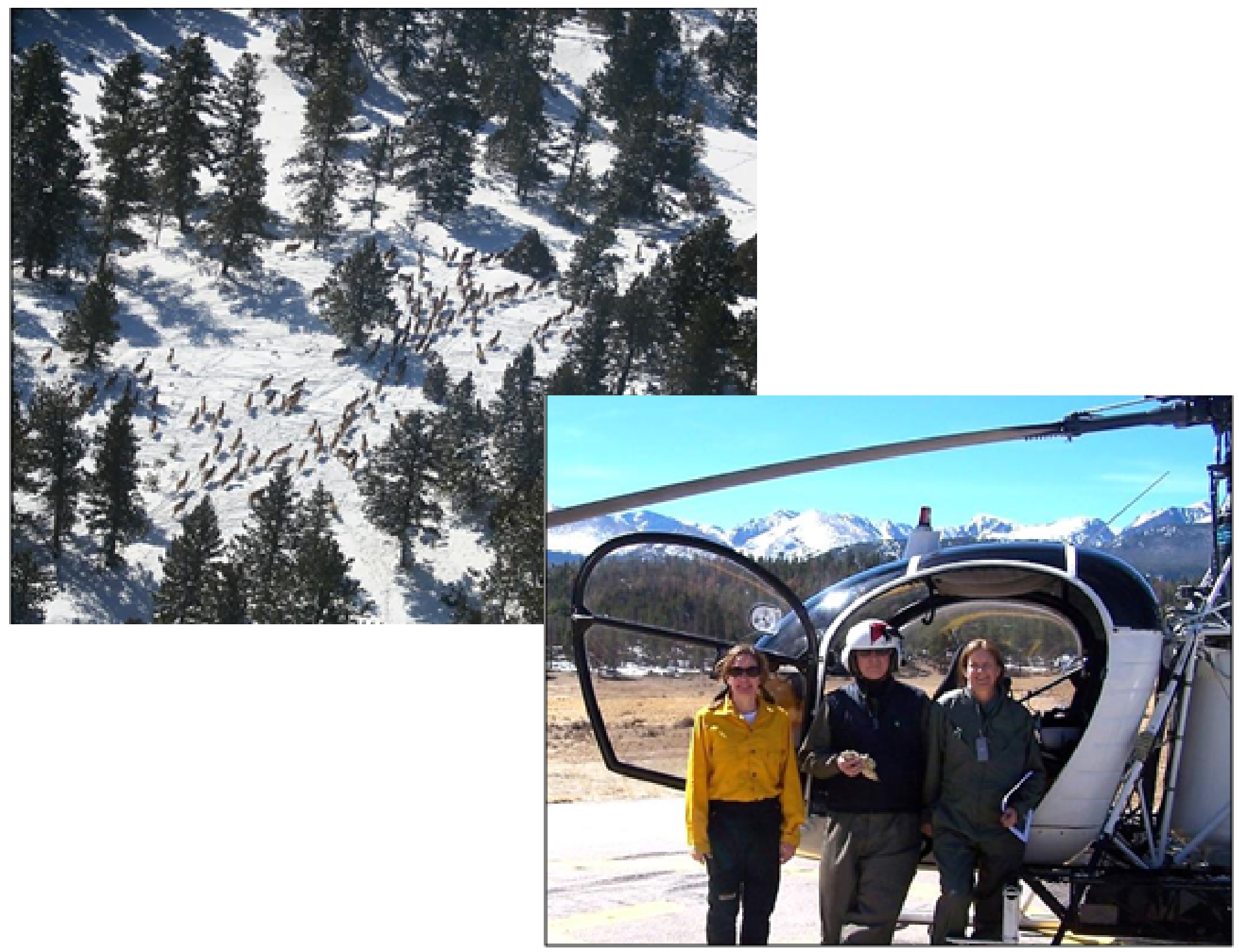

Open-File Report 2018-1085

U.S. Department of the Interior

U.S. Geological Survey 
Cover. Left: Elk group observed from helicopter. Photograph by K.A. Schoenecker, USGS. Right: Observers and pilot. Photograph by K.A. Schoenecker, USGS. 


\section{Development of an Aerial Population Survey Method for Elk (Cervus elaphus) in Rocky Mountain National Park, Colorado}

By Kathryn A. Schoenecker, Bruce C. Lubow, and Therese L. Johnson

Prepared in cooperation with Colorado State University and the National Park Service

Open-File Report 2018-1085 


\section{U.S. Department of the Interior \\ RYAN K. ZINKE, Secretary}

\section{U.S. Geological Survey James F. Reilly II, Director}

\section{U.S. Geological Survey, Reston, Virginia: 2018}

For more information on the USGS - the Federal source for science about the Earth, its natural and living resources, natural hazards, and the environment-visit https://www.usgs.gov or call 1-888-ASK-USGS.

For an overview of USGS information products, including maps, imagery, and publications, visit https://store.usgs.gov.

Any use of trade, firm, or product names is for descriptive purposes only and does not imply endorsement by the U.S. Government.

Although this information product, for the most part, is in the public domain, it also may contain copyrighted materials as noted in the text. Permission to reproduce copyrighted items must be secured from the copyright owner.

Suggested citation:

Schoenecker, K.A., Lubow, B.C., and Johnson, T.L., 2018, Development of an aerial population survey method for elk (Cervus elaphus) in Rocky Mountain National Park, Colorado: U.S. Geological Survey Open-File Report 2018-1085, 45 p., https://doi.org/10.3133/ofr20181085.

ISSN 2331-1258 (online) 


\section{Acknowledgments}

We thank volunteer aerial observers Sheri Huwer (Colorado Parks and Wildlife), Jason Ransom (National Park Service [NPS]), and Zac Wiebe (Larimer County Parks and Recreation). Thanks to NPS helicopter managers Craig Brower, Mark DeGregorio, and Patti Shafer; and our pilots Jim Hennessey (TransAero), Dave Stinson (Sky Aviation), and Lanny Coulter (Coulter Aviation). We thank the NPS elk ground darting and capture crew, who made the radio-collar work possible: Dan Baker, Scott Esser, Ryan Monello, Jenny Powers, Scott Ratchford, Lindsay Reynolds, Mary Kay Watry, Margaret Wild, and NPS volunteer Fred Renner. We are grateful for logistical and overall project support from John Mack and Judy Visty, NPS, and Colorado State University. This project was funded by the U.S. Geological Survey Natural Resources Preservation Program, Washington, D.C., with additional funding from the Rocky Mountain National Park Resources Management program.

\section{Contents}

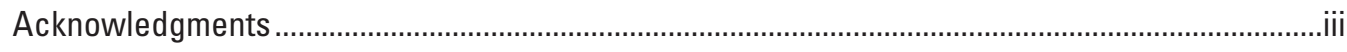

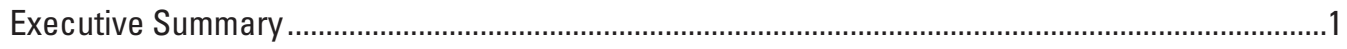

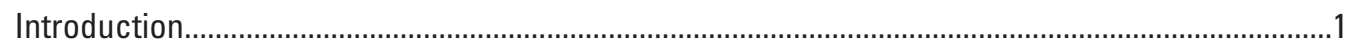

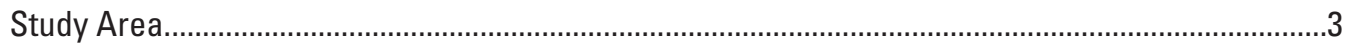

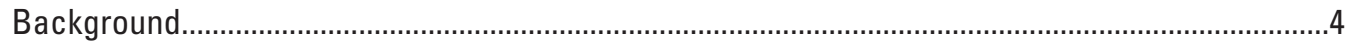

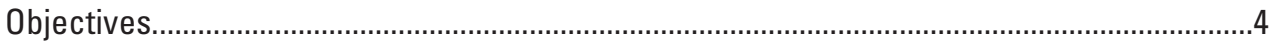

Part 1. Developing the Survey Design ........................................................................................5

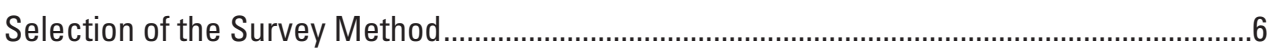

Sightability Correction Model .......................................................................................6

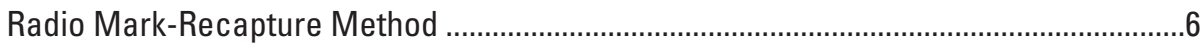

Simultaneous Double-Observer Method ............................................................................6

Line-Transect or Distance Sampling ...............................................................................

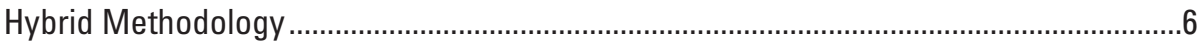

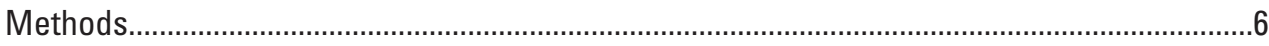

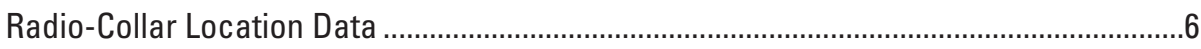

Very High Frequency Telemetry ........................................................................

Global Positioning System Telemetry ..................................................................8

Geographic Information System Analysis ..........................................................8

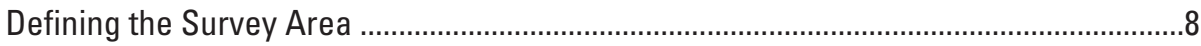

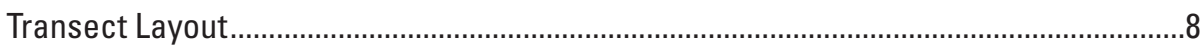

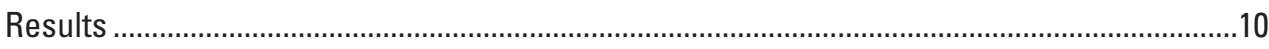

Survey Area Boundary Results ...............................................................................

Transect Layout Results.......................................................................................................10

Spatial and Temporal Variation of Elk Use of the Park ......................................................12

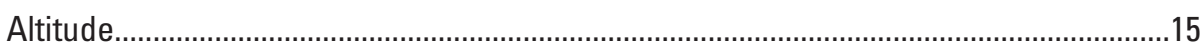

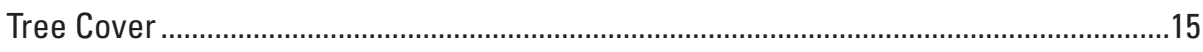

Bull Elk Locations on Aerial Survey Days .....................................................................19

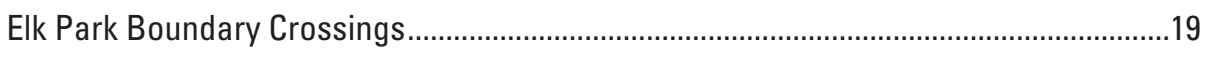


Part 2. Implementing and Testing the Survey Design..................................................................

Using a Hybrid Double-Observer Model with Sighting Covariates to Estimate the Elk Population in Rocky Mountain National Park, 2008-2011 ...........................................22

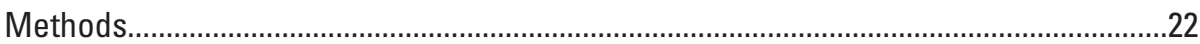

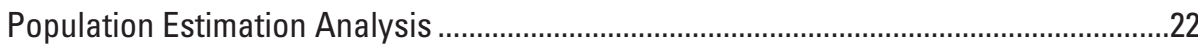

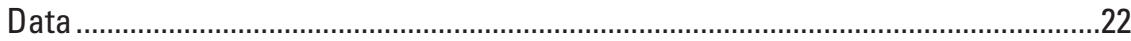

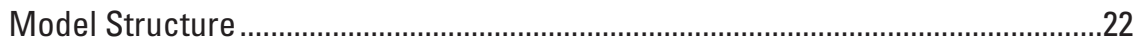

Model Fitting and Selection ..................................................................................2

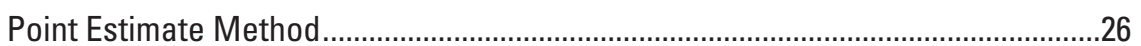

Estimating Variance in Abundance Estimates with Bootstrapping ..........................26

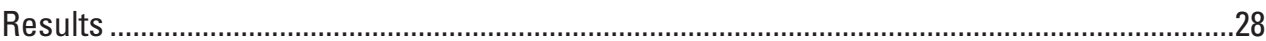

Model Fitting and Support............................................................................................28

Population Estimates and Precision ..............................................................................29

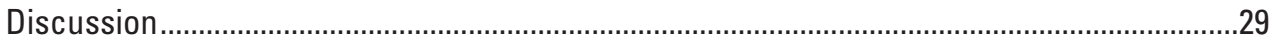

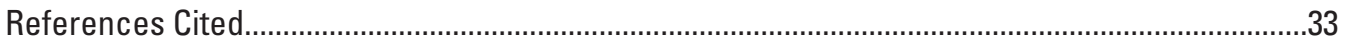

Appendix 1. Description of Aerial Survey Methods Considered for Elk Surveys in Rocky Mountain National Park, Colorado ....................................................................................36

Radio (Known-Fates) Mark-Recapture Method ........................................................................36

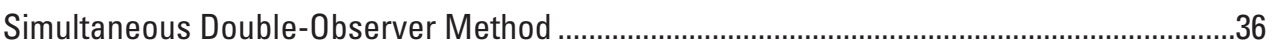

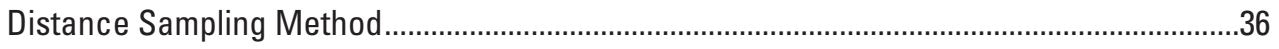

Sightability Bias Correction Method ….................................................................................

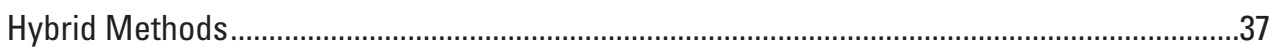

Appendix 2. Discussion of Considerations for Aerial Work in Rocky Mountain National

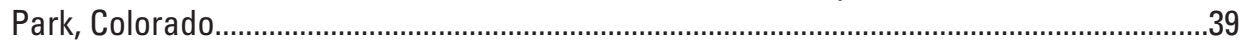

Appendix 3. Instructional Protocols and Datasheets for Simultaneous Double-Observer Aerial Surveys in Rocky Mountain National Park, Colorado .................................................41

Field Protocols for Simultaneous Double-Observer Aerial Elk Surveys ....................................41 


\section{Figures}

1. Elk population estimates for Rocky Mountain National Park, Colorado, 2000-2005 .........2

2. The general elk winter range in Rocky Mountain National Park and the Estes Valley, Colorado .3

3. Modified bull elk radio collars showing expandable section developed by T. Johnson for elk population study in Rocky Mountain National Park, Colorado, 2008-2011. 9

4. Final survey area boundary, showing key elk habitat elevation contours of 2,800 meters and 3,300 meters in Rocky Mountain National Park, Colorado . .10

5. Final north and south aerial survey routes for Rocky Mountain National Park elk surveys

6. Percent of winter very high frequency collar locations east of the Continental Divide that were inside Rocky Mountain National Park, Colorado, by month and year.

7. Percent of winter global positioning system bull collar locations inside Rocky Mountain National Park (RMNP), Colorado, by month of the study, 2008-2011.

8. Winter elk telemetry locations from multiple sources in Rocky Mountain National Park, Colorado

9. Winter altitude distribution of elk locations in elk population study in Rocky Mountain National Park, Colorado, 2008-2011

10. Use of dense cover by bull elk wearing global positioning system collars within Rocky Mountain National Park, Colorado, by month of the study, 2008-2011.

11. Use of dense tree cover by global positioning system-collared bull elk during the winter period by hour of the day in Rocky Mountain National Park, Colorado, 2008-2011.

12. Locations of radio-collared bull elk during aerial helicopter surveys in Rocky Mountain National Park, Colorado, 2008-2011

13. Distribution of elk groups by group size in Rocky Mountain National Park, Colorado, elk population estimation study, 2008-2011, demonstrating the tendency toward larger groups in winter.

14. Distribution of elk groups by major sighting characteristics, percent vegetation cover and percent snow cover, in elk population study in Rocky Mountain National Park, Colorado, 2008-2011

15. Distribution of sighting probabilities for combined front and rear observers for all elk groups marked with radio collars, illustrating how groups varied widely in visibility

16. Sighting probability for combined front and rear observers, using rear observer with highest sighting probability, for elk population estimation study in Rocky Mountain National Park, 2008-2011.

17. Sighting probability for combined front and rear observers, using rear observer with lowest sighting probability, for elk population estimation study in Rocky Mountain National Park, 2008-2011. 


\section{Tables}

1. Dataset description, source, and how the information was used in our analysis to develop an improved aerial survey method for estimating the elk population in Rocky Mountain National Park, Colorado, 2008-2011

2. Summary of global positioning system telemetry data collection showing deployment and collection date of each bull collar in study of elk population in Rocky Mountain National Park, Colorado, 2008-2011

3. Altitude distribution of winter elk locations reported in different datasets and studies

4. Distribution of winter bull elk global positioning system locations by cover class and vegetation type in study of elk population in Rocky Mountain National Park, Colorado, 2008-2011

5. Covariates and corresponding model coefficients for each unique elk group used in the population estimation model for elk in Rocky Mountain National Park, Colorado, 2008-2011

6. Sightability model alternatives with fit and selection statistics for elk population estimation study in Rocky Mountain National Park, Colorado, 2008-2011

7. Sightability model parameters and model weighted average estimates for elk population estimation study in Rocky Mountain National Park, Colorado, 2008-2011 ...28

8. Elk population estimates and precision, comparing analyses with and without radio-collar data, for elk population estimation study in Rocky Mountain National Park, 2008-2011 


\section{Conversion Factors}

U.S. customary units to International System of Units

\begin{tabular}{lcc}
\hline Multiply & By & To obtain \\
\hline foot $(\mathrm{ft})$ & Length & meter $(\mathrm{m})$ \\
\hline & 0.3048 & \\
mile per hour $(\mathrm{mi} / \mathrm{h})$ & Flow rate & kilometer per hour $(\mathrm{km} / \mathrm{h})$ \\
\hline
\end{tabular}

International System of Units to U.S. customary units

\begin{tabular}{lcl}
\hline \multicolumn{1}{c}{ Multiply } & By & \multicolumn{1}{c}{ To obtain } \\
\hline centimeter $(\mathrm{cm})$ & Length & \\
meter $(\mathrm{m})$ & 0.3937 & inch (in.) \\
& 3.281 & foot $(\mathrm{ft})$ \\
\hline hectare $(\mathrm{ha})$ & Area & acre \\
\hline & 2.471 & \\
\hline kilometer per hour $(\mathrm{km} / \mathrm{h})$ & Flow rate & mile per hour $(\mathrm{mi} / \mathrm{h})$ \\
\hline
\end{tabular}

\section{Datum}

Altitude, as used in this report, refers to distance above the vertical datum.

\section{Abbreviations}

$\begin{array}{ll}> & \text { greater than } \\ < & \text { less than } \\ \leq & \text { less than or equal to } \\ \text { AIC } & \text { Akaike information criterion } \\ \text { CV } & \text { coefficient of variation } \\ \text { GPS } & \text { global positioning system } \\ \text { NPS } & \text { National Park Service } \\ \text { RMNP } & \text { Rocky Mountain National Park } \\ \text { USGS } & \text { U.S. Geological Survey } \\ \text { VHF } & \text { very high frequency }\end{array}$





\title{
Development of an Aerial Population Survey Method for Elk (Cervus elaphus) in Rocky Mountain National Park, Colorado
}

\author{
By Kathryn A. Schoenecker, ${ }^{1}$ Bruce C. Lubow, ${ }^{2}$ and Therese L. Johnson ${ }^{3}$
}

\section{Executive Summary}

Since the early 1990s, substantial effort and funding have been expended to conduct research to guide development of a 20-year Elk and Vegetation Management Plan for Rocky Mountain National Park (RMNP) in Colorado. One goal of the plan is to maintain the elk (Cervus elaphus) population size at the lower end of the natural range of variation. To implement management actions called for in the plan, accurate and reliable population estimates are needed, as well as a better understanding of the spatial and temporal distribution of elk. The previous aerial survey protocol and population estimation model used by the park had not been updated since the model's initial calibration more than 15 years ago and the model was developed with an insufficient number $(n=44)$ of observations. Thus we initiated research to reevaluate, update, and improve elk population estimation protocols for RMNP.

We considered several alternative survey and analysis methods, and concluded that a hybrid population-estimation model using a simultaneous double-observer technique with sighting covariates was the most appropriate and effective aerial survey methodology for this population and the environmental conditions in RMNP. Instructional protocols for conducting these surveys in the future, along with datasheets, are provided in this report's appendixes.

To develop an improved method for aerial elk surveys, we used elk radio-collar location data from our study and other studies, and applied geographic information system analyses to define the survey area and develop effective, repeatable survey transect lines. We used telemetry data from radio-collared elk to inform our understanding of the temporal and spatial scale of elk movements across the park boundary, elk use of tree cover during potential survey hours, and elk use of different elevations within their range. Determining where elk were during surveys helped to fine-tune a survey design that improved spatial coverage and decreased costs where possible, while standardizing the method to make it repeatable from year to year. We conducted aerial helicopter surveys to test our methodology in an adaptive, iterative process during three winters: 2007-2008, 2008-2009, and 2009-2010. We gained new information on each survey and used results to refine subsequent surveys.

Our results confirm that elk movements were highly dynamic with respect to park boundary crossings; an average of six round trips from the park to Estes Park, Colorado, and back per month were taken by global positioning systemcollared bull elk. We observed a strong diurnal temporal pattern of bull elk use of trees; elk were found in dense tree cover from 15:00-22:00 but not as often during morning and early afternoon hours when surveys were conducted. We used information on elk use of different altitudes to refine and establish a more efficient survey area.

During the time of our study, a concurrent study in the park deployed 120 very high frequency radio collars on elk cows. We used those collar locations during our flights to increase sample size and to evaluate the level of precision we would gain by using "known fates analysis" (in which elk were known to be in the survey area, out of the survey area, or deceased based on radio-collar locations collected simultaneously during aerial surveys). Using radio-collar locations reduced bias by 1.1-8.8 percent and increased precision (that is, reduced the width of confidence intervals). This report provides final population estimates analyzed with and without radio-collar data to demonstrate what is gained by using marked individuals.

\section{Introduction}

Public surveys have shown that wildlife viewing is extremely important to Rocky Mountain National Park (RMNP) visitors. Many visitors visit the park in autumn specifically to view elk (Cervus elaphus), as well as the fall colors provided by willow (Salix spp.) and aspen (Populus tremuloides). An important part of this experience is the opportunity to observe natural elk behavior and healthy

\footnotetext{
${ }^{1}$ U.S. Geological Survey

${ }^{2}$ Colorado State University

${ }^{3}$ National Park Service
} 
vegetation conditions. Visitors also visit the park to observe beaver and a large variety of bird and butterfly species that depend on aspen and willow. Management of elk and vegetation is a high priority in the park due to habitat damage from previous elk herbivory (Singer and Zeigenfuss, 2002) and potential other causes (Kacynski, 2013).

Beginning in the 1990s, substantial effort and funding were expended to conduct research and develop a 20 -year Elk and Vegetation Management Plan for the park (National Park Service, 2008). The goals of the plan are to maintain the elk population size near the lower end of the natural range of variation, and to restore vegetation, particularly in aspen and willow communities. A number of activities have been, and continue to be, implemented to address different aspects of the plan. The elk population size was reduced by culling, and temporary fences were built to begin restoration of vegetation by protecting aspen and willow from elk herbivory. The elk winter range extends over multiple jurisdictions, so park staff work in cooperation with personnel from Colorado Parks and Wildlife (formerly Colorado Division of Wildlife), which has management authority for elk beyond the park boundary.

In order to take the management actions called for in the plan, accurate and reliable population estimates are needed to guide elk population reductions. Inaccurate estimates of population size or an incomplete understanding of the spatialtemporal distribution patterns could result in unknowingly missing the target population levels, with potentially long-term herd or ecosystem impacts. Estimates of the number of elk wintering inside the park can shift by several hundred animals overnight; recent population estimates from sequential years have differed by as much as 100 percent and have been characterized by nonoverlapping confidence intervals despite no evidence of significant change in elk mortality or productivity (fig. 1). These differences are thought to be attributed to differences in elk distribution in winter in response to different foraging conditions and snow cover. Changes in elk distribution between the park and Estes Valley outside the park are a plausible explanation for the marked variation in estimates of population size, supported by both earlier movement (Bear, 1989; Larkins, 1997) and modeling (Lubow and others, 2002) studies. Thus, an improved understanding of the fluctuating elk distribution and updated elk population survey method were vital to guiding management under the new plan (National Park Service, 2008).

All wildlife survey techniques are based on a set of assumptions about how the data are collected. If the biology or behavior of the animals, the conditions in the field, the skills of the observers, or the technology of field methods lead to violations of assumptions, required accuracy will not be achieved, and results may appear to be precise when they are actually substantially biased, and management will have no indication that the survey is misleading. In conducting our study, we considered that survey methods must be implemented so that fundamental assumptions can be met in practice.

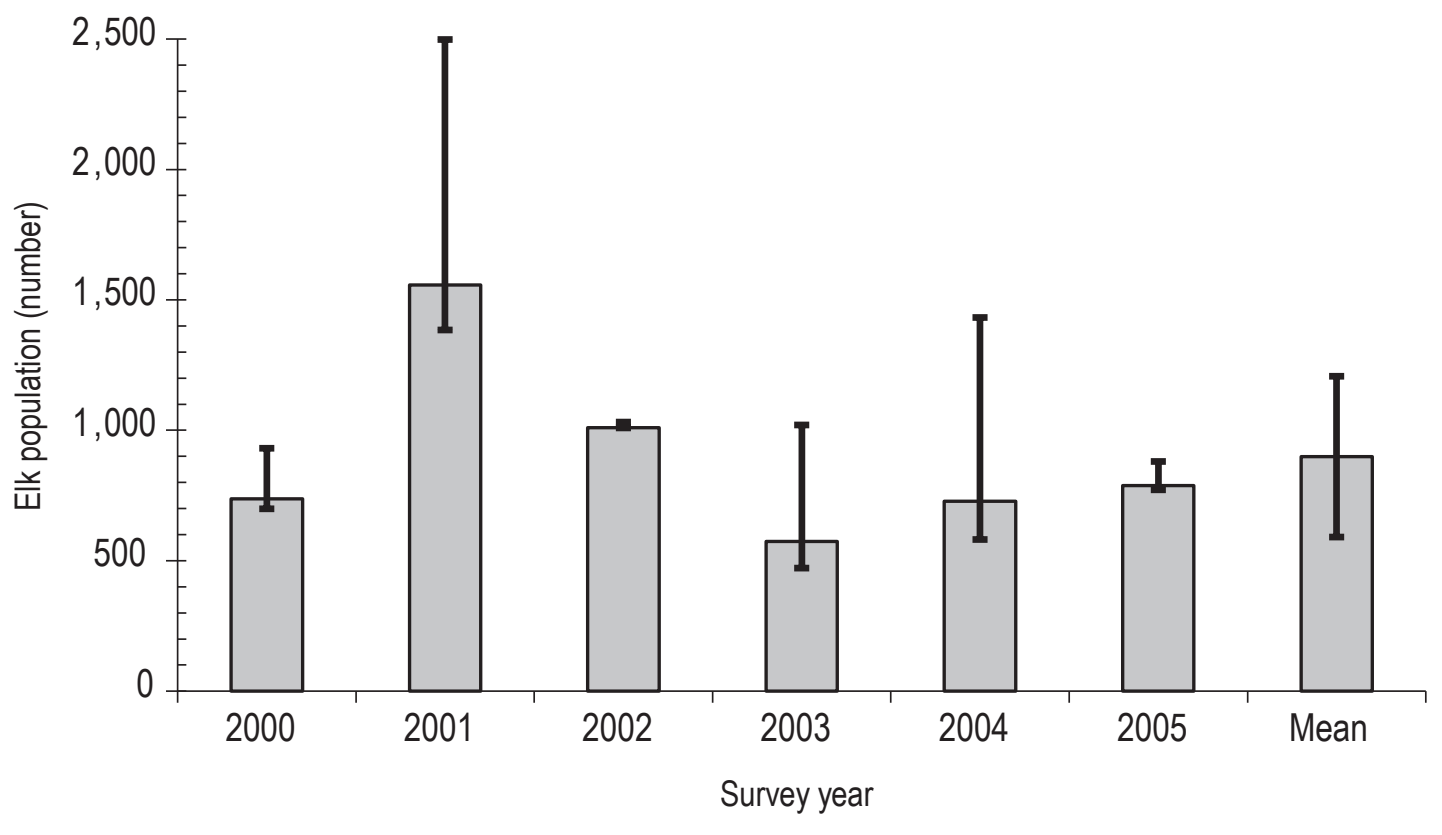

Figure 1. Elk population estimates for Rocky Mountain National Park (RMNP), Colorado, 2000-2005 (National Park Service, 2007), illustrating large annual differences. Error bars show 95 percent confidence intervals. 


\section{Study Area}

Our study area was the low-elevation elk winter range of RMNP encompassing approximately 15,000 hectares (ha) in the upper montane zone on the eastern slope of the Continental Divide (fig. 2). This winter range spans both sides of the eastern boundary of the park. Elk are free to move between the national park and a mix of public and private lands in the Estes Valley and areas further east. Glacial moraines running east-west divide the park area into four major valleys, and the town of Estes Park lies in the middle of a broad, park-like valley (Gysel, 1960; Stevens, 1980; Hobbs and others, 1982; Zeigenfuss and others, 1999). Elevations in the study area range from 2,300 meters (m) at the lower end of the Estes Valley to 2,800 $\mathrm{m}$ on moraine ridge tops. Elk habitat on the alpine tundra ranges from approximately $3,300 \mathrm{~m}$ to $3,800 \mathrm{~m}$. Mean annual precipitation is 41 centimeters, mostly occurring as wet spring snow.

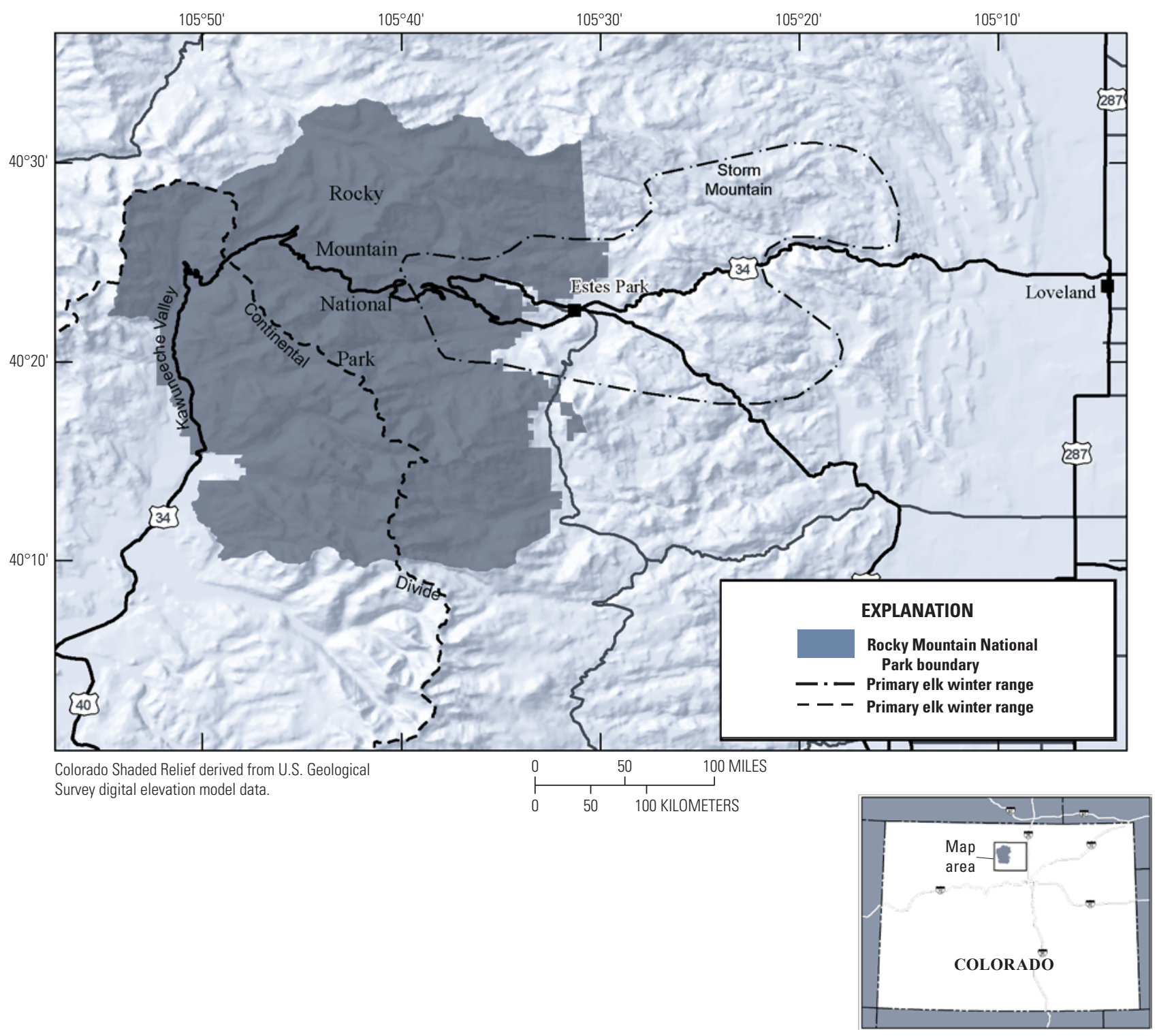

Figure 2. The general elk winter range (black dashed line) in Rocky Mountain National Park and the Estes Valley, Colorado. The cities of Estes Park and Loveland, Storm Mountain, and the Continental Divide are indicated for reference. Inset shows location of Rocky Mountain National Park within Colorado. 


\section{Background}

Prior to our study, a single aerial survey to count elk was conducted annually, usually between January and March when snow and flying conditions permitted, with a single observer in the helicopter. The aerial observer counted the number of animals in each elk group that was found and recorded several covariates describing the sighting conditions for each group. These counts were conducted within predefined count units bounded by easily recognizable landmarks. However, the helicopter flight path (coverage of the survey area) was left to the discretion of the aerial observer and pilot, sometimes resulting in areas being missed or surveyed inadequately, and inconsistencies from year to year. Surveys were limited to within park boundaries at elevations where elk were believed to overwinter. A minimum count of elk in the adjacent Estes Valley was made by volunteer ground observers from the existing road network on the same day as the aerial survey in the park.

These previous aerial surveys were analyzed with a sightability bias correction model (Samuel and Pollock, 1981; Samuel and others, 1987; Steinhorst and Samuel, 1989) developed under an earlier project conducted by the National Park Service (NPS) and U.S. Geological Survey (USGS) (Lubow and others, 2002). The model used the number of elk within each elk group, their activity, and snow cover to estimate the probability that each group would be sighted. Using these estimates, adjustments were made for the proportion of similar groups that would be expected, by chance, to be missed during a typical survey. The adjusted estimate was then used for management purposes. The calibration of this sightability model was completed greater than $(>) 15$ years ago and utilized only 44 elk groups for model development, which is far fewer than the minimum of 100 observations recommended to develop such a model based on statistical simulation studies (Wong, 1996). Due to these limitations, we initiated research to update and improve elk population estimation protocols. We determined that a complete winter survey of this entire population over its full spatial range in the park, Estes Valley, and further east was logistically almost impossible, far too costly, and probably unnecessary. What was needed by park management was the ability to quantify elk use of park resources during the critical winter months (November, December, January, February, and March). To do this, we also needed to understand the temporal variation in elk numbers on the eastern slope within the park.

\section{Objectives}

Our objectives were to:

1. Determine temporal variation in the number of elk present in the park over winter and elk movement patterns that could affect detection probability and population estimates.

2. Update the design of, and revise field protocols for conducting, aerial surveys.

3. Develop statistical models for estimating elk detection probabilities fitted to the most current and complete data available and provide procedures for continuously updating this model with data from ongoing annual surveys.

4. Develop population estimates for elk within RMNP with statistical confidence intervals from multiple aerial surveys conducted under differing environmental and aerial sighting conditions.

We present the results of this study in two parts: 1. Developing the Survey Design, and 2. Implementing and Testing the Survey Design. Part 1 presents a discussion of aerial survey methods we considered and how we selected the survey method to apply in RMNP. We present analyses of radio-collar telemetry data from this and other studies that provided information about spatial and temporal patterns of elk use in the park, which we used to determine the survey area boundaries and survey design. Part 2 describes how we tested the aerial survey method, statistical methods used to analyze aerial survey data, and the resulting population estimates with measures of precision. The alpine tundra could not be surveyed annually due to high wind, thus results are presented independently for this area of the park.

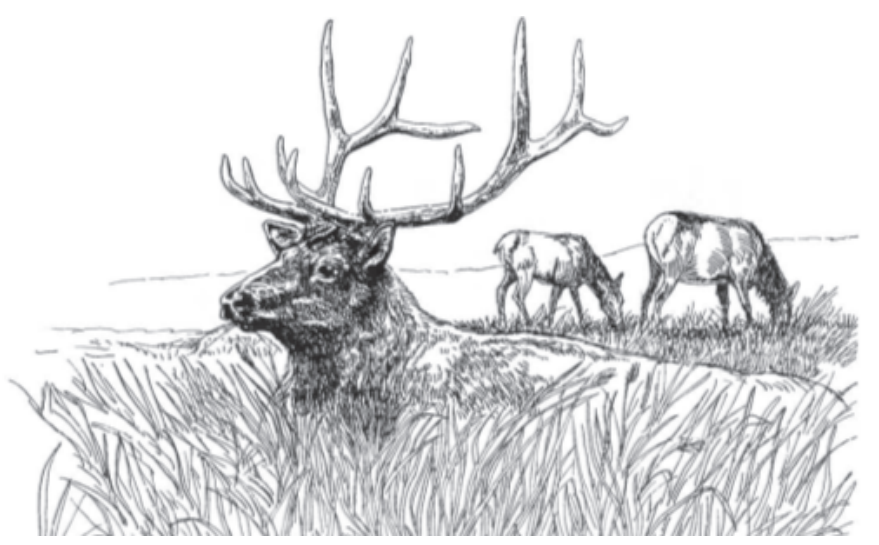




\section{Part 1. Developing the Survey Design}

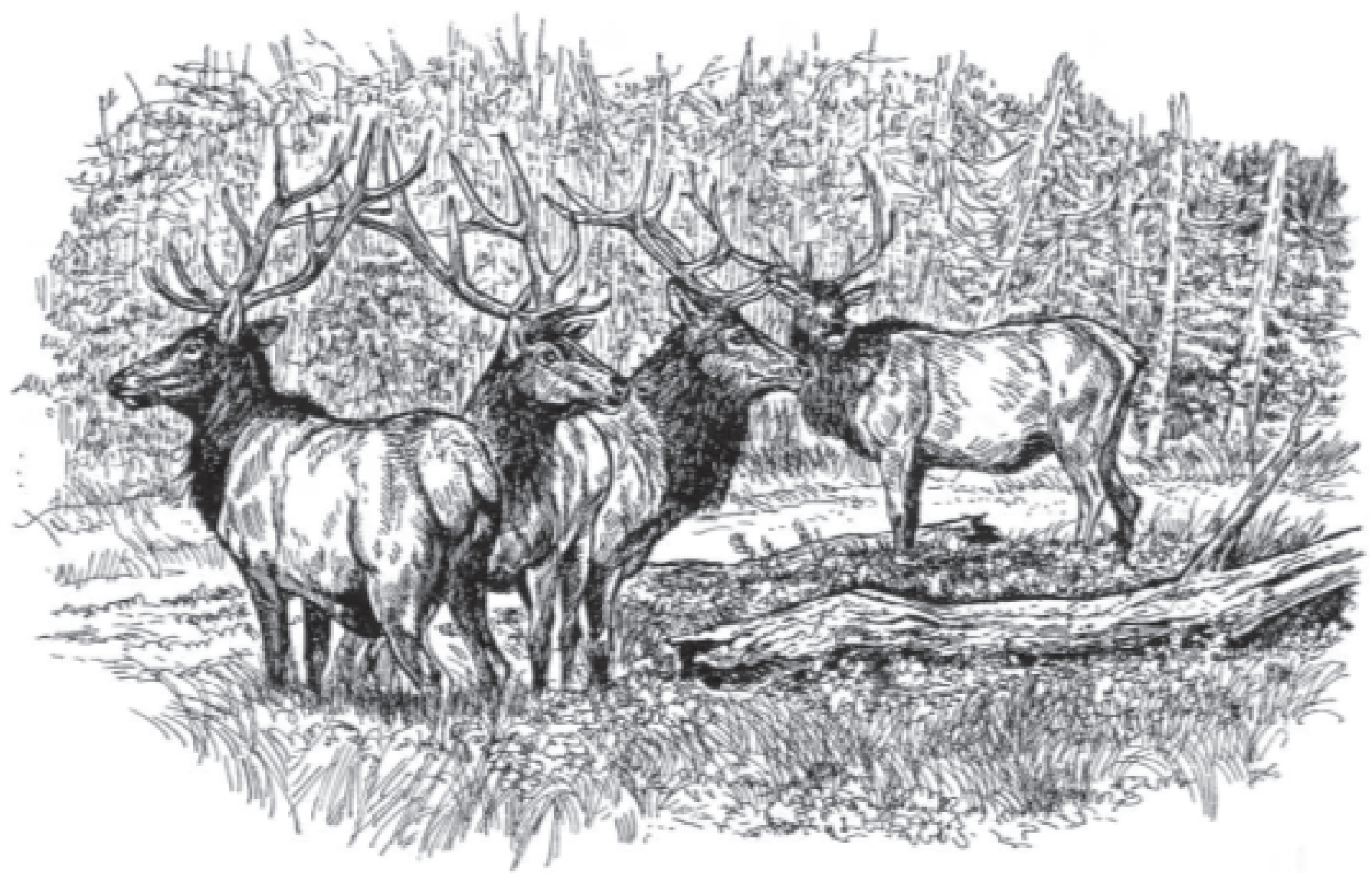




\section{Selection of the Survey Method}

We evaluated the potential utility of the following survey methodologies to estimate elk abundance in RMNP: (1) sightability correction model, (2) radio mark-recapture method, (3) simultaneous double-observer method, (4) line-transect or distance sampling, and (5) a hybrid methodology that applies a combination of several techniques. Each technique offers advantages and disadvantages, as well as tradeoffs between cost and precision, and each requires different assumptions to be met during application. A brief description of these survey methods is presented in appendix 1 . We reviewed all potential aerial survey methods and their limitations in light of the environmental conditions in RMNP.

\section{Sightability Correction Model}

Lubow and others (2002) demonstrated that obtaining an adequate sample size of detected elk groups to properly calibrate a sightability model was very difficult - their study recorded data on only 44 groups over 5 years. This obstacle is primarily caused by elk behavior; most of the elk on winter range are clustered into a small number of very large groups. Also, this method does not account for differences in the sighting abilities of individual observers or changes in sighting rates due to other factors or over time, which we suspected were likely and would not even be known if this method were chosen.

\section{Radio Mark-Recapture Method}

The mark-resight (also known as mark-recapture) method using radio-marked animals is often considered the "gold standard" for population surveys (Seber, 1982; Bowden and Kufeld, 1995; White, 1996). The major advantage of this approach is that sighting probabilities do not need to be homogeneous, because the marked groups have 100 percent sighting probability due to the radios. The greatest obstacle to applying this method is the high cost and intrusiveness of placing and maintaining radio collars on a large number of elk, especially given the requirement that they be randomly distributed across all elk in the study area.

\section{Simultaneous Double-Observer Method}

The simultaneous double-observer method is another form of the broader methodology of mark-resight survey (Seber, 1982; Bowden and Kufeld, 1995; White 1996). The double sample is obtained by having two observers record sightings in such a way that sightings of the same individual elk or groups can be determined concurrently or post hoc. Advantages of this method are that animals do not need to be marked and that variation in sighting probability that occur with different survey conditions can be accounted for. However, this method does not account for variation in sighting probability among elk groups, which we believed to be prevalent in this population.

\section{Line-Transect or Distance Sampling}

Distance sampling would not be effective because the number of independent elk groups would be far too small for an adequate sample size. Most elk surveys in the park record 10-12 groups per survey. To compensate, it would be necessary to fly multiple passes over the park during each survey - both a costly and impractical option due to challenging flying conditions in the park. Also, accurate measurement of distances from an aerial platform in the rugged topography of the park would be very difficult to implement with available technology.

\section{Hybrid Methodology}

We concluded that combining simultaneous doubleobserver methodology with a sightability correction model would be most effective and appropriate for this population. Given variable availability of specific personnel to conduct surveys in the park and the likelihood of personnel changes over time, a method such as simultaneous double-observer that accounts for differences in observers is important. At the same time, variability in sighting conditions related to factors such as snow cover, tree cover, and elk group size make a sightability correction model to address heterogeneity in elk detection important. This method allows for pooling observations across surveys to cumulatively increase the sample size and potentially detect changes in detection effects over time. Finally, collecting data on animal sighting covariates during a simultaneous double-observer survey would not increase survey costs.

\section{Methods}

\section{Radio-Collar Location Data}

We used elk radio-collar location data collected during our study and other studies (table 1) to define the spatial survey area. Radio-collar locations came from both very high frequency (VHF) and global positioning system (GPS) collars deployed at different times during different captures, sometimes within and outside of the park and other times solely within the park boundaries, depending on the study (table 1). For this reason, the locations are not a representative sample of overall elk movements but helped us understand and answer questions about how often and for what duration elk moved in and out of the park, and the spatial extent of their movements. We used radio-collar data to evaluate elk use of tree cover during potential survey hours, and elk use of different elevations within their range to inform our selection of the survey area boundary and survey timing. The radio-collar data we utilized for analysis varied by capture technique between studies (table 1). Because of this variability in radio-collar deployments, we caution that these results should not be used to extrapolate in other ways. 
Table 1. Dataset description, source, and how the information was used in our analysis to develop an improved aerial survey method for estimating the elk population in Rocky Mountain National Park (RMNP), Colorado, 2008-2011.

[GPS, global positioning system; VHF, very high frequency]

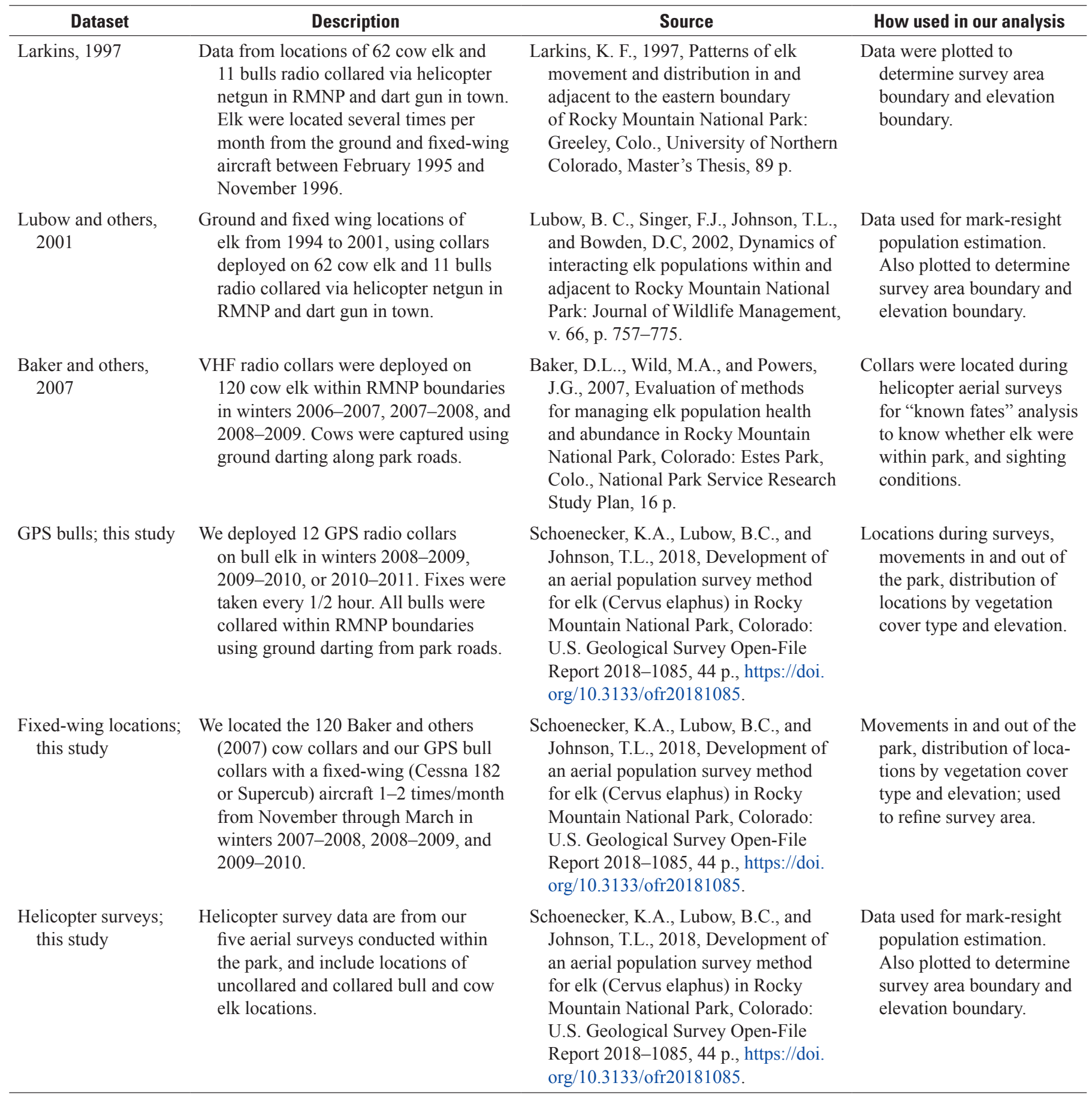




\section{Very High Frequency Telemetry}

As shown in table 1, we used VHF telemetry data from Larkins (1997) and Lubow and others (2002) to evaluate spatial and temporal patterns of elk use within the park and to determine our survey area. We collected data from $120 \mathrm{VHF}$ radio collars deployed on cow elk in a previous study (Baker and others, 2007). We located the Baker and others (2007) cow collars and our GPS bull collars (see the "Global Positioning System Telemetry" section of this report) with a fixed-wing (Cessna 182 or Supercub) aircraft 1-2 times per month from November through March in winters 2007-2008, 2008-2009, and 2009-2010 (table 1).

\section{Global Positioning System Telemetry}

To better understand spatial movements of elk at small temporal scales, we placed 12 store-on-board GPS radio collars (Sirtrack Limited, New Zealand) on bull elk in winters 2007-2008, 2008-2009, and 2009-2010. Bull elk are often missed in aerial surveys (McCorquodale, 2001) and were not represented among the 120 Baker and others (2007) collars, which were all placed on cows. We fitted GPS collars on bull elk captured inside the park boundaries, and redeployed collars if recovered before the end of the study. Working with the capture team of the NPS Wildlife Health Branch, we captured bull elk by dart gun at locations along park roadsides where they were accessible and approachable. We worked with Sirtrack to develop an expandable collar that bulls could break out of if needed, but the elastic on the expandable section disintegrated within 6 weeks after deployment. T. Johnson (USGS) developed a canvas cover modification to protect the Sirtrack expansion pieces (fig. 3), which was successful. Collars were programmed to release after 1 year, and the final drop-off date was March 2011. These GPS collars were also equipped with a VHF signal, so they were located during all helicopter surveys as well as independent fixed-wing flights. Collar fix intervals were every $1 / 2$ hour during winter. One collar did not record any data, one collar released while the bull was in the alpine tundra when road access was closed and we could not recover the collar, and one collar did not release as programmed and the collar was not recovered.

The GPS data provided accurate locations at frequent time intervals during winter, making it the most useful for identifying frequency and duration of bull movements in and out of the park. Conclusions are limited, however, by the small number of individual bulls monitored, and by the bias in capture distribution (all bulls were ground darted near roads within park boundaries).

\section{Geographic Information System Analysis}

The Geospatial Centroid at Colorado State University conducted analyses of GPS and VHF radio-collar locations, which were downloaded and plotted in a geographic information system using ArcMap Version 10. Time and date stamps from GPS data were used to filter for winter locations (November 16-March 15). We analyzed locations using the geographic information system to determine the percent of elk that were in or outside of the park and east or west of the Continental Divide during winter. We used the park's vegetation raster-based coverage and reclassified it into "cover types" to estimate when elk were in the open versus under tree cover where they could be missed by aerial observers in winter. Attributes generated by the geographic information system were IN_OUT (inside or outside of the park boundary), elevation (derived from a digital elevation model), West_East (east or west of the Continental Divide), and cover type (reclassified from the RMNP vegetation raster into five categories: dense tree, mixed-low shrub, mixed-open tree, open, or no data).

\section{Defining the Survey Area}

To define the aerial survey area, we started by including all the area inside the park boundary below 3,000 m and east of the Continental Divide. Although it is known that some elk overwinter in the tundra above $3,000 \mathrm{~m}$, they were not the focus of this study. We used evidence of past elk locations from multiple datasets (table 1), slope, and vegetation to determine which portions of the park within the 2,750- to $3,000-\mathrm{m}$ altitude range to include in the survey area.

At the beginning of the study, we surveyed areas that were not within these criteria to confirm we were not missing elk groups (by searching for tracks in snow) or important areas of habitat. In these initial two surveys, we included nearly the entire region defined by the park boundary and the $3,000 \mathrm{~m}$ contour east of the Continental Divide. As we continued with annual surveys, we used additional data gained from helicopter surveys to refine or confirm criteria for slope and vegetation.

\section{Transect Layout}

We developed the survey flight path in an adaptive process. After each survey, we modified transect lines and survey routes to obtain the best coverage for the terrain, taking into consideration sighting conditions based on vegetation cover and a reasonable and safe flight path for the helicopter. Our goal was to define a repeatable flight path that pilots could program into their GPS, placing full navigation responsibilities on the pilot and leaving observers free to look for elk. We consulted with a pilot from TransAero Helicopters (Fort Collins, Colo.) to develop final transect lines. We arranged transects so distinct areas of the park would be surveyed within a short time, and to cover one area before moving to another so observers would not double count elk that moved during the survey. We drew transect lines in Google Earth so they could be viewed against 3-dimensional satellite photographs of the terrain and vegetation cover of the survey area.

We conducted aerial helicopter surveys to test our methodology in an adaptive, iterative process in winters 2007-2008, 2008-2009, and 2009-2010. We gained new information on each survey and used results to inform subsequent surveys. 


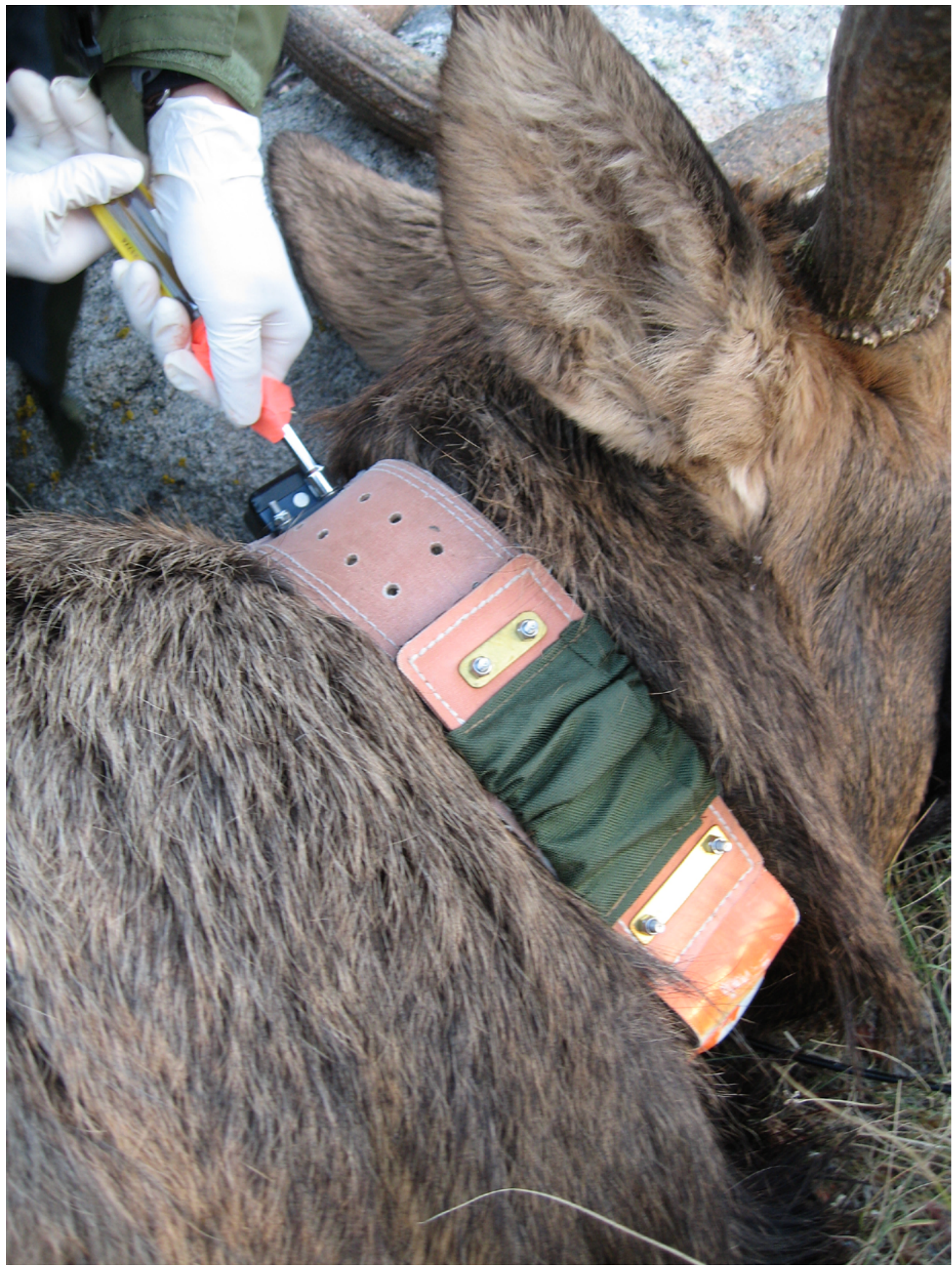

Figure 3. Modified bull elk radio collars showing expandable section developed by T. Johnson for elk population study in Rocky Mountain National Park, Colorado, 2008-2011. Photograph by K.A. Schoenecker, USGS. 


\section{Results}

\section{Survey Area Boundary Results}

We found several areas of the park had little evidence of winter elk use based on radio-collar location data from multiple sources and lack of tracks in snow. The largest of these was the southern portion, south of Bierstadt Moraine and Emerald Mountain. There were also several areas of steep terrain $\left(>45^{\circ}\right.$ slope) that were not habitat for elk according to Skovlin and others (2002), and confirmed by an absence of recorded locations in these areas. Steep terrain included portions of Lumpy Ridge, Castle Mountain, the ridge north of Horseshoe Park (stretching between Bighorn and McGregor Mountains), the walls of Spruce Canyon (Cub Lake area), and some smaller sections of the study area (fig. 4). These were removed from the flight survey route. We found little or no evidence from radio-collar locations of elk use in elevations between $2,750 \mathrm{~m}$ and 3,000 m; most telemetry locations in this altitude were from Hidden Valley where former ski runs provided unforested slopes, or from Deer Mountain where forest cover is sparse on the relatively flat, wind-blown top of the mountain. The remainder of this altitude range is heavily forested and moderately steep. Except for Hidden Valley and Deer Mountain, we found little support for including altitudes $>2,800 \mathrm{~m}$. We excluded the elevation range between 2,750 and 2,800 m south of Hollowell Park, as well as a few other small portions of this range. Otherwise, all areas less than $(<) 2,800 \mathrm{~m}$ inside the park and east of the Continental Divide were included in the final survey area (fig. 4), except for south of Bierstadt Moraine where absence of elk and elk tracks in snow helped confirm previous anecdotal and telemetry data indicating lack of elk in this area.

\section{Transect Layout Results}

We found that evenly spaced transect lines were too wide for dense tree cover, and too narrow for open meadow valleys. Our final aerial survey transect lines were drawn narrower over heavy cover and wider over open meadow valleys with high visibility (fig. 5).

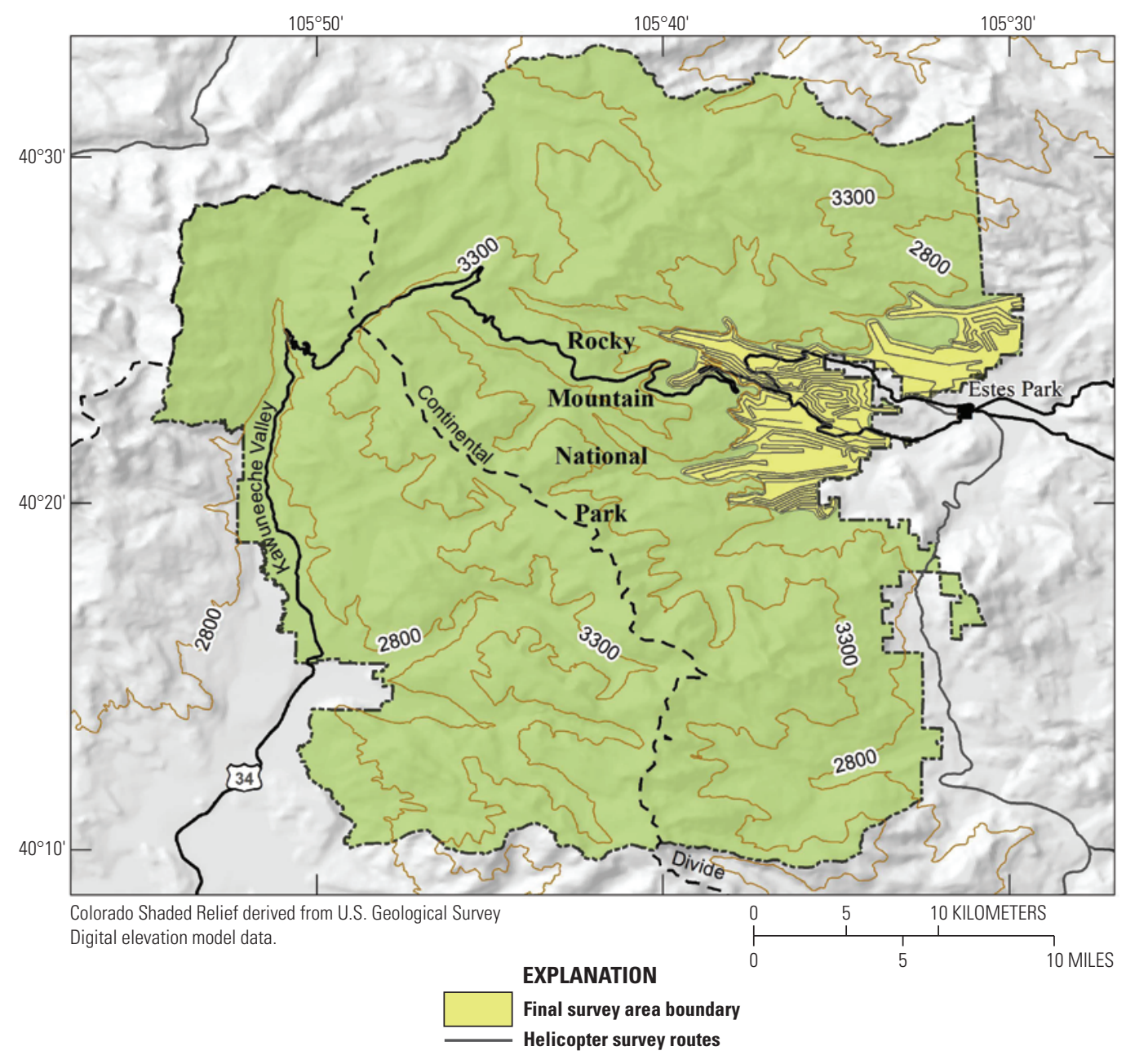

Figure 4. Final survey area boundary, showing key elk habitat elevation contours of 2,800 meters and 3,300 meters in Rocky Mountain National Park, Colorado. 


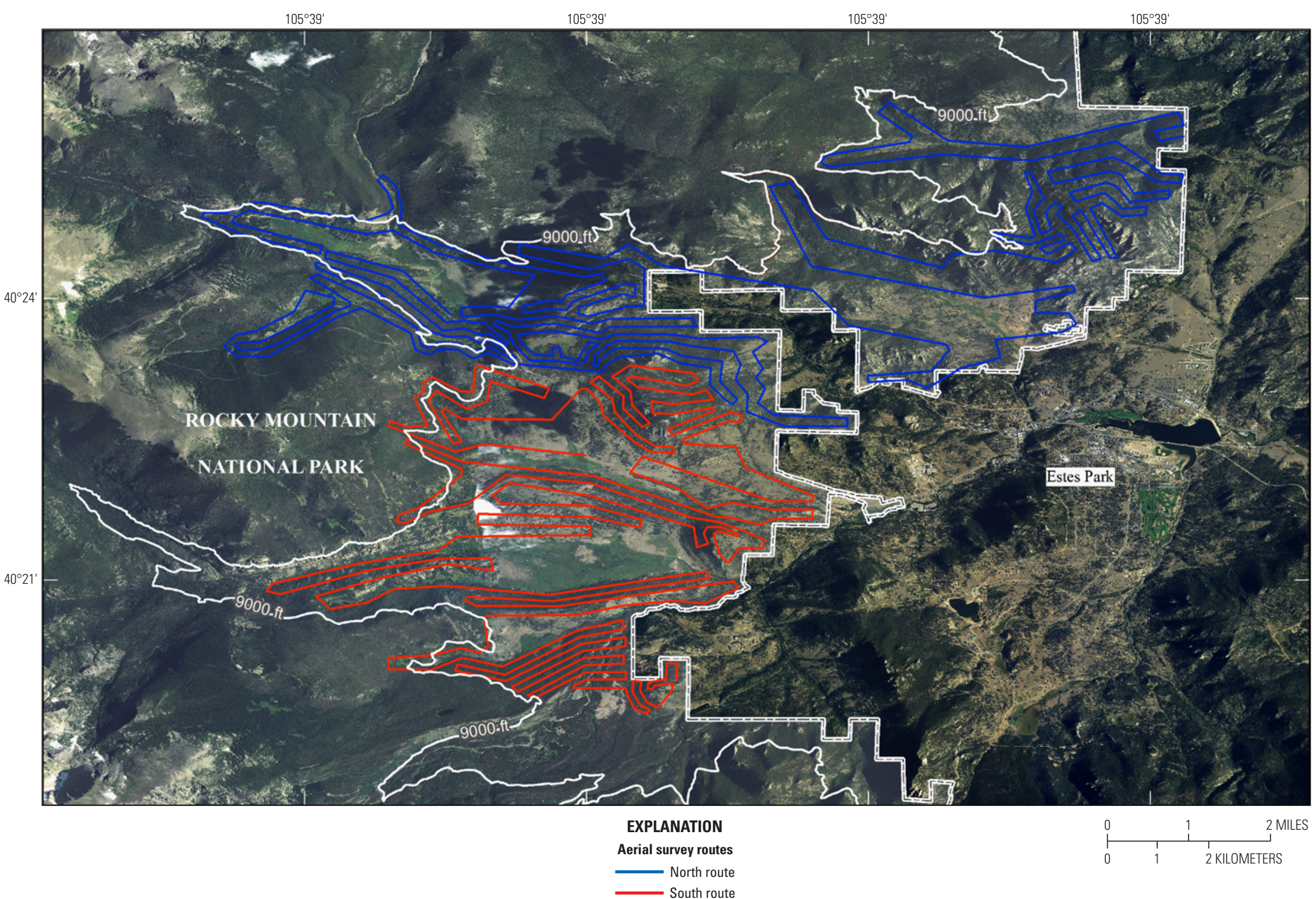

Figure 5. Final north and south aerial survey routes for Rocky Mountain National Park elk surveys. Dashed white line is the park boundary, and the solid white line is the 2,800-meter elevation contour. (ft, foot) 


\section{Spatial and Temporal Variation of Elk Use of the Park}

We obtained 52,425 winter elk locations from GPS collars over a total of 1,355 elk-days (table 2). We discarded eight GPS locations we classified as anomalies where a single location was far from the previous and subsequent location. All elk that were radio collared for the different studies were captured and collared either on the low elevation winter range in the park or just outside the park boundary in the town of Estes Park. Constraints on capture methods prevented us from obtaining a true random sample of collared individuals, so we cannot draw conclusions about the percent of time either bulls or cows spent inside the park, but it is clear that both bulls and cows spend time both inside and outside the park.

Although all bulls were captured and radio collared inside the park, only 59.9 percent of winter bull locations were inside the park boundaries (fig. 6). Of the winter GPS bull locations,

Table 2. Summary of global positioning system telemetry data collection showing deployment and collection date of each bull collar in study of elk population in Rocky Mountain National Park, Colorado, 2008-2011.

\begin{tabular}{ccccc}
\hline $\begin{array}{c}\text { Bull elk } \\
\text { identification }\end{array}$ & $\begin{array}{c}\text { First } \\
\text { date }\end{array}$ & $\begin{array}{c}\text { Last } \\
\text { date }\end{array}$ & $\begin{array}{c}\text { Number days of } \\
\text { recorded data }\end{array}$ & $\begin{array}{c}\text { Number of locations } \\
\text { recorded }\end{array}$ \\
\hline 819 & $10 / 3 / 2009$ & $9 / 16 / 2010$ & 115 & 4,684 \\
$819 \mathrm{~b}$ & $11 / 13 / 2010$ & $5 / 15 / 2011$ & 120 & 5,521 \\
831 & $10 / 9 / 2009$ & $6 / 30 / 2010$ & 117 & 5,124 \\
$831 \mathrm{~b}$ & $11 / 6 / 2010$ & $3 / 31 / 2011$ & 52 & 1,887 \\
856 & $10 / 9 / 2009$ & $8 / 23 / 2010$ & 120 & 4,859 \\
881 & $10 / 7 / 2009$ & $4 / 27 / 2011$ & 223 & 6,192 \\
894 & $11 / 8 / 2008$ & $4 / 29 / 2009$ & 120 & 5,063 \\
$894 \mathrm{~b}$ & $11 / 5 / 2010$ & $4 / 23 / 2011$ & 120 & 4,677 \\
906 & $11 / 8 / 2008$ & $2 / 15 / 2009$ & 92 & 3,867 \\
$906 \mathrm{x}$ & $12 / 19 / 2009$ & $9 / 29 / 2010$ & 87 & 3,599 \\
918 & $1 / 6 / 2010$ & $4 / 22 / 2011$ & 189 & 6,952 \\
& & Total & $\mathbf{1 , 3 5 5}$ & $\mathbf{5 2 , 4 2 5}$ \\
\hline
\end{tabular}

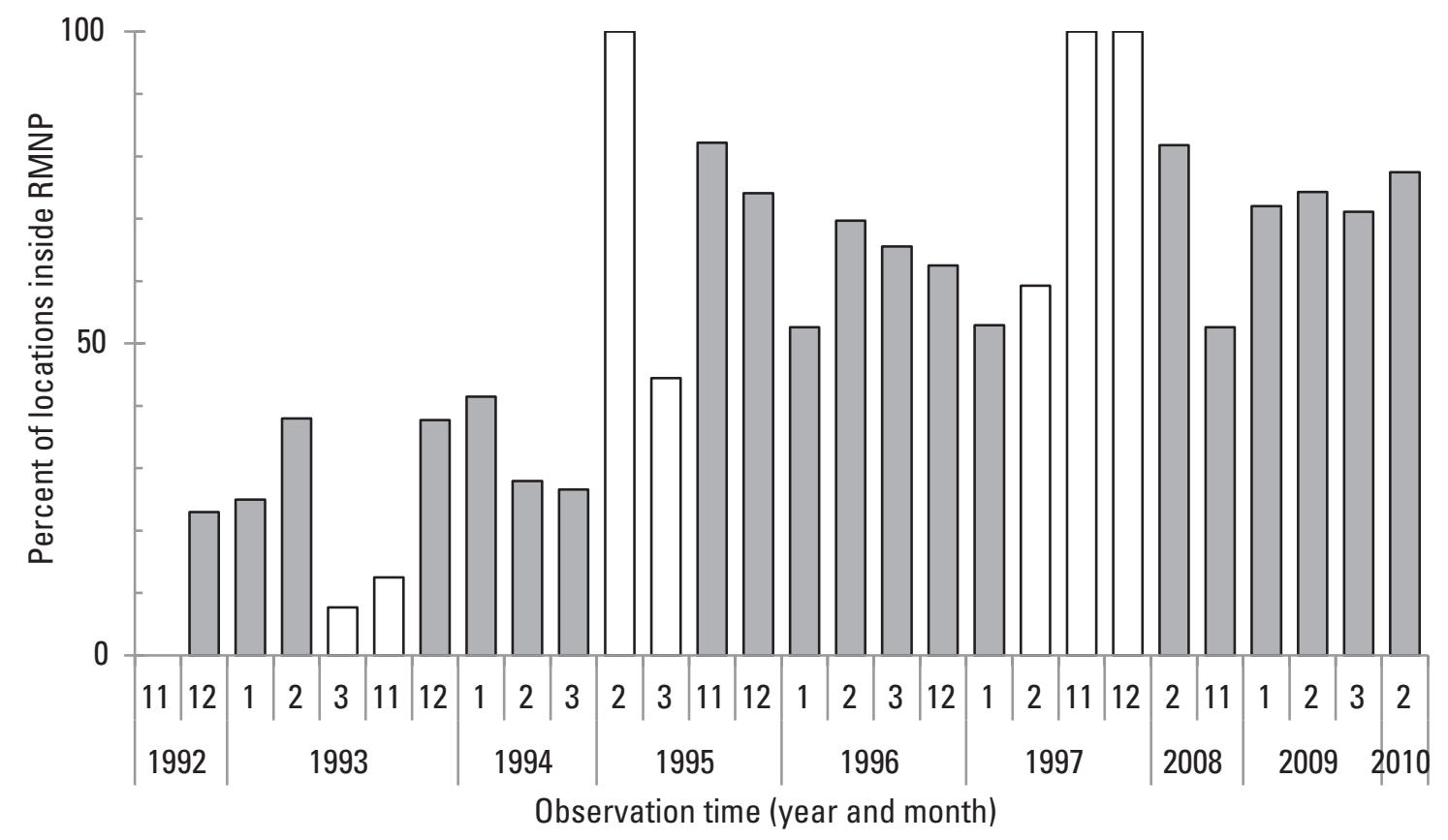

Figure 6. Percent of winter very high frequency collar locations east of the Continental Divide that were inside Rocky Mountain National Park (RMNP), Colorado, by month and year. White bars are based on less than 30 elk locations for that month. Data are from very high frequency locations of cow elk from Larkins (1997), Lubow and others (2002), and this study (2008-2011). 
100 percent were east of the Continental Divide. Radio collars put on cow elk in both the park and in the town of Estes Park as discussed in Larkins (1997) and Lubow and others (2002) revealed 61.1 percent of winter cow elk locations were inside the park, with 99.7 percent east of the Continental Divide (fig. 6). The 120 cows that were radio collared inside the park boundary for the Baker and others (2007) study were relocated inside the park 74.2 percent of the time during winter. Our sample size of GPS bull collars was small and collars were deployed for different time periods on each elk, so quantitative conclusions are limited. Similar to the 120 VHF-collared cows, bull elk were radio collared only within park boundaries, so these results cannot be used to quantify the percent of time bulls spend in the park. However, some qualitative patterns were observed and can be informative. Winter use of the park by GPS-collared bull elk was highly variable among years and months, ranging from a low of 0.4 percent of locations during February 2009 to as high as 70.1 percent in January 2010 (fig. 7).

The majority of bull elk winter use occurred in the lower altitude, open park areas, including Horseshoe Park, Beaver Meadows, Moraine Park, and Hollowell Park (fig. 8). GPS telemetry locations revealed more limited bull elk use of the Cow Creek, Hidden Valley, and Deer Mountain areas. Based on both VHF and GPS location data, we found almost no cow or bull elk use of the Glacier Basin drainage in the southern portion of the park (fig. 8).

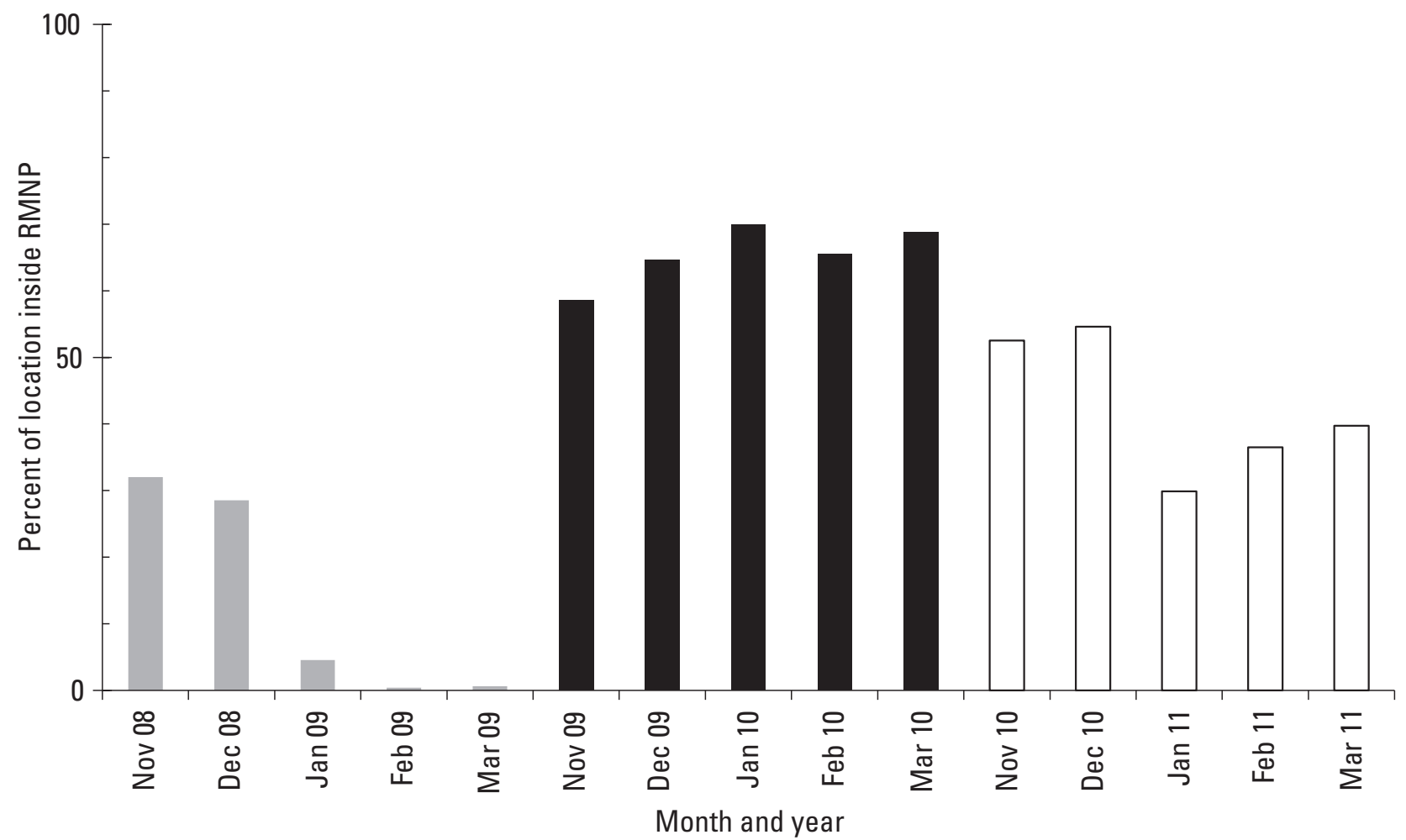

Figure 7. Percent of winter global positioning system bull collar locations inside Rocky Mountain National Park (RMNP), Colorado, by month of the study, 2008-2011. The three distinct winter periods are distinguished by unique shading. 

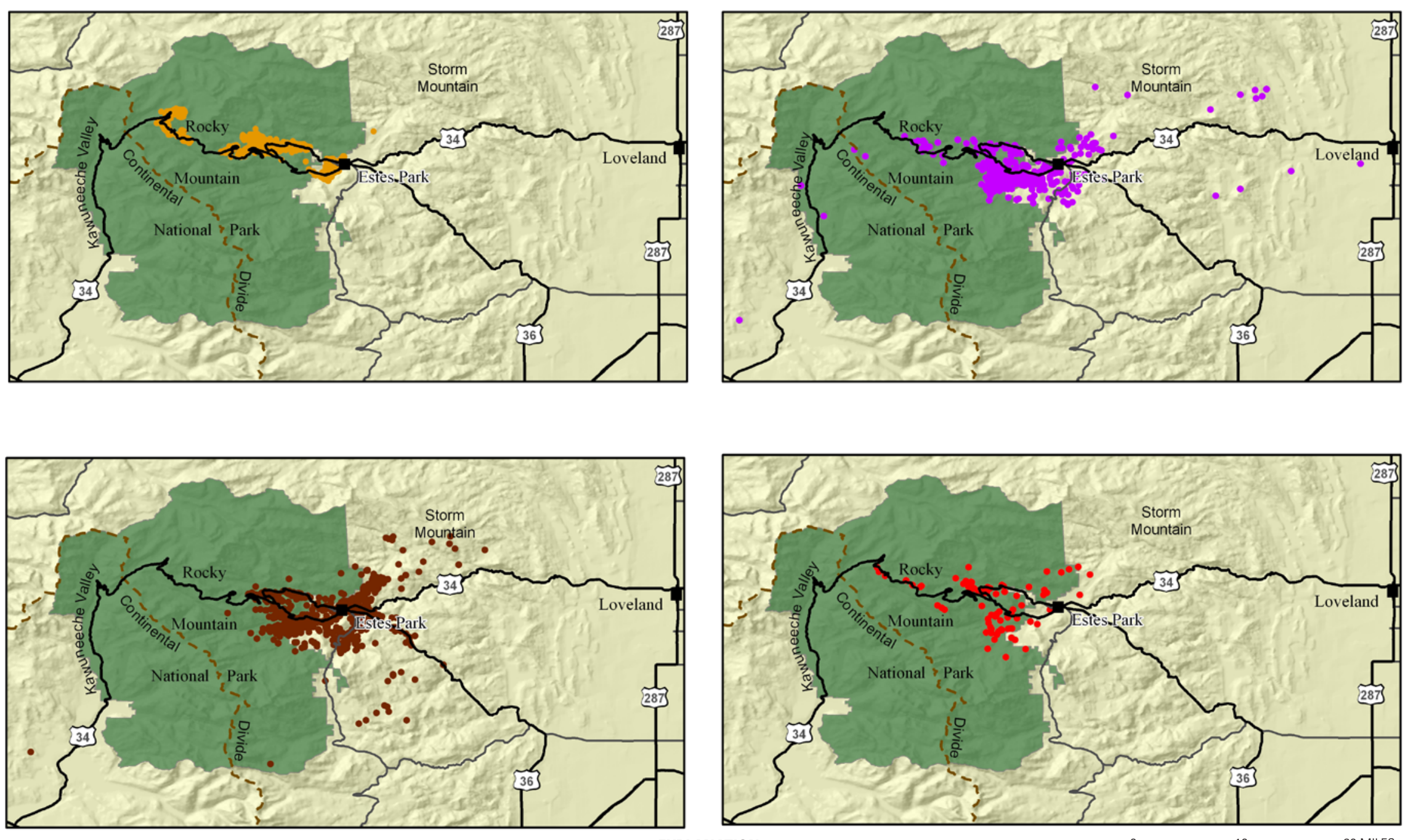

Colorado Shaded Relief derived from U.S. Geological Survey

\section{EXPLANATION}

GPS bulls (12 individuals) - Helicopter surveys within Park

- Fixed wing 120 VHF collars - Ground VHF (Larkins 1997)

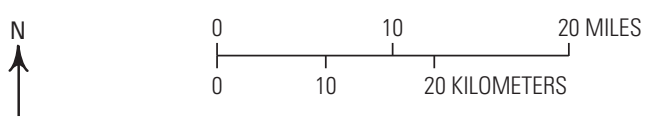

Figure 8. Winter elk telemetry locations from multiple sources in Rocky Mountain National Park, Colorado. For data description and source see table 1. 


\section{Altitude}

Of the GPS bull locations, 76.8 percent were at altitudes less than or equal to $(\leq) 2,800 \mathrm{~m}$ and 17.2 percent were at altitudes $>3,300 \mathrm{~m}$, which is alpine tundra habitat (table 3 ). In the altitude band between these extremes, only 5.1 percent of locations were between 2,801 and $3,000 \mathrm{~m}$, and 0.1 percent were between 3,000 and 3,300 m (table 3). Bull elk locations between 2,800 and 3,000 m were almost exclusively in Hidden Valley or on top of Deer Mountain. In the helicopter, fixed-wing, and Larkins (1997) telemetry datasets we evaluated, the altitude pattern was very similar to the GPScollared elk in this study (fig. 9). Locations between 2,800 and 3,300 m constituted only 2.4 percent of our fixed-wing data, 0 percent of helicopter sightings in our test flights, and 4.0 percent from Larkins (1997).

Table 3. Altitude distribution of winter elk locations reported in different datasets and studies. For detailed description of each dataset see table 1.

[GPS, global positioning system; VHF, very high frequency; $\leq$, less than or equal to; $\%$, percent; >, greater than]

\begin{tabular}{ccccc}
\hline & \multicolumn{4}{c}{ Data source } \\
\cline { 2 - 5 } $\begin{array}{c}\text { Elevation range } \\
\text { (meters) }\end{array}$ & $\begin{array}{c}\text { 11 GPS radio-collared } \\
\text { elk bulls } \\
\text { (this study) }\end{array}$ & $\begin{array}{c}\text { 12 fixed-wing surveys } \\
\text { of the Baker and others } \\
\text { (2007) elk cows } \\
\text { (this study) }\end{array}$ & $\begin{array}{c}\text { Larkins (1997; ground } \\
\text { data of 73 VHF-collared } \\
\text { cows and bulls) }\end{array}$ & $\begin{array}{c}\text { Helicopter locations } \\
\text { from five elk surveys } \\
\text { (this study) }\end{array}$ \\
\hline$\leq 2,800$ & $76.8 \%$ & $94.0 \%$ & $95.8 \%$ & $91.2 \%$ \\
$2,801-3,000$ & $5.1 \%$ & $1.6 \%$ & $3.7 \%$ & $0 \%$ \\
$3,001-3,299$ & $0.1 \%$ & $0.8 \%$ & $0.3 \%$ & $0 \%$ \\
$>3,300$ (alpine) & $17.2 \%$ & $3.7 \%$ & $0.2 \%$ & $8.8 \%$ \\
\hline
\end{tabular}

\section{Tree Cover}

Of winter bull elk GPS locations inside the park ( $\leq 3,000$ m altitude), 21.7 percent were in dense tree cover with montane Douglas-fir composing the largest portion of the vegetation (table 4). Another 25.9 percent were in mixed low shrubs, mostly riparian shrubs. An additional 18.4 percent were in mixed open trees. The remaining 34 percent of GPS locations were in open habitats composed of herbaceous cover types (table 4). Daily GPS elk locations in dense tree cover varied widely among winter days from a low of 0 percent to a high of 100 percent (mean=24.2 percent, standard deviation $=22.6$ percent). Monthly averages for GPS elk locations in dense trees ranged from 12.4 percent to 27.6 percent (fig. 10). There appeared to be more GPS locations in dense tree cover during February and March than earlier months of 2010 and 2011 (fig. 10).

Winter bull elk GPS locations combined over months and years showed a strong diurnal temporal pattern of increased use of dense trees during the evening hours, rising above 20 percent between 15:00 and 22:00, but remaining relatively consistent across the morning and early afternoon daylight hours when surveys are typically conducted (fig. 11).

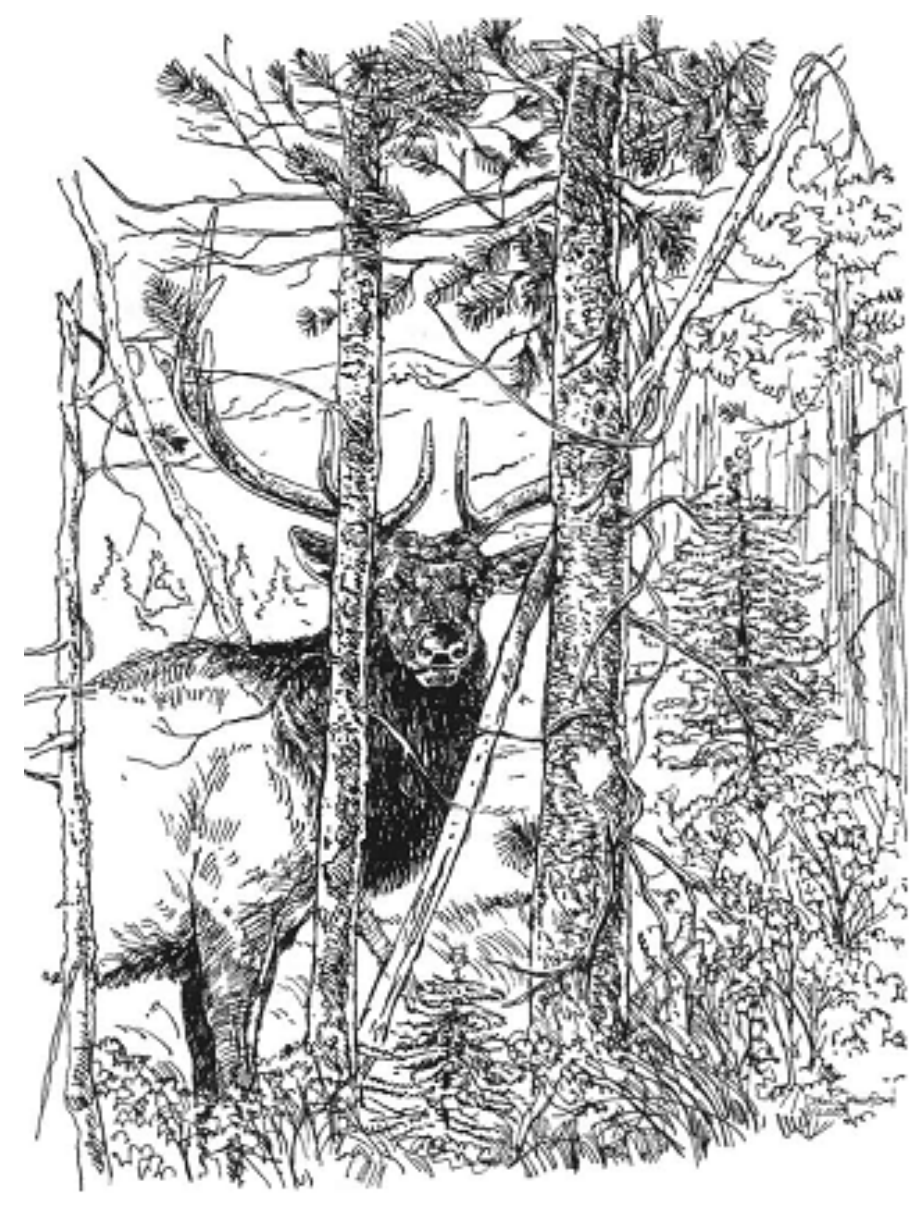




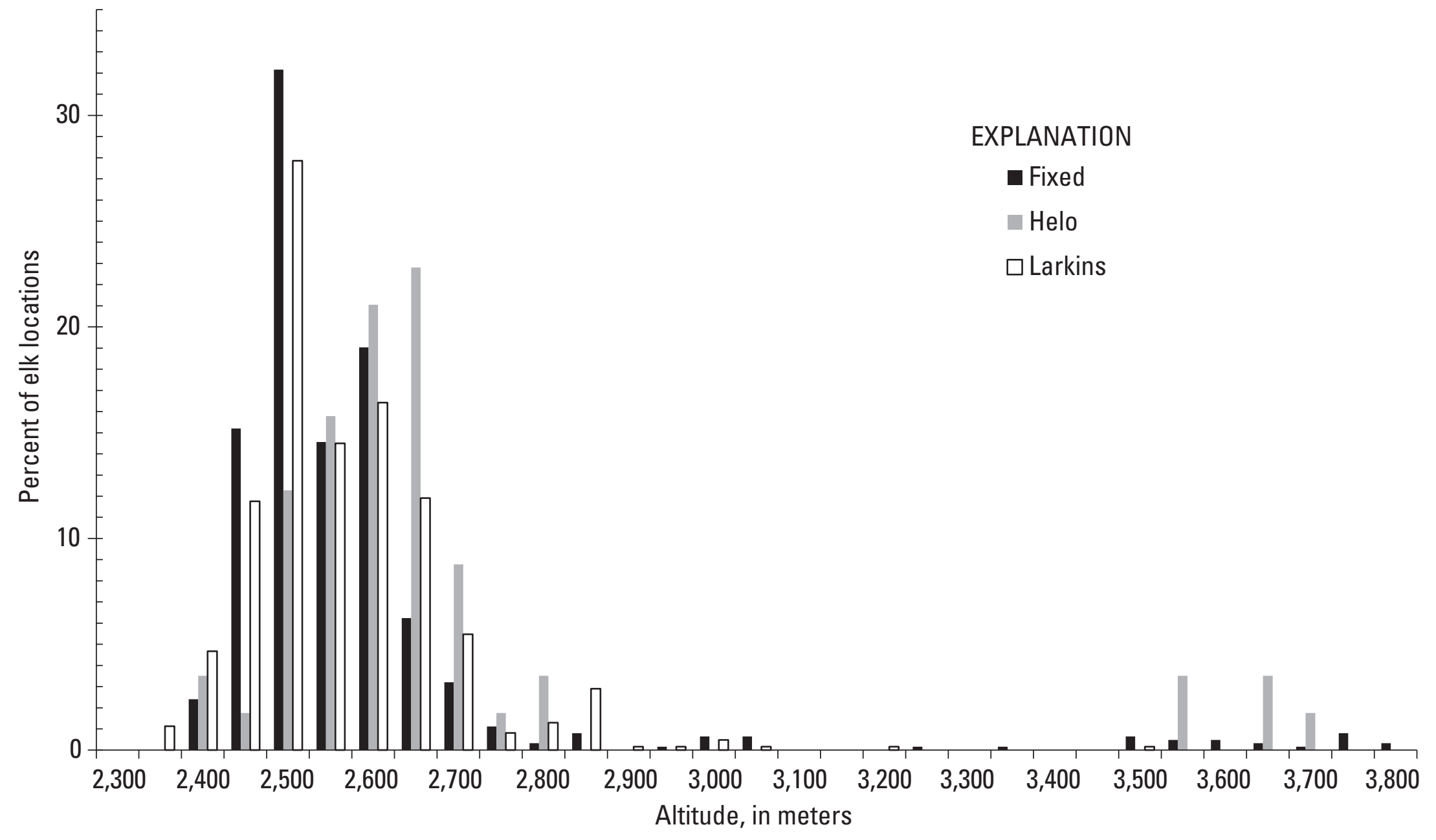

Figure 9. Winter altitude distribution of elk locations in elk population study in Rocky Mountain National Park, Colorado, 2008-2011, from fixed-wing observations of 120 very high frequency-collared cows (Baker and others, 2007), helicopter observations of both bull and cow groups (this study), and very high frequency-collared elk from Larkins (1997). (Helo, helicopter) 
Table 4. Distribution of winter bull elk global positioning system locations by cover class and vegetation type in study of elk population in Rocky Mountain National Park, Colorado, 2008-2011. (Totals may not equal due to rounding.)

[No., number; >, greater than; m, meter; \%, percent; <, less than]

\begin{tabular}{|c|c|c|}
\hline Vegetation type & $\begin{array}{l}\text { No. of elk } \\
\text { locations }\end{array}$ & $\begin{array}{c}\text { Percent of elk } \\
\text { locations }\end{array}$ \\
\hline \multicolumn{3}{|l|}{ Dense tree } \\
\hline Lodgepole pine- - High elevation $(>2,900 \mathrm{~m})$ & 104 & $0.4 \%$ \\
\hline Lodgepole pine-Low elevation $(<2,900 \mathrm{~m})$ & 962 & $3.7 \%$ \\
\hline Mixed conifer with aspen (Douglas-fir) & 69 & $0.3 \%$ \\
\hline Mixed conifer with aspen (lodgepole pine) & 170 & $0.7 \%$ \\
\hline Mixed conifer with aspen (ponderosa pine) & 200 & $0.8 \%$ \\
\hline Montane Douglas-fir & 2,457 & $9.5 \%$ \\
\hline Riparian aspen & 919 & $3.5 \%$ \\
\hline Riparian lower montane mixed conifer $(<2,590 \mathrm{~m})$ & 101 & $0.4 \%$ \\
\hline Riparian upper montane mixed conifer $(>2,590 \mathrm{~m})$ & 374 & $1.4 \%$ \\
\hline Subalpine limber pine & 2 & $0.0 \%$ \\
\hline Subalpine mixed conifer & 272 & $1.0 \%$ \\
\hline Subtotal & 5,630 & $21.7 \%$ \\
\hline \multicolumn{3}{|c|}{ Mixed low shrub } \\
\hline Juniper & 5 & $0.0 \%$ \\
\hline Shrub riparian cross zone $(<2,925 \mathrm{~m})$ & 5,644 & $21.7 \%$ \\
\hline Shrub upland lower montane-Big sagebrush & 5 & $0.0 \%$ \\
\hline Shrub upland lower montane-Bitterbrush & 157 & $0.6 \%$ \\
\hline Shrub upland lower montane-Undifferentiated & 903 & $3.5 \%$ \\
\hline Subtotal & 6,714 & $25.9 \%$ \\
\hline \multicolumn{3}{|c|}{ Mixed open tree } \\
\hline Cottonwood & 26 & $0.1 \%$ \\
\hline Disturbance_-Dead and down & 1 & $0.0 \%$ \\
\hline Ponderosa pine, graminoid & 2,453 & $9.4 \%$ \\
\hline Ponderosa pine, rockland & 702 & $2.7 \%$ \\
\hline Ponderosa pine, shrubland & 1,384 & $5.3 \%$ \\
\hline Upper montane aspen & 220 & $0.8 \%$ \\
\hline Subtotal & 4,786 & $18.4 \%$ \\
\hline \multicolumn{3}{|l|}{ Open } \\
\hline Herbaceous upland montane $(<2,925 \mathrm{~m})$ & 5,206 & $20.0 \%$ \\
\hline Herbaceous wetland cross zone-Marsh & 5 & $0.0 \%$ \\
\hline Herbaceous wetland cross zone-Wetland & 2,578 & $9.9 \%$ \\
\hline Herbaceous wetland subalpine/alpine meadow & 24 & $0.1 \%$ \\
\hline Natural lakes_-Ponds & 13 & $0.1 \%$ \\
\hline Outwash & 427 & $1.6 \%$ \\
\hline Reservoirs-Stock tanks & 32 & $0.1 \%$ \\
\hline Rock (alpine-upper subalpine) & 3 & $0.0 \%$ \\
\hline Rock (foothill-lower subalpine) & 74 & $0.3 \%$ \\
\hline Streams-Rivers & 1 & $0.0 \%$ \\
\hline Unvegetated surface & 479 & $1.8 \%$ \\
\hline Subtotal & 8,842 & $34.0 \%$ \\
\hline Total & 25,972 & $100.0 \%$ \\
\hline
\end{tabular}




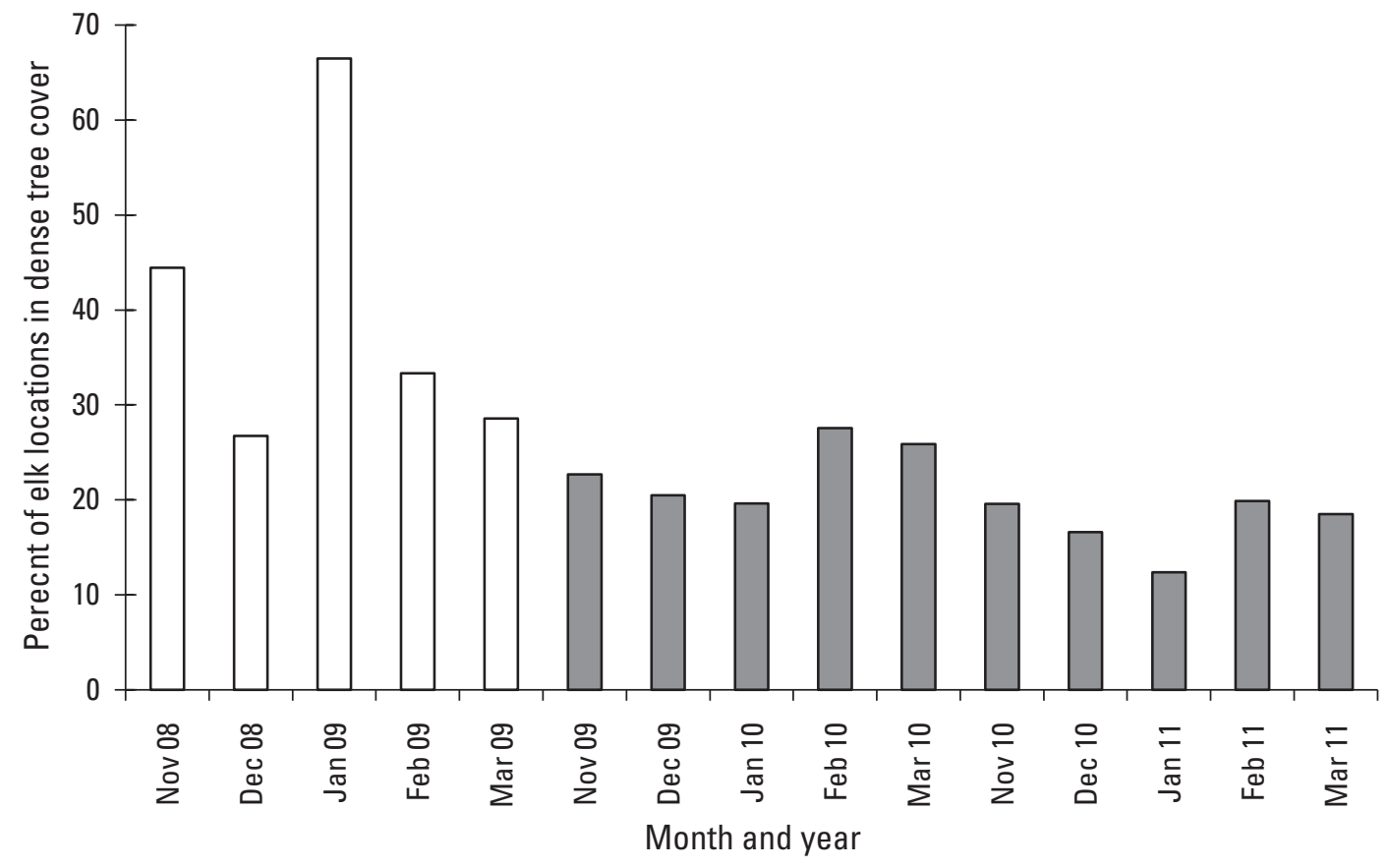

Figure 10. Use of dense cover by bull elk wearing global positioning system collars within Rocky Mountain National Park, Colorado, by month of the study, 2008-2011. White bars indicate months when fewer than 4 of the 11 GPS-collared bulls spent time inside the park.

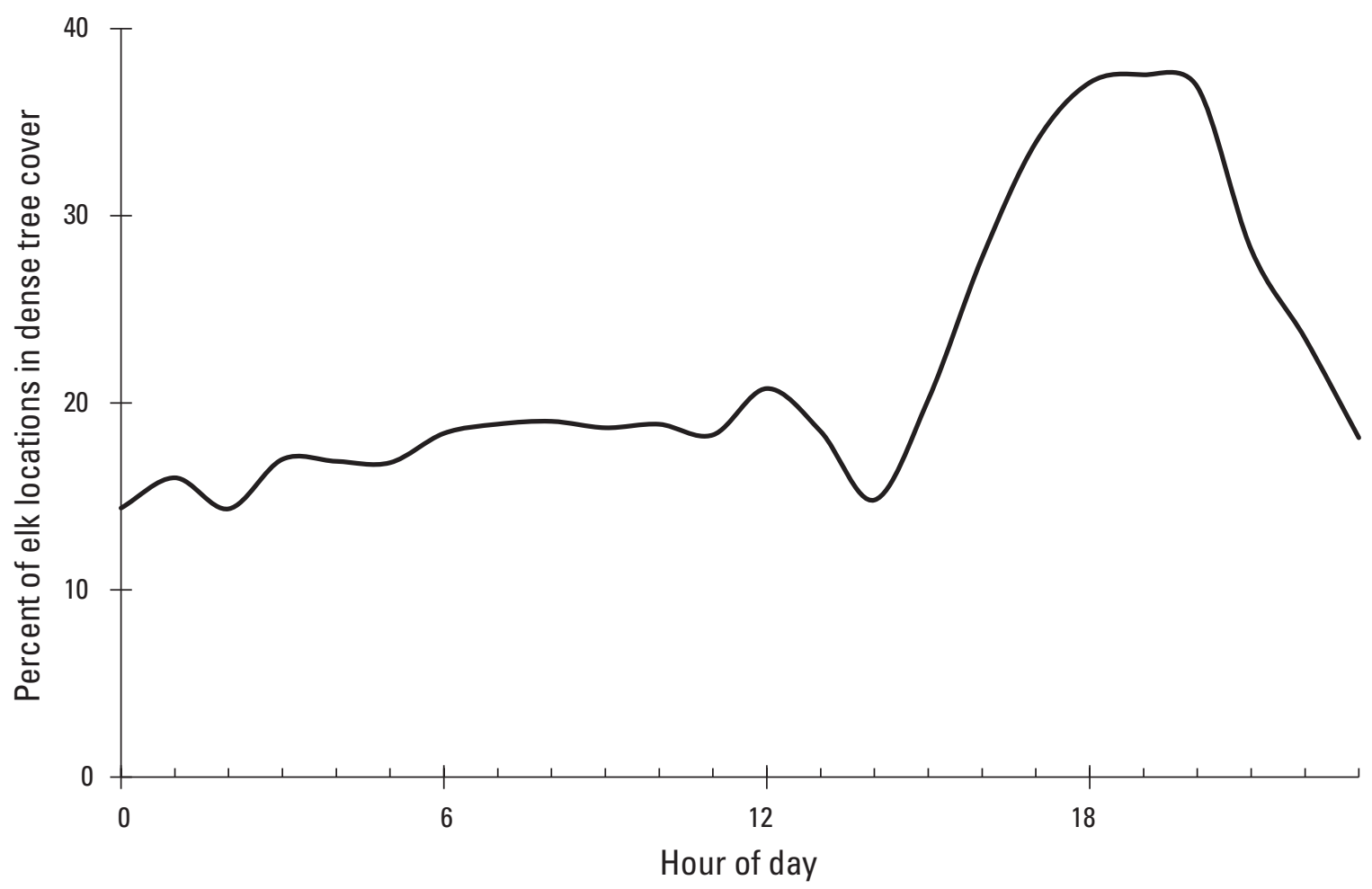

Figure 11. Use of dense tree cover by global positioning system-collared bull elk during the winter period by hour of the day in Rocky Mountain National Park, Colorado, 2008-2011. 


\section{Bull Elk Locations on Aerial Survey Days}

We plotted the location of radio-collared bull elk on helicopter survey days to see where they were located during our surveys (fig. 12). Of the observed radio-collared bull elk, 47 percent $(n=7)$ were outside of the survey area during aerial helicopter surveys and 53 percent $(n=8)$ were inside the survey area boundary (fig. 12). Four radio-collared bulls were not located on survey days. Pilots invested ample flight effort to find missing radio-collared individuals during surveys, but if the collared individual was too far outside the survey area boundary, it may have been recorded as "not found." All collars were functioning with audible signals at the time of our surveys. If the four bulls that were searched for but not found during aerial helicopter surveys are assumed to be outside of the survey area boundary (see fig. 4), then 58 percent $(n=11)$ of radio-collared bulls were outside the survey area boundary during helicopter surveys and 42 percent $(n=8)$ were within.

During our study years, the majority of bull elk winter use occurred in Horseshoe Park, Beaver Meadows, Moraine Park, and Hollowell Park, with more limited bull elk use of the Cow Creek, Hidden Valley, and Deer Mountain areas. Based on both VHF and GPS location data, we found almost no cow or bull elk use of the Glacier Basin drainage in the southern portion of the park.

\section{Elk Park Boundary Crossings}

We recorded GPS-collared bull elk crossing the park boundary 801 times during winter. The GPS bulls were captured only within park boundaries and the information on boundary crossings provides a relative indication of the amount of movement by bulls, but should not be interpreted or used as a firm number of crossings because of the nonrandomized capture method we used. Our data indicated there were 711 crossings lasting 1 hour or more, of which 581 were $\leq 1$ day, 124 were between 1 and 30 days, and 6 were $>30$ days. We recorded GPS-collared bull elk locations over 1,838 winter elk-days with an average of 0.387 crossings per elk-day of 1 hour or longer duration, or 11.8 crossings per elk-month. That is approximately six round trips from park to Estes Park and back per month per bull during the winter period. In addition to these crossings, there were 90 crossings of $<1$ hour duration. Some of these may have resulted from bulls wandering near the boundary, but others may have been due to error in GPS location estimates.

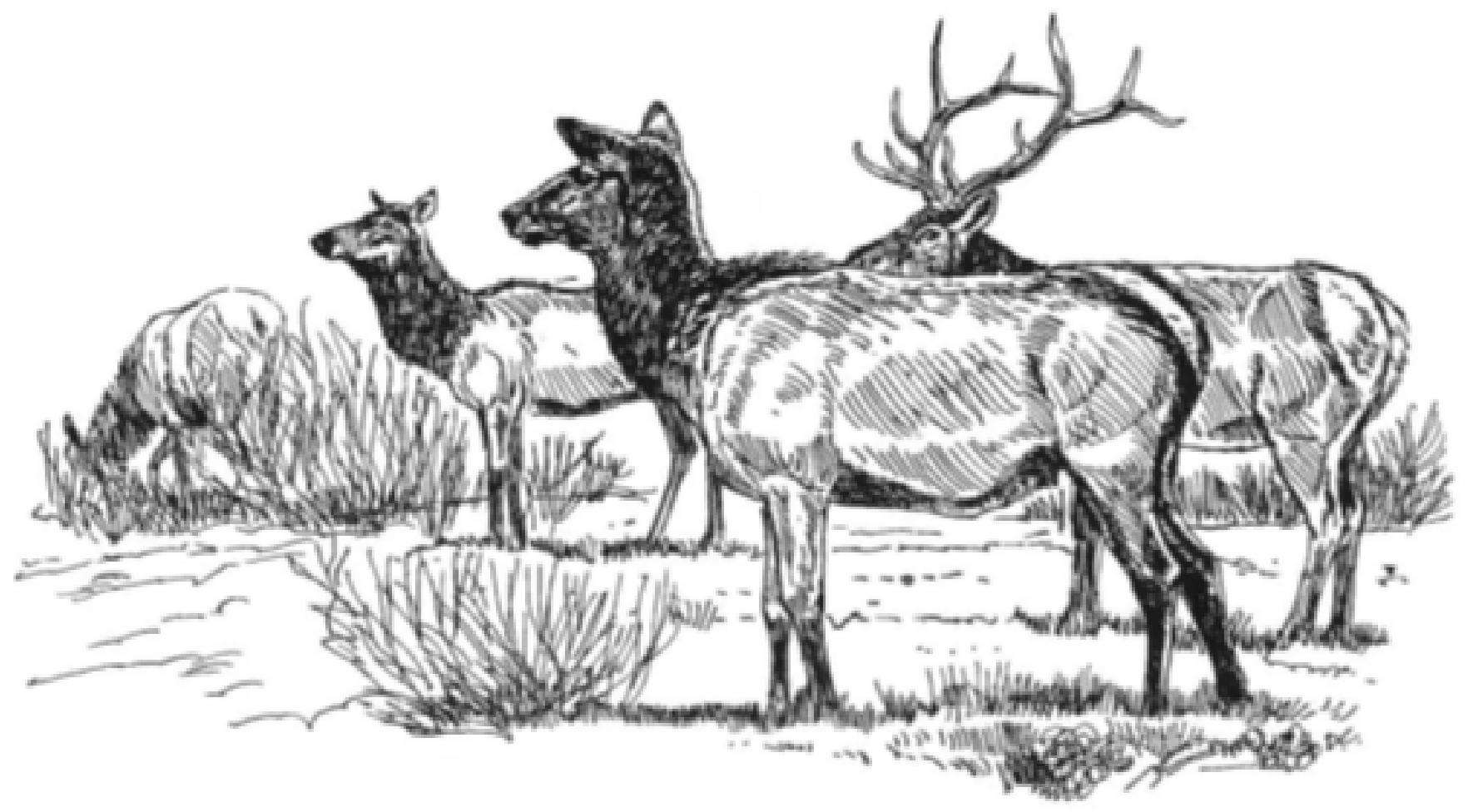



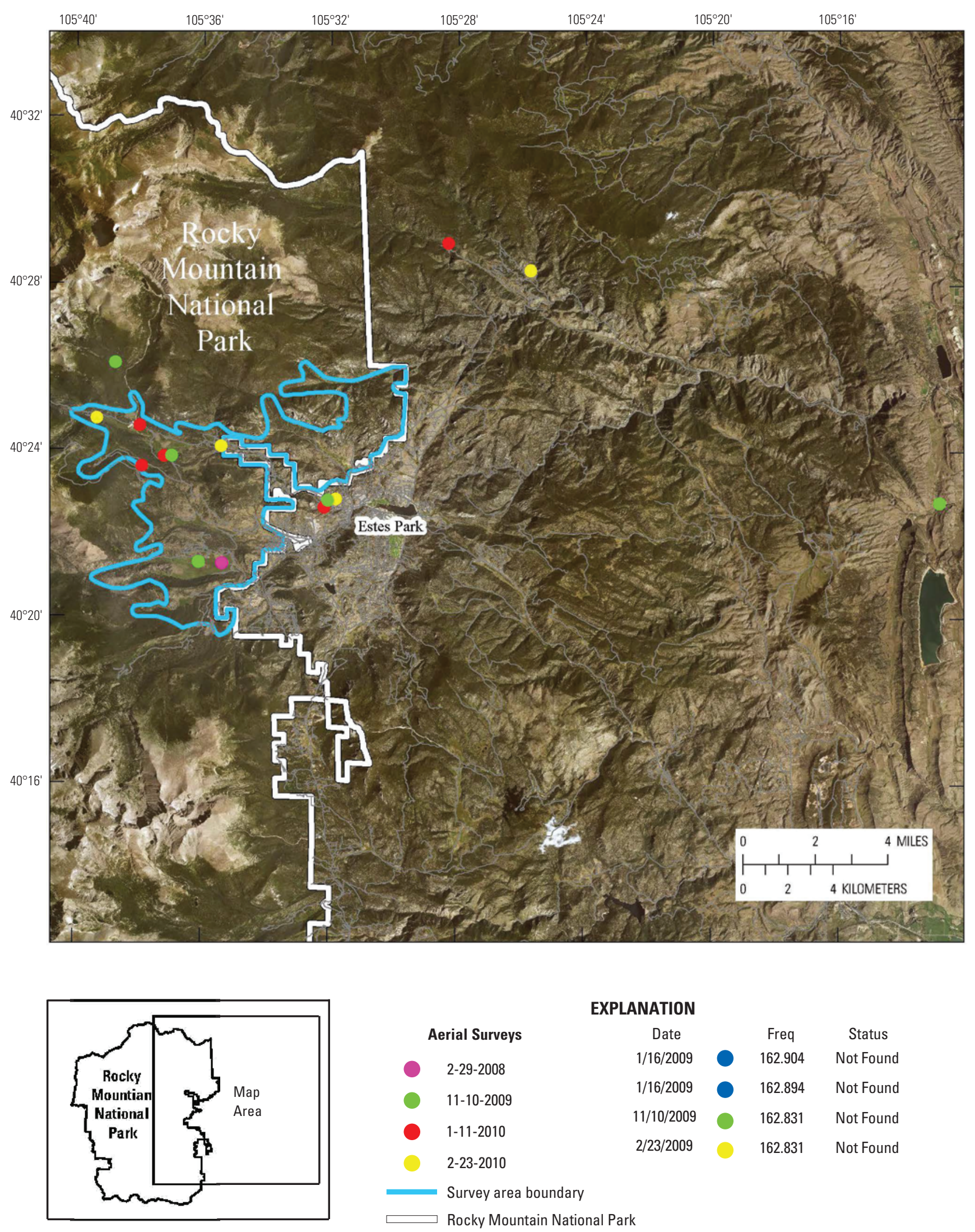

Figure 12. Locations of radio-collared bull elk during aerial helicopter surveys in Rocky Mountain National Park, Colorado, 2008-2011 ( $n=11$ radio-collared bull elk located on five aerial surveys during three winters). Dates when individual frequencies were not found during the survey are shown. (Freq., frequency) 


\section{Part 2. Implementing and Testing the Survey Design}

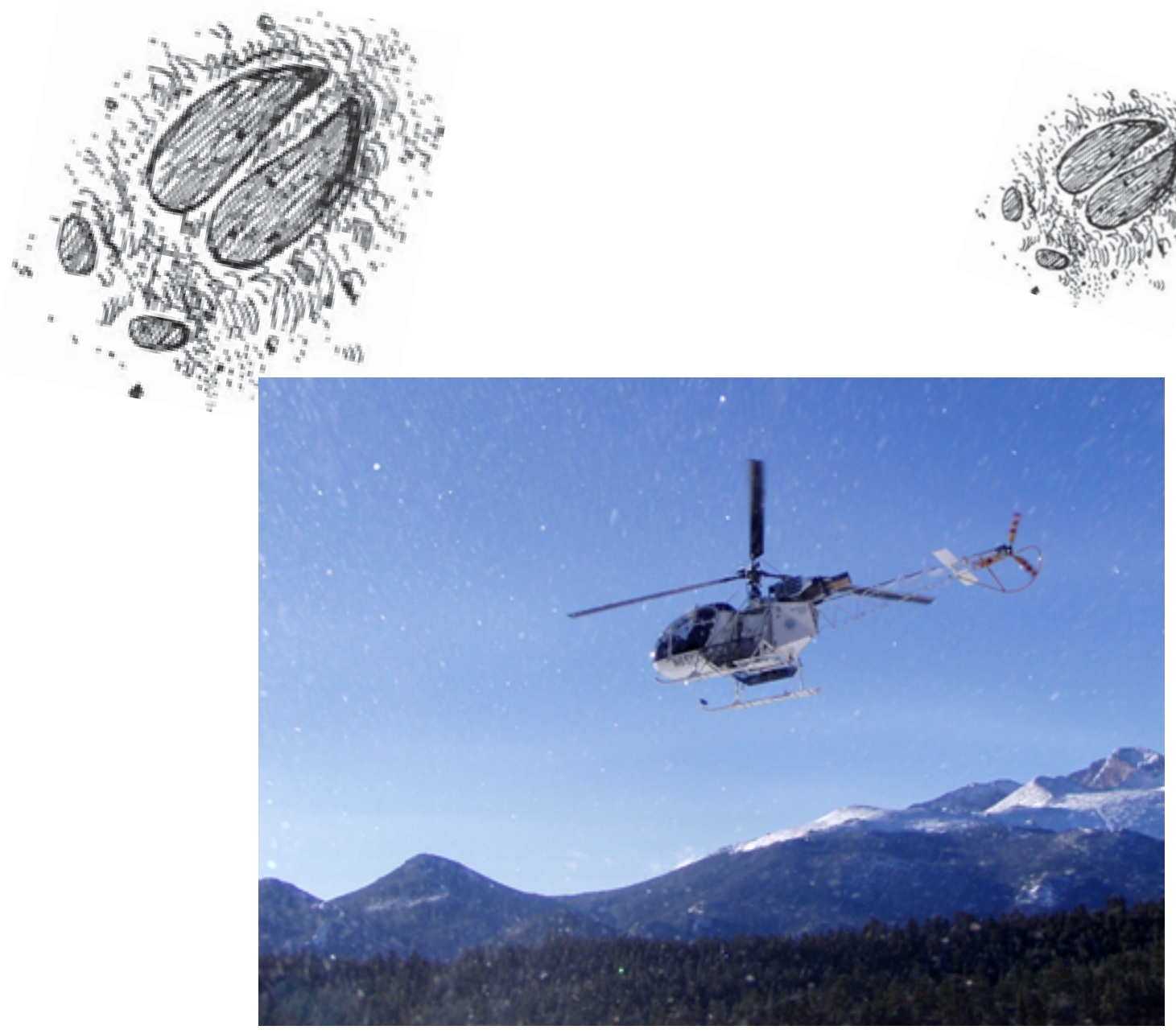

Photograph by K.A. Schoenecker, USGS.

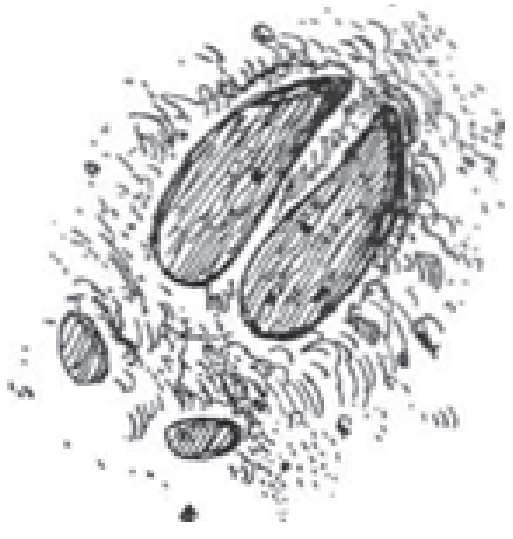




\section{Using a Hybrid Double-Observer Model with Sighting Covariates to Estimate the Elk Population in Rocky Mountain National Park, 2008-2011}

In order to achieve a more precise and accurate estimate for the elk population within RMNP, we used information obtained as discussed in part 1, and incorporated it into a methodology using a hybrid population-estimation model; we used simultaneous double-observer protocols and collected sighting covariates for all surveys. Instructions for this method and the flight forms for data collection are provided in appendix 3 .

\section{Methods}

We flew five combined helicopter-fixed-wing surveys over three winters: 2007-2008, 2008-2009, and 2009-2010 using a Lama helicopter (pilot J. Hennessey of TransAero) and Supercub or Cessna 182 fixed-wing aircraft (pilots Dave Stinson of Sky Aviation and Lanny Coulter of Coulter Aviation, respectively). We flew predefined transects (fig. 5) using an onboard GPS (Garmin GPSmap, Garmin International, Olathe, Kansas).

USGS ecologist K. Schoenecker was located in the frontleft seat of the helicopter for all surveys. A second observer, NPS biologist T. Johnson, and a third observer (NPS, USGS, Colorado Parks and Wildlife, or volunteer) switched positions between the left and right rear seats at each refueling to be able to calculate individual sighting probabilities against the front-left seat observer. The pilot was not asked to search for elk, although any elk detected by the pilot contributed to the recorded detections for the primary front observer. The pilot would discretely notify the front seat observer of any elk groups spotted without notifying the rear seat observers.

During helicopter surveys, a fixed-wing aircraft, occupied only by the pilot, flew near but above the helicopter to locate elk with radio collars. Using the 120 VHF radio collars from the Baker and others (2007) study enabled us to use a knownfates, mark-resight population estimation for our trials; that is, during our aerial surveys, elk not seen by the helicopter crew were known to be available or unavailable (outside of the survey area or dead) because of simultaneous collar location data collected by the fixed-wing pilot.

Initially, we had the fixed-wing pilot record covariates for all radio-collared elk, and at the end of the survey we compared the group size, time of observation, presence of radio collars in a group, and Universal Transverse Mercator locations to determine which groups with radio collars were seen or not seen by the observers in the helicopter. But because fixed-wing pilots were not always able to get a group size or record covariates, it became difficult to match up groups to determine if they were seen or not seen by the helicopter. Thus, we modified communication so the pilots would remain in continuous radio contact with the helicopter pilot; the fixed-wing pilot flew ahead of the helicopter's path to locate radio-collared elk and then climbed to a higher altitude while the helicopter pilot and observers surveyed an area. The fixed-wing pilot watched the helicopter and informed the helicopter pilot and crew about any radio-marked elk that had been passed and appeared to have been missed (because the helicopter did not circle or slow down to count). The helicopter crew then flew to the missed elk and recorded sighting conditions for these groups. To maintain safe separation, we restricted the helicopter to fly $<300 \mathrm{ft}$ above ground level and the airplane to fly $>500 \mathrm{ft}$ above ground level.

\section{Population Estimation Analysis}

Data

Our final dataset included five helicopter surveys and data from three fixed-wing surveys conducted at the same time as the helicopter surveys. Two additional fixed-wing flights had missing values and were dropped. We had a total of 27 groups with radio collars located by the fixed-wing that were available to helicopter observers during surveys. During the 5 helicopter surveys, 67 elk groups were located by the fixed-wing aircraft that were available to helicopter observers (27 elk groups with known locations and covariates due to radio collars and 40 groups without). Lubow and others (2002) provided data on an additional 44 groups with radio collars. The combined dataset includes 111 observations.

Observations were well distributed among the major covariates: 59.1 percent of groups were moving when sighted, group sizes ranged from 1 to 491 (fig. 13), and cover of vegetation that could obscure elk observations, such as trees and (or) tall shrubs, was fairly uniformly distributed across the full range from 0 percent to 100 percent (fig. 14). Snow cover was most commonly either 0 percent or 100 percent, but partial snow cover occurred for 44.5 percent of groups (fig. 14). The wide distribution of covariates across all possible conditions means that we were able to obtain information about this full range of sighting conditions to build our models.

\section{Model Structure}

The observed number of elk in a survey underestimates the true number because of detection bias- the failure to detect elk groups that were present but not seen. Thus, the inverse of each group's detection probability $\left(1 / \hat{p}_{i}\right)$ is an expected correction factor $\left(\hat{\theta}_{i}\right)$ that represents the number of elk present in the surveyed area per elk seen in that group. Applying the group-specific correction factor to the group sizes and composition of observed elk groups leads to point estimates of abundance and composition that account for detection bias.

We prepared data from detection of elk groups by individual observers as detection events in a mark-releaserecapture analysis framework. We used a closed-capture modeling approach that allowed for individual elk group covariates to influence detection probability (Huggins, 1991). 


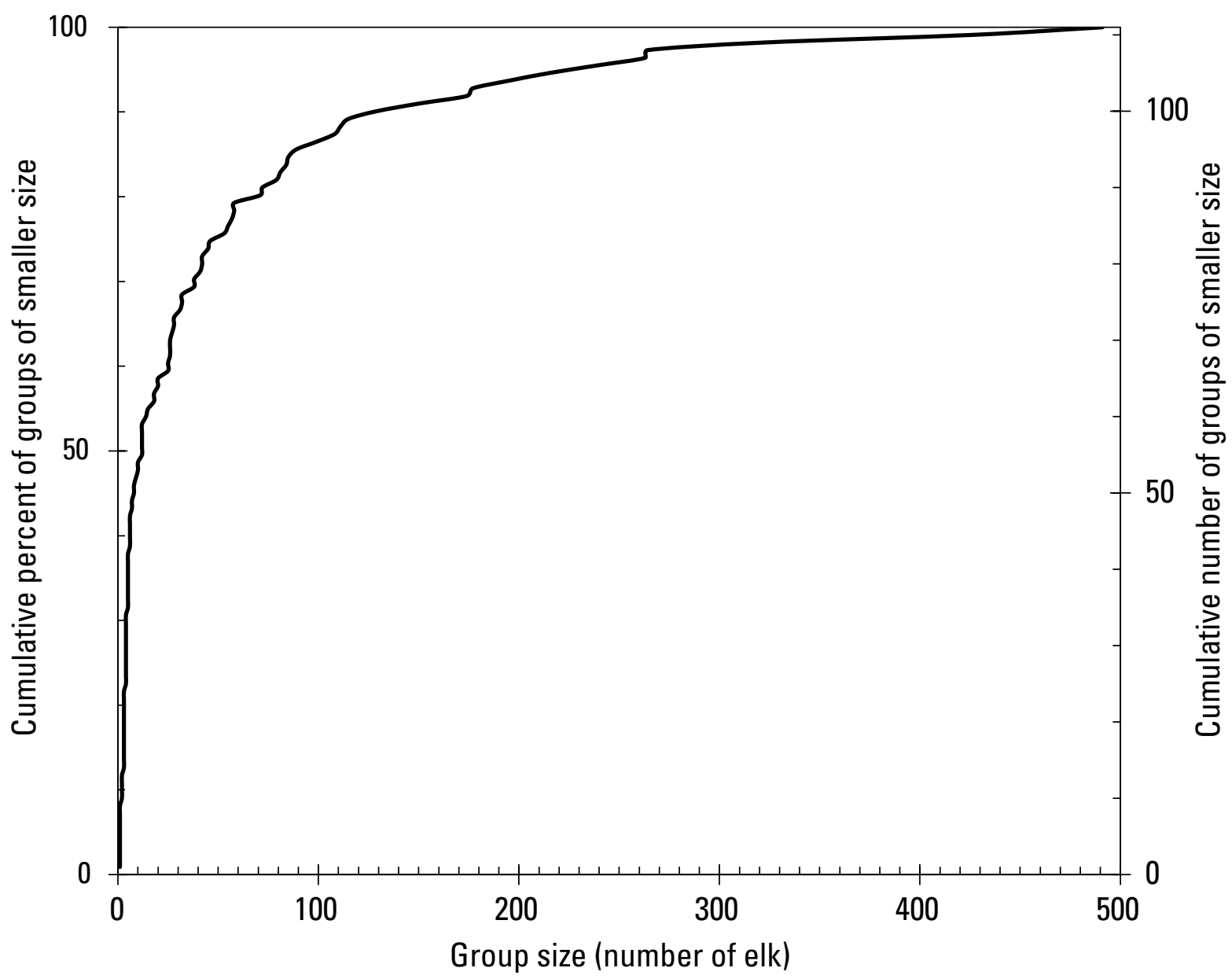

Figure 13. Distribution of elk groups by group size in Rocky Mountain National Park, Colorado, elk population estimation study, 2008-2011, demonstrating the tendency toward larger groups in winter.

In all of the candidate models that we tested, we set the recapture probability, $c$, equal to the initial detection probability, $p$. This reflects the explicit assumption of double-observer analyses (Barker, 2008) that each observer's detection records are independent.

The sightability calibration surveys (Lubow and others, 2002) were two-occasion mark-resight trials, where the presence of a radio collar was the first marking occasion and the observation (or failure to observe) by the aerial helicopter crew was the second resighting occasion. In our study, there could be three sighting occasions: (1) by the fixed-wing pilot if a radio-collared elk was in the group, (2) by the helicopter front observer, and (3) by the helicopter rear observers. There were only two possible sighting occasions for each elk that was not marked with a radio collar.

To model these differing structures, we defined four potential sighting-resighting occasions: one for each radiocollared group, one for the single aerial observer in Lubow and others (2002), and one each for the front and rear observers in the helicopter in the current study. No single survey actually had all four of these sighting occasions. For example, the study by Lubow and others (2002) did not have sightings by front and rear observers, and only the pilot in the fixed-wing aircraft could locate elk groups with radio collars. Consequently, probabilities were fixed at 0 for occasions that did not apply to a particular group and this model structure was reduced mathematically to a two-occasion survey for the Lubow and others (2002) data (radio and aerial) and to three occasions (radio, front, and back) for the current dataset. Structuring the model this way enabled us to estimate common parameters for the effects of covariates, such as group size and vegetation, across the different studies while maintaining separate intercept parameters for the different sighting occasions. We fixed the probability of detection of a radio-collared group by the fixed-wing pilot at $p_{\text {radio }}=1$. 

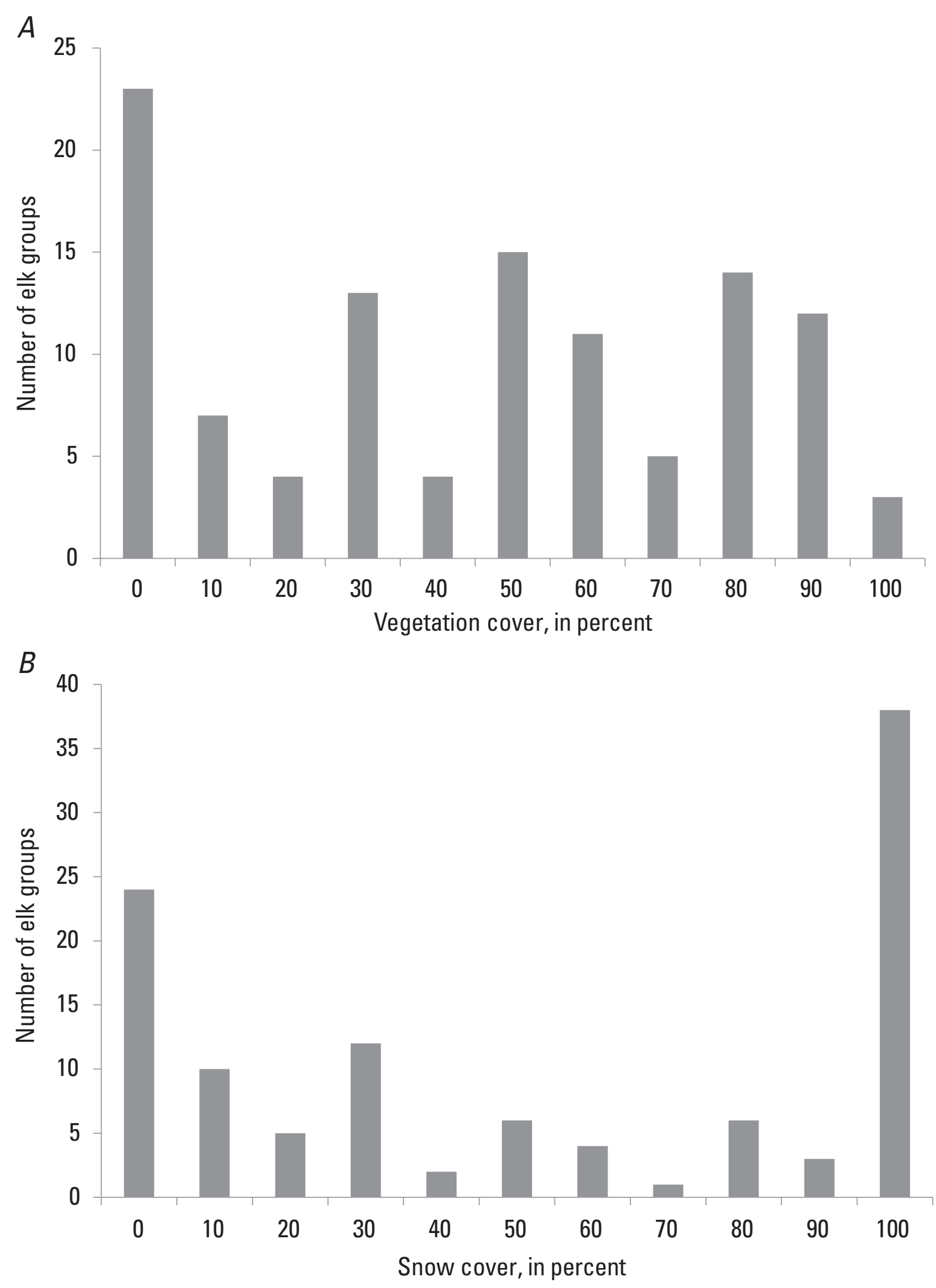

Figure 14. Distribution of elk groups by major sighting characteristics, $A$. percent vegetation cover, and B. percent snow cover, in elk population study in Rocky Mountain National Park, Colorado, 2008-2011. 
In all candidate models, the sighting probability for an elk group was defined by the logistic function, which specifies that detection probabilities are a logit function of the summed products of covariates multiplied by beta $(\beta)$ coefficient parameters. Sighting probability for each elk group $i$ on occasion $j$ can be thought of as having a unique intercept beta parameter, and potentially including a number of other additive effects represented by the product of other covariates and beta parameters (eq. 1).

$$
\mathrm{Pi}, \mathrm{j}=\frac{e^{\left(\beta x_{i, j}^{\prime}\right)}}{1+e^{\left(\beta x_{i, j}^{\prime}\right)}}
$$

where

$$
\begin{gathered}
\beta \quad \begin{array}{c}
\text { is a vector of fitted coefficients for the logistic } \\
\text { model (beta parameters); and }
\end{array} \\
x_{i, j}^{\prime} \quad \text { is a transpose of the vector of observed } \\
\text { covariates for an elk group } i \text { on occasion } j .
\end{gathered}
$$

The $\beta$ and $x_{i, j}^{\prime}$ vectors for a given elk group consist of the intercept for one of the observers, plus additional covariates that might affect the sighting probability of elk groups with those characteristics.

We considered structuring a general model with parameters for each observer and each survey. However, the number of groups sighted during many of the surveys is too small to effectively estimate unique effects for each. Consequently, we dropped consideration of parameters to describe effects due to individual surveys.

In a fully parameterized model, the probability of detecting elk could differ for the left and right sides of the aircraft. In the rear, this is due to different observers on each side; in the front, it is due to different angles and obstructions affecting visibility for the front observer and the extent to which the pilot assists in observing. We included two intercepts for the front observer: for elk on the left, $\beta_{L}$, and right, $\beta_{R}$, sides of the aircraft. We considered four intercepts for the four different individuals who observed from the rear on various surveys; however, we determined that it was necessary to pool data for two observers (Jason Ransom [JR] and Sheri Huwer [SH]) due to insufficient data for SH. Thus, the effects of JR and SH were assumed to be the same, which we believe is reasonable because these are both highly experienced observers. This left three intercept parameters for the rear: $\beta_{J R}=\beta_{S H}, \beta_{T,}, \beta_{Z W}$ (where TJ stands for Therese Johnson and ZW stands for Zac Wiebe).

In the Lubow and others (2002) study, the observer and pilot worked as a team to record elk groups; therefore, we considered a single parameter, $\beta_{A l l}$, for the sighting probability of the aerial observer during that study.

A difficulty arises in incorporating the radio-collar data into this model structure. When a radio-collared group is missed by all helicopter observers, there is no way to know which side of the aircraft it was on when the helicopter flew by it. Consequently, we structured the model to use the mean of the estimated left and right sighting probabilities for these groups.

In addition to the six intercept parameters described above, we considered the following five covariates unique to each elk group: (1) number of elk in group, (2) percent vegetation cover, (3) activity of elk group (moving or not moving), (4) percent snow cover, and (5) squared value of percent snow cover (table 5). We included only additive effects for these five covariates, rather than considering unique effects for each observer, because of the insufficient data for each observer. We also did not consider interactions among the covariates because of the small sample size. We included snow cover squared, $x_{S}^{2}$, because of the likelihood that snow cover affects sightability in a nonlinear manner. In total, there were up to 6 intercepts and four linear covariates, as well as a quadratic covariate, for a maximum of 11 parameters to be estimated for the most general model. Given the 111 observations, there is a ratio of 10 observations for each parameter to be estimated.

\section{Model Fitting and Selection}

The influence of covariates on detection probability was unknown, so we used a model-comparison framework (Burnham and Anderson, 1998) to assess which covariates influenced detection probability. We used optimization software (Frontline Systems Inc., Incline Village, Nevada) in program Excel (Microsoft Corp., Redmond, Washington) to find the maximum likelihood, Akaike information criterion (AIC)

Table 5. Covariates and corresponding model coefficients for each unique elk group used in the population estimation model for elk in Rocky Mountain National Park, Colorado, 2008-2011.

\begin{tabular}{ccl}
\hline $\begin{array}{c}\text { Observed } \\
\text { covarariate }\end{array}$ & $\begin{array}{c}\text { Model } \\
\text { coefficient }\end{array}$ & \multicolumn{1}{c}{ Description } \\
\hline$x_{N}$ & $\beta_{N}$ & Group size (number of elk) \\
$x_{C}$ & $\beta_{C}$ & Proportion of ground in vicinity of elk group covered by vegetation tall enough to obscure elk (0.0-1.0) \\
$x_{A}$ & $\beta_{A}$ & Activity: 0 if inactive (bedded or standing), 1 if active (elk moving) \\
$x_{S}$ & $\beta_{S}$ & Proportion of ground in vicinity of elk group covered by snow $(0.0-1.0)$ \\
$x_{S}{ }^{2}$ & $\beta_{S}{ }^{2}$ & Squared value of proportion of ground in vicinity of elk group covered by snow $(0.0-1.0)$ \\
\hline
\end{tabular}


values, and beta parameter estimates for each of the alternative models. Based on the resulting model weights and matrix of parameter estimates, we then found the group-specific correction factors using equation 1 for each alternative model.

We compared the parsimony of the candidate models using AIC adjusted for small sample size, $\mathrm{AIC}_{c}$ (Burnham and Anderson, 1998). We examined the evidence supporting various effects by evaluating the evidence ratio between the alternative models both with and without the effect of interest. The evidence ratio is the ratio between the support for the better model and the weaker model; that is, a ratio of 2.0 means there is twice as much support for the stronger model. We selected models with $\triangle \mathrm{AIC}_{\mathrm{c}}<4.0$ to include in our inference set, which we used to estimate population size. We also compared the strength of evidence for the models in this set using $\mathrm{AIC}_{c}$ model weights.

The most general model (11 parameters) fit the data well, with a variance inflation factor of $c=1.54$ (values $<2$ are considered indicative of an adequate model structure). Consequently, we did not use a variance inflation adjustment to the likelihood estimation.

In addition to the general model, we fit and evaluated alternatives with each slope parameter removed, one at a time, and with two different constraints on the observer-specific intercepts: (1) $\beta_{F L}=\beta_{F R}$, (FL stands for front-left and FR stands for front-right) and (2) $\beta_{T J}=\beta_{J H}=\beta_{S H}=\beta_{Z W}$ (subscripts are initials of observers). After concluding that $\beta_{N}$ (group size), $\beta_{A}$ (elk activity), and $\beta_{C}$ (vegetation cover) were strongly supported and that the constraint $\beta_{T J}=\beta_{J H}=\beta_{S H}=\beta_{Z W}$ was strongly disfavored, we considered all combinations of the remaining variables with intermediate support: $\beta_{S}$ (snow cover), $\beta_{S}{ }^{2}$ (snow cover squared), and $\beta_{F L}=\beta_{F R}$. In total, we considered 12 models. Of these, eight had $\triangle \mathrm{AIC}_{\mathrm{c}}<4.0$, and so were sufficiently supported to include in our final inference set (table 6). We used these eight models to estimate population size and used the model-weighted average of these to generate the final estimate of population size.

\section{Point Estimate Method}

The unconditional overall detection probability $\left(p_{i}\right)$ for elk group $i$ is one minus the probability that it was missed by all observers (eq. 2).

$$
p_{i}=1-\left(1-p_{\text {radio }, i}\right)\left(1-p_{\text {all }}\right)\left(1-p_{F L}\right)\left(1-p_{F R}\right)\left(1-p_{T J}\right)\left(1-p_{J R=S H}\right)\left(1-p_{Z W}\right)
$$

Note that elk groups with at least one radio-collared animal have $\rho_{\text {radio }}=1$, so their $\rho_{i}=1$. For elk groups with no radio-collared animals, $\rho_{\text {radio }}=0$, the $\rho_{i}$ for those elk groups is a function of $\rho_{\text {all }}, \rho_{F L}, \rho_{F R}, \rho_{T,}, \rho_{J R=S H}$ and $\rho_{Z W}$. Recall that, for any given survey and elk group, only some of these observers are present, so all inapplicable values are fixed at 0 . The groupspecific correction factor $\left(\hat{\theta}_{i}\right)$ is the inverse of the group's unconditional overall detection probability (Steinhorst and Samuel, 1989; eq. 3).

$$
\theta \mathrm{i}=\frac{1}{p_{i}}
$$

Correction factors can be thought of as the per-observedelk contribution to the overall estimate of abundance; it is one plus a corresponding number of unseen elk that occur in groups with the same covariates as that observed. The contribution to an abundance estimate coming from group $i$ is the product of its observed group size $\left(n_{i}\right)$ times its group-specific correction factor, $\hat{\theta}_{i}$. For a given survey, the total estimated abundance $(N)$ is the sum of the products of group size weighted by group-specific correction factors (eq. 4).

$$
\mathrm{Ni}=\Sigma \theta j * \mathrm{nj}
$$

\section{Estimating Variance in Abundance Estimates with Bootstrapping}

The variance of abundance estimates was calculated from bootstrapped simulations of the observation data (Wong, 1996; Lubow and others, 2002). The motivation for this method comes from the notion that the observed elk groups were drawn from a larger set of elk groups that could have been observed. This larger set is considered to be a "super-population" in the statistical sense (Hartley and Sielken, 1975).

We use the group-specific correction factors estimated from the double-observer sightability model to simulate a set of potentially observable groups in the super-population, having group size and other sighting covariates identical to those in the observed dataset. Each simulated elk group retains covariates corresponding to those in the actual dataset and retains its membership as belonging to a certain survey. Observed groups "represent" themselves as well as additional, undetected groups in the super-population. The correction factor is a measure of how many groups each observed group represents. So, each observed group was replicated $\hat{\theta}_{j}$ times, to define the superpopulation. By definition, each elk group with one or more radio-collared elk has a $\hat{\theta}_{j}$ value of one, because such groups are always detected via radio telemetry. However, for each iteration of generating a super-population, decimal fractions of simulated groups were either included or not included depending on a comparison against a random number. As an example, an observed group with an estimated sighting probability of 0.4 and $\hat{\theta}_{j}$ of 2.5 represents two and one-half comparable elk groups with identical covariates. In this example, two elk groups would be included in the super-population in every iteration of the bootstrap dataset creation; in addition, to account for the additional fraction of a group, another group would be added during each iteration only if a randomly generated number (uniform distribution ranging from $0-1$ ) was less than the remaining fraction (in this case, 0.5).

From that putative super-population, we simulated observations that were included in the dataset by testing whether each elk group, in turn, was detected by the front or rear observer, or if the group had a radio-collared elk, by the radio telemetry 
Table 6. Sightability model alternatives with fit and selection statistics for elk population estimation study in Rocky Mountain National Park, Colorado, $2008-2011$.

[obs., observer; $\operatorname{Ln}(\mathrm{L})$, natural log; no., number; N, observations; K, parameters; AIC, Akaike information criterion; \%, percent]

\begin{tabular}{|c|c|c|c|c|c|c|c|c|c|c|c|c|}
\hline \multicolumn{13}{|c|}{ Model } \\
\hline Rank & 1 & 2 & 3 & 4 & 5 & 6 & 7 & 8 & 9 & 10 & 11 & 12 \\
\hline \multicolumn{13}{|c|}{ Intercepts ${ }^{\mathrm{a}}$} \\
\hline Front & 1 & 1 & 1 & 1 & 2 & 2 & 2 & 2 & 1 & 1 & 1 & 1 \\
\hline Rear & 3 & 3 & 3 & 3 & 3 & 3 & 3 & 3 & 3 & 1 & 3 & 3 \\
\hline combined (single obs.) & 1 & 1 & 1 & 1 & 1 & 1 & 1 & 1 & 1 & 1 & 1 & 1 \\
\hline \multicolumn{13}{|c|}{ Slopes ${ }^{\mathrm{a}}$} \\
\hline Group size & 1 & 1 & 1 & 1 & 1 & 1 & 1 & 1 & 1 & 1 & 1 & 0 \\
\hline Cover & 1 & 1 & 1 & 1 & 1 & 1 & 1 & 1 & 1 & 1 & 0 & 1 \\
\hline Activity & 1 & 1 & 1 & 1 & 1 & 1 & 1 & 1 & 0 & 1 & 1 & 1 \\
\hline Snow & 0 & 0 & 1 & 1 & 0 & 0 & 1 & 1 & 1 & 1 & 1 & 1 \\
\hline Snow squared $\left(\right.$ Snow $\left.^{2}\right)$ & 1 & 0 & 1 & 0 & 1 & 0 & 0 & 1 & 1 & 1 & 1 & 1 \\
\hline \multicolumn{13}{|c|}{ Model fit and selection statistics } \\
\hline $\operatorname{Ln}(L)$ & -78.40 & -79.77 & -77.61 & -78.83 & -78.40 & -79.77 & -78.83 & -77.60 & -81.04 & -82.43 & -85.35 & -87.13 \\
\hline Deviance & 156.8 & 159.5 & 155.21 & 157.7 & 156.8 & 159.5 & 157.7 & 155.2 & 162.1 & 164.9 & 170.7 & 174.3 \\
\hline no. Observations $(N)$ & 111 & 111 & 111 & 111 & 111 & 111 & 111 & 111 & 111 & 111 & 111 & 111 \\
\hline No. of Parameters $(K)$ & 9 & 8 & 10 & 9 & 10 & 9 & 10 & 11 & 9 & 8 & 9 & 9 \\
\hline Degrees of freedom & 102 & 103 & 101 & 102 & 101 & 102 & 101 & 100 & 102 & 103 & 102 & 102 \\
\hline Variance Inflation Factor ( $(\hat{c})$ & 1.54 & 1.55 & 1.54 & 1.55 & 1.55 & 1.56 & 1.56 & 1.55 & 1.59 & 1.60 & 1.67 & 1.71 \\
\hline $\mathrm{AIC}_{c}$ & 176.6 & 177.0 & 177.41 & 177.5 & 179.0 & 179.3 & 179.9 & 179.9 & 181.9 & 182.3 & 190.5 & 194.0 \\
\hline Delta $\mathrm{AIC}_{c}$ & 0.00 & 0.37 & 0.82 & 0.86 & 2.42 & 2.74 & 3.28 & 3.28 & 5.28 & 5.69 & 13.88 & 17.44 \\
\hline Relative model weight & 1.00 & 0.83 & 0.66 & 0.65 & 0.30 & 0.25 & 0.19 & 0.19 & 0.07 & 0.06 & 0.00 & 0.00 \\
\hline Model weight ${ }^{\mathrm{b}}$ & $25.7 \%$ & $21.4 \%$ & $17.0 \%$ & $16.7 \%$ & $7.7 \%$ & $6.5 \%$ & $5.0 \%$ & $5.0 \%$ & & & & \\
\hline Evidence ratios & 1.0 & 1.2 & 1.5 & 1.5 & 3.3 & 3.9 & 5.1 & 5.2 & 14.0 & 17.2 & 1,034 & 6,136 \\
\hline
\end{tabular}

avalues indicate number of parameters included in given model.

${ }^{b}$ Model weights computed for inference set only. 
observer. Front, rear, combined, and radio telemetry observer detections were simulated for each elk group from the simulated super-population of elk groups. Each simulated elk group in the super-population was recorded as either detected or not detected by each observer, based on evaluating a random number against the original estimates of detection probabilities for that observer. The simulated observation dataset for each iteration only included elk groups that were detected by at least one of the simulated observers.

Each dataset of simulated observations was used to solve for the parameter estimates and $\mathrm{AIC}_{c}$ estimates for each of the eight contributing models in our inference set. These lead to group-specific correction factors $\left(\hat{\theta}_{j}\right)$ for the simulated groups, which were multiplied by group sizes to yield the abundance $(\hat{N})$ estimates for each simulated survey. We generated 100 such simulated observation datasets, solved for model parameters and weights, applied correction factors, and found estimated abundances from each. The coefficient of variation for the point estimate of abundance, $\widehat{C V}(\hat{N})$, and associated confidence limits were calculated based on the range of simulated abundance estimates.

\section{Results}

\section{Model Fitting and Support}

The most strongly supported model received 25.7 percent of the model weight (table 6). This model included nine parameters, which did not include the $\beta_{S}$, but did include $\beta_{S}{ }^{2}$ and constrained $\beta_{F L}=\beta_{F R^{*}}$ Of the eight models in the inference set, snow effects (linear or quadratic) were supported by 73.4 percent of the model weight. Differences between front left and front right sighting probabilities were supported by only 23.9 percent of model weight. Comparison of the best model to others revealed overwhelming support (evidence ratios given for each effect; table 6) for inclusion of parameters for population size (evidence ratio $=6,136$ ), activity (evidence ratio $=1,034$ ), cover (evidence ratio $=14$ ), and differences among rear observers (evidence ratio $=17.2$ ).

Several effects received some support, which justified including models with these parameters in the final inference set. We included the eight models in this set that had $\triangle \mathrm{AIC}_{\mathrm{c}}$ $<4.0$. The base model had 33.7 percent of the model weight among those in this set.

Model-weighted averages of the parameters using the inference set (see table 5) indicated effects in the expected direction: higher sighting probabilities for larger groups, active groups, and less cover (table 7). Sighting probability for the pooled data on the two most experienced rear observers was highest, followed by the combined observers in the Lubow and others (2002) study, then by the front observer, and finally by the two less experienced rear observers. Snow effects involve both positive linear and negative quadratic terms in two of the models, which result in higher estimated sighting probabilities for very low and very high snow cover,
Table 7. Sightability model parameters and model weighted average estimates for elk population estimation study in Rocky Mountain National Park, Colorado, 2008-2011.

[See table 5 for definitions of the variables $\beta_{N}, \beta_{A}, \beta_{C}, \beta_{S}$, and $\beta_{S}{ }^{2} . \beta_{L}$, left side of aircraft; $\beta_{R}$, right side of aircraft; $\beta_{T J}$, observer TJ; $\beta_{J R=S H}$, observers JR and $\mathrm{SH} ; \beta_{Z W}$, observer ZW; $\beta_{A l l}$, all observers]

\begin{tabular}{ccc}
\hline Parameter & $\begin{array}{c}\text { Model weighted } \\
\text { average estimates }\end{array}$ \\
\hline$\beta_{L}$ & Intercepts \\
$\beta_{R}$ & -1.0837 \\
$\beta_{T J}$ & -1.0804 \\
$\beta_{J R=S H}$ & -0.8642 \\
$\beta_{Z W}$ & 1.8375 \\
$\beta_{A l l}$ & -0.5570 \\
& & 0.4786 \\
\hline$\beta_{N}$ & Slopes & \\
$\beta_{A}$ & 0.0156 \\
$\beta_{C}$ & 1.9910 \\
$\beta_{S}$ & -2.1014 \\
$\beta_{S}{ }_{S}$ & -0.5846 \\
\hline
\end{tabular}

and lower for intermediate snow cover, which corresponds to patchy conditions (table 7).

Predicted sighting probabilities varied greatly (fig. 15) and were strongly affected by the observer, group size, activity, vegetation cover, and snow cover (figs. 16 and 17). There was no evidence of a difference between sighting probabilities of groups with and without radio collars ( $\mathrm{x} 2=0.91)$. Under the worst possible conditions of a single inactive elk in 100 percent vegetation cover and 20 percent snow cover, sighting probability for the front and rear observers, combined, was only 1.5 percent when using the least experienced rear observer. However, this worst case improved to 5.5 percent when using the best rear observer. Nevertheless, the worst conditions actually encountered resulted in a combined sighting probability of 6.7 percent. Only 11.3 percent of radio-collared groups and 9.0 percent of all groups had $\leq 30$ percent sighting probability because worst-case conditions were rarely encountered. For a more typical sighting, an inactive group of 10 elk in 50 percent vegetation cover and 100 percent snow cover, combined sighting probability was 73.2 percent using the best observer in the rear, but dropped to 37.0 percent with the less experienced observer in the rear. 


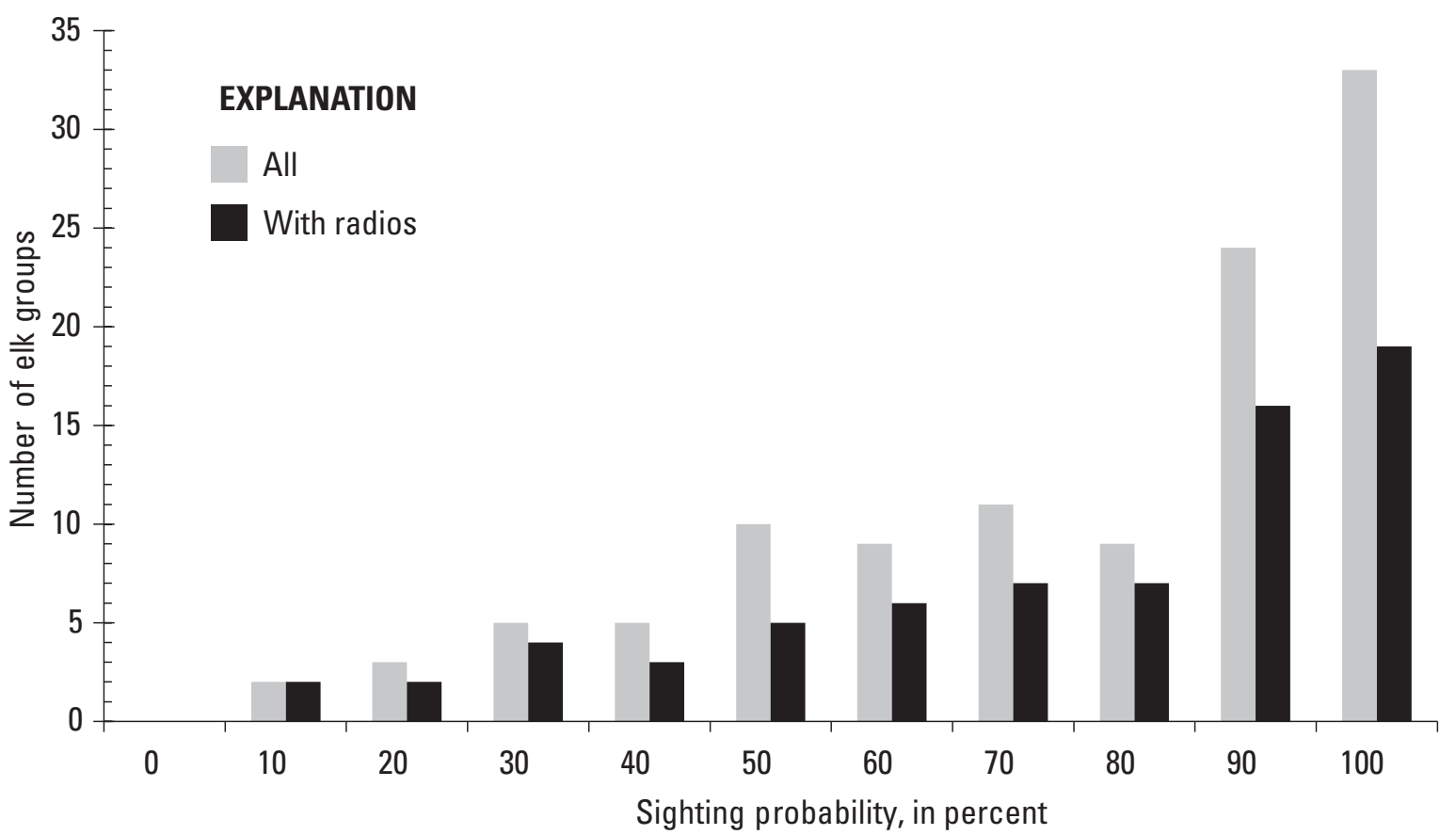

Figure 15. Distribution of sighting probabilities for combined front and rear observers for all elk groups marked with radio collars, illustrating how groups varied widely in visibility. Bar heights indicate the number of groups observed that had the indicated sighting probability estimate. (\%, percent)

\section{Population Estimates and Precision}

Population estimates (table 8 ) had very good estimated precision $(\leq 16$ percent standard error $[\mathrm{SE}])$. Snow conditions were ideal (100 percent cover) for the February 2010 survey, which resulted in the excellent precision of 3.1 percent $\mathrm{CV}$. Although snow conditions were not as good in January 2010, our most experienced observer was in the rear and that overcame the reduced sighting probabilities caused by snow conditions, resulting in the best precision of the five surveys (2.7 percent $\mathrm{CV}$ ). The earliest two surveys did not have data from radio-marked elk, which reduced their precision.

For comparison, we also estimated the populations during the three surveys where radio-collar data were available without including the data from these collared elk (table 8). These estimates reflect what would have been obtained had the surveys been conducted by only the helicopter crew using the double-observer method with the corrections estimated in this study. Without the radio-collar data, precision dropped, as expected. The worst case was November 2009 when precision without radio-collar data would have been 27.0 percent $\mathrm{CV}$. This was due to a combination of patchy snow conditions and the absence of the most experienced rear observers. The estimates without radio-collar data also ranged from 8.8 percent lower to 1.1 percent higher (mean $=4.1$ percent, $\mathrm{SE}=2.9$ percent). This suggests the possibility of a small residual negative bias due to uncorrected sighting heterogeneity, although the confidence intervals overlap 0 percent, so evidence for a residual bias is inconclusive.
Our estimates indicate that between 84 percent and 97 percent of elk were seen by the combined observers during these surveys, with the lowest estimated portion of the population seen during the November 2009 survey for the same reasons the precision on that survey was lowest, as discussed above. Although sighting probability can be very low for some groups, larger groups have higher sighting probability. Therefore, the number of elk missed by aerial observers is relatively low.

\section{Discussion}

One of the major challenges of estimating the number of elk in RMNP is the difficulty of obtaining an adequate sample size of observed elk groups to fit sighting probability models. This is primarily caused by the clustering of elk into a small number of very large groups and a few smaller groups. The cost and logistical difficulty of aerial surveys exacerbate this problem. One of the benefits of the double-observer method used in our study is that each survey cumulatively adds to the dataset of observations used to calibrate the sighting probability models. Consequently, results can continue to improve over time as regular monitoring adds additional observations.

Furthermore, if observers and sighting conditions change over time, these changes can eventually (with enough data) be detected and accounted for using our method, which was not possible with just the sightability calibration approach that was previously used. For example, our results strongly support differences in sighting probability among individual observers, 

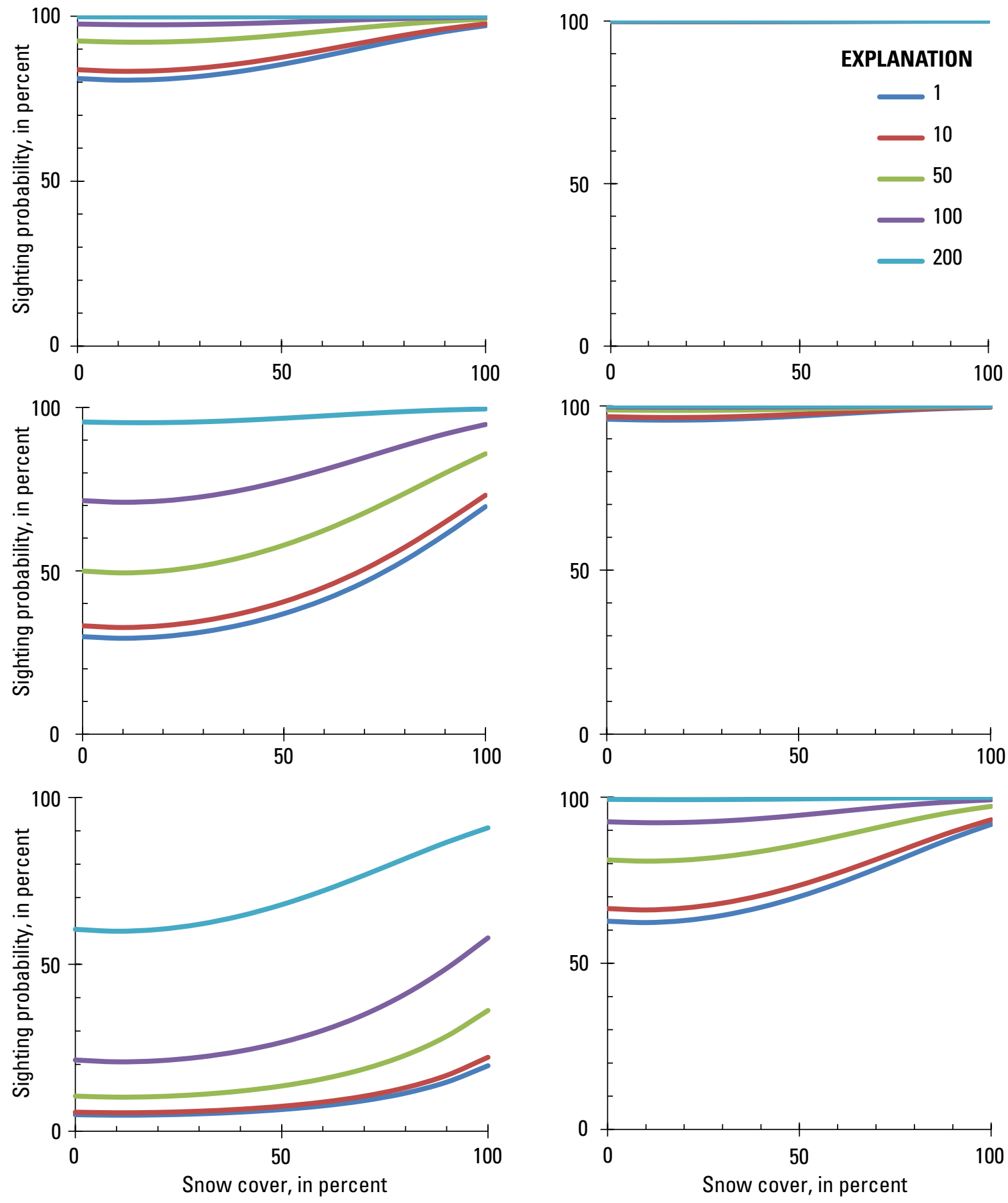

Figure 16. Sighting probability for combined front and rear observers, using rear observer with highest sighting probability, for elk population estimation study in Rocky Mountain National Park, 2008-2011. 

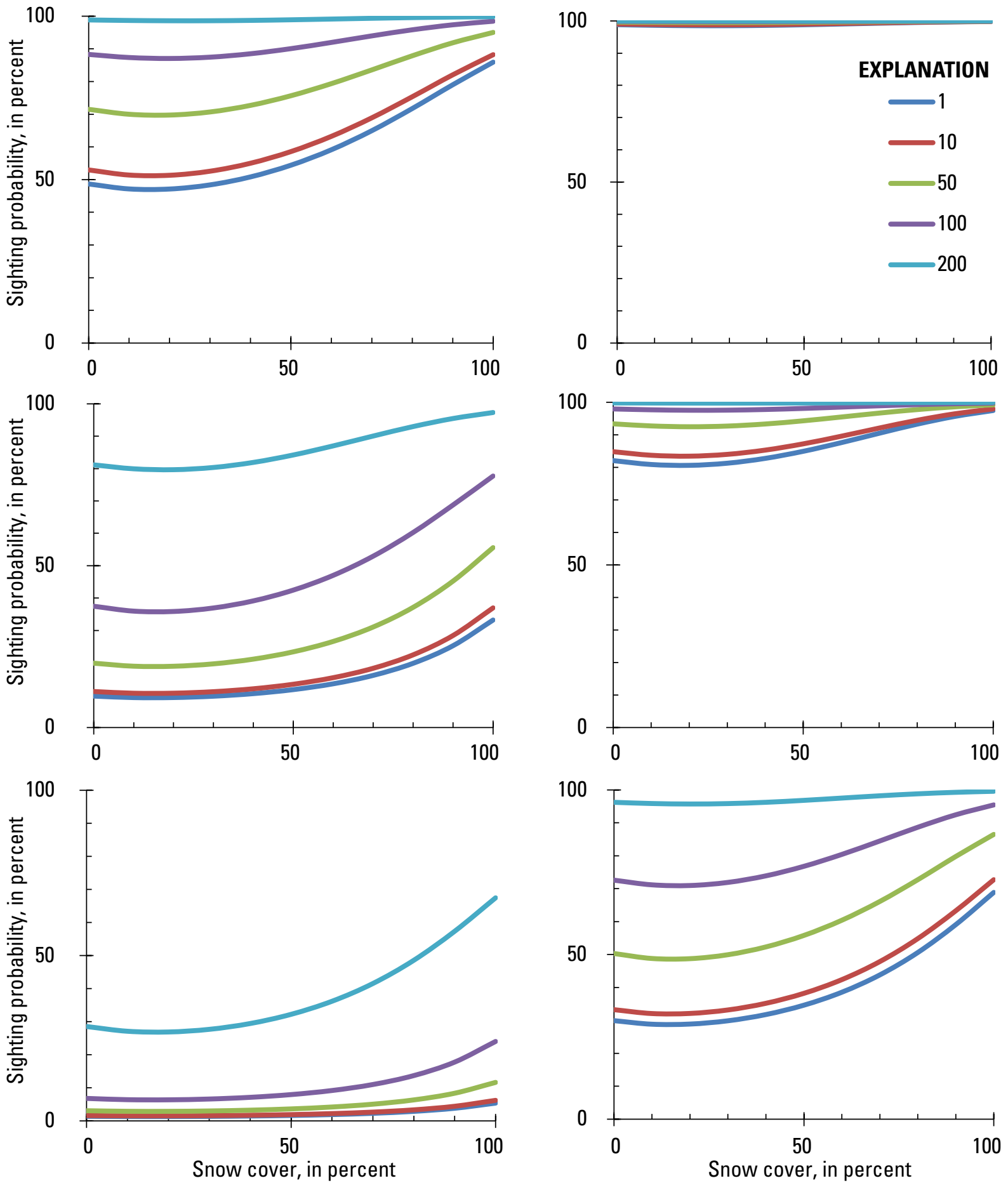

Figure 17. Sighting probability for combined front and rear observers, using rear observer with lowest sighting probability, for elk population estimation study in Rocky Mountain National Park, 2008-2011. 
Table 8. Elk population estimates and precision, comparing analyses with and without radio-collar data, for elk population estimation study in Rocky Mountain National Park, 2008-2011.

[No., number; - , no data; SE, standard error; CV, coefficient of variation; \%, percent, $\mathrm{Cl}$, confidence interval]

\begin{tabular}{|c|c|c|c|c|c|c|c|c|c|c|c|}
\hline & \multicolumn{5}{|c|}{ Survey date } & & \multicolumn{5}{|c|}{ Survey date } \\
\hline & Feb-10 & Jan-10 & Nov-09 & Jan-09 & Feb-08 & & Feb-10 & Jan-10 & Nov-09 & Jan-09 & Feb-08 \\
\hline \multicolumn{6}{|c|}{ Using radio-collar data in population estimates } & \multicolumn{6}{|c|}{ Without using radio-collar data in population estimates ${ }^{1}$} \\
\hline No. elk seen & 464 & 523 & 586 & - & - & No. elk seen & 432 & 508 & 526 & 508 & 381 \\
\hline Estimate (no. elk) & 476 & 532 & 683 & - & - & Estimate (no. elk) & 454 & 538 & 623 & 559 & 402 \\
\hline CV & $3.1 \%$ & $2.7 \%$ & $16.8 \%$ & - & - & CV & $15.6 \%$ & $6.8 \%$ & $27.0 \%$ & $13.6 \%$ & $14.0 \%$ \\
\hline$\%$ seen & $97 \%$ & $98 \%$ & $86 \%$ & - & - & $\%$ seen & $95 \%$ & $94 \%$ & $84 \%$ & $91 \%$ & $95 \%$ \\
\hline Lower 95\% Cl & 458 & 514 & 550 & - & - & Lower $95 \% \mathrm{Cl}$ & 372 & 492 & 442 & 469 & 336 \\
\hline Upper 95\% Cl & 495 & 551 & 847 & - & - & Upper 95\% Cl & 555 & 587 & 877 & 666 & 482 \\
\hline
\end{tabular}

${ }^{1}$ Estimates based on double-observer helicopter survey only; radio collars ignored.

${ }^{2}$ We developed elk survey protocols and transect flight lines for the alpine tundra area of the park, however, tundra surveys are only conducted when wind conditions allow for safe flying, which is not an annual occurrence. Therefore, population estimates for the alpine are shown independently, and are not included in other population estimates shown.

so the ability to account for these differences in our method improves precision of estimates. The result showing differences in sighting probability among observers emphasizes the importance of retaining observers for multiple surveys so that their individual sighting probabilities can be adequately measured and accounted for in statistical corrections. Frequent changes in personnel will reduce the precision of the estimates and risk uncorrected biases as well.

A second challenge to reliable elk population estimation in RMNP is heterogeneous sighting probabilities. A simple double-observer approach would underestimate the population because it assumes that all groups have equal probability of being sighted. By combining a double-observer method with a sighting covariate model, we corrected for the major sighting probability differences among elk groups. Nevertheless, comparison of estimates made with and without radio collars suggests a small residual bias remains unexplained by our models. A larger sample size with radio-collared elk would enable a future analysis to fit models to correct for this additional bias following the methods of Griffin and others (2013).

Our models predicted poor sighting probabilities for worst-case conditions. Two of these, snow cover and observer ability, can be managed to some extent. It is likely that surveys conducted under low and patchy snow conditions using less experienced observers will have low precision and may not be worth the cost. Nevertheless, it is possible to obtain adequate sighting probability, even in dense vegetation, if these other factors are optimized. But restricting surveys to ideal snow conditions and the availability of the most experienced observers exacerbates the logistical difficulty of scheduling and conducting surveys.

The study was limited by the small number of radio collars on bull elk combined with the small sample size of elk groups overall, which precluded estimation of different sighting probabilities for bull groups. This raises concerns about the applicability of our method to estimation of the bull population segment. Of particular concern was the possibility that bulls were out of the sampling area or in different sighting conditions that could make them more difficult to observe during our surveys.

The park allocated funds to purchase and deploy 12 GPS radio collars on bull elk in order to help answer this question. We found that bulls were typically in smaller groups than females and single bulls wearing radio collars were missed more frequently in aerial surveys than radio-collared cows, consistent with McCorquodale (2001); however, our corrections for group size allowed us to address this effect for bulls.

In addition, the GPS collars allowed us to obtain evidence suggesting that dense tree cover may not be an important contribution to biased bull estimates. Only 22 percent of radiocollared bull locations in winter were in dense tree cover, whereas the remaining locations were in open meadow, low shrub, or open mixed trees, all vegetation types with higher sightability. Also, bulls used dense tree cover more frequently 
between 15:00 and 22:00, as opposed to mornings and early afternoons when aerial surveys were conducted. Mean daily use of dense trees by bulls was approximately 24 percent and monthly average use was approximately 28 percent. This was similar to the percentages of cow groups observed during surveys that were in dense vegetation cover. Given that there is little evidence of differences in cover use between age-sex classes, the estimated sightability corrections for vegetation cover in our models should be adequate to address the effect of dense tree cover.

Of greater concern, however, is our finding that between 47 percent and 58 percent of radio-collared bulls were out of the survey area during aerial surveys, and were more often outside the park than simply outside of the survey area. This finding is limited by small sample size, but suggests that roughly half of the bulls are not within the survey area at the time of a survey. Bulls remain challenging to count because of their movement rates, particularly in and out of the park. Bull elk in our study made approximately 6 round trips from the park to Estes Park and back per month per bull during 1,838 winter elk-days. Despite fine tuning the survey area to account for elevation limits and areas that do not appear to be used by elk, little can be done to account for bulls that are not present during the survey. This emphasizes the importance of interpreting survey results as only an estimate of the elk present at the time of the survey, and not as an estimate of a fixed population.

Our study defined a survey area boundary that included nearly all winter elk locations within the park and east of the Continental Divide (excluding the tundra). These boundaries excluded large, mostly densely wooded areas in the southern portion of the park, despite meeting our elevation criteria. Reconfirming that elk continue to avoid these areas in winter may be warranted every 3 to 5 years.

Obtaining accurate estimates of the elk population that use winter range in RMNP is challenging. We considered and reconsidered these challenges throughout our study and developed an aerial survey methodology that can be applied into the future to provide repeatable and reliable estimates of the elk population. Consistent, repeatable surveys of the defined survey area will provide data needed to support future decisions by park managers. However, given the frequent movements of elk in and out of the survey area, it is important that the results of individual surveys be interpreted correctly as estimates of elk use of the park at the time of each survey. Probably the most useful measurement for management purposes is an average of estimates from multiple surveys conducted on multiple dates (three or more) selected randomly from the time window of interest. This approach provides an estimate of the average elk use of the park during the time window sampled, rather than an estimate of the total population of elk inhabiting the park and Estes Valley.

\section{References Cited}

Anderson, D.R., and Southwell, C., 1995, Estimates of macropod density from line transect surveys relative to analyst experience: Journal of Wildlife Management, v. 59, p. $852-857$.

Baker, D.L., Wild, M.A., and Powers, J.G., 2007, Evaluation of methods for managing elk population health and abundance in Rocky Mountain National Park, Colorado: Estes Park, Colo., National Park Service Research Study Plan, 16 p.

Barker, R., 2008, Theory and application of mark-recapture and related techniques to aerial surveys of wildlife: Wildlife Research, v. 35, p. 268-274.

Bayliss, P., and Yeomans, K.M., 1989, Correcting bias in aerial survey population estimates of feral livestock in northern Australia using the double-count technique: Journal of Applied Ecology, v. 26, p. 925-933.

Bear, G.D., 1989, Seasonal distribution and population characteristics of elk in Estes Valley, Colorado: Fort Collins, Colo., Colorado Division of Wildlife Special Report No. 65, $52 \mathrm{p}$.

Bodie, W.L., Garton, E.O., Taylor, E.R., and McCoy, M., 1995, A sightability model for bighorn sheep in canyon habitats: Journal of Wildlife Management, v. 59, p. 832-840.

Borchers, D.L., Buckland, S.T., Goedhart, P.W., Clarke, E.D., and Hedley, S.L., 1998a, Horvitz-Thompson estimators for double-platform line transect surveys: Biometrics, v. 54, p. $1221-1237$.

Borchers, D.L., Zucchini, W., and Fewster, R.M., 1998b, Mark-recapture models for line transect surveys: Biometrics, v. 54, p. 1207-1220.

Bowden, D.C., and Kufeld, R.C., 1995, Generalized marksight population size estimation applied to Colorado moose: Journal of Wildlife Management, v. 59, p. 840-851.

Buckland, S.T., Anderson, D.R., Burnham, K.P., and Laake, J.L., 1993, Distance sampling - Estimating abundance of biological populations: London, Chapman and Hall, 446 p.

Burnham, K.P., and Anderson, D.R., 1976, Mathematical models for nonparametric inferences from line transect data: Biometrics, v. 32, p. 325-336.

Burnham, K.P., and Anderson, D.R., 1998, Model selection and inference-A practical information-theoretic approach: New York, Springer-Verlag, 355 p.

Cook, R.D., and Jacobson, J.O., 1979, A design for estimating visibility bias in aerial surveys: Biometrics, v. 35, p. 735-742. 
Daigle, G., Rivest, L.P., and Crepeau, H., 1995, Statistical methods for aerial surveys using the double observer technique to correct visibility bias: Biometrics, v. 51, p. 461-470.

Gogan, P.J.P., Thompson, S.C., Pierce, W., and Barrett, R.H., 1986, Line transect censuses of fallow and black-tailed deer on the Point Reyes Peninsula: California Game and Fish, v. 72, p. $47-61$.

Graham, G.W., and Bell, R., 1989, Investigating observer bias in aerial survey by double observers: Journal of Wildlife Management, v. 53, p. 1009-1016.

Griffin, P.C., Lubow, B.C., Jenkins, K.J., Vales, D.J., Moeller, B.J., Reid, M., Happe, P.J., McCorquodale, S.M., Tirhi, M.J., Schaberl, J.P., and Beirne, K., 2013, A hybrid doubleobserver sightability model for aerial surveys: Journal of Wildlife Management, v. 77, p. 1532-1544.

Gysel, L.W., 1960, An ecological study of the winter range of elk and mule deer in the Rocky Mountain National Park: Journal of Forestry, v. 58, p. 696-703.

Hartley, H.O., and Sielken, R.L., 1975, A "super-population viewpoint" for finite population sampling: Biometrics, v. 31, p. $411-422$.

Hobbs, N.T., Baker, D.L., Ellis, J.E., Swift, D.M., and Green, R.A., 1982, Energy- and nitrogen-based estimates of elk winter range carrying capacity: Journal of Wildlife Management, v. 46, p. 12-21.

Huggins, R.M., 1991, Some practical aspects of a conditional likelihood approach to capture experiments: Biometrics, v. 47 , p. $725-732$.

Johnson, B.K., Lindzey, F.G., and Guenzel, R.J., 1991, Use of aerial line transect surveys to estimate pronghorn populations in Wyoming: Wildlife Society Bulletin, v. 19, p. 315-321.

Kacynski, K., 2013, Riparian willow decline in ColoradoInteractions of ungulate browsing, native birds, and fungi: Fort Collins, Colo., Colorado State University, Ph.D. dissertation, $94 \mathrm{p}$.

Larkins, K.F., 1997, Patterns of elk movement and distribution in and adjacent to the eastern boundary of Rocky Mountain National Park: Greeley, Colo., University of Northern Colorado, Master's Thesis, $89 \mathrm{p}$.

Lubow, B. C., Singer, F.J., Johnson, T.L., and Bowden, D.C., 2002, Dynamics of interacting elk populations within and adjacent to Rocky Mountain National Park: Journal of Wildlife Management, v. 66, p. 757-775.

Manly, B.F.J., McDonald, L.L., and Garner, G.W., 1996, Maximum likelihood estimation for the double-count method with independent observers: Journal of Agricultural, Biological, and Environmental Statistics, v. 1, p. 170-189.
McCorquodale, S.M., 2001, Sex-specific bias in helicopter surveys of elk-Sightability and dispersion effects: Journal of Wildlife Management, v. 65, p. 216-225.

National Park Service, 2007, Final Environmental Impact Statement, Elk and Vegetation Management Plan, Rocky Mountain National Park, Colorado: Washington, D.C., National Park Service, 535 p.

National Park Service, 2008, Record of Decision/Final Environmental Impact Statement-Elk and Vegetation Management Plan, Rocky Mountain National Park, Colorado: Washington, D.C., National Park Service, 21 p.

Pollock, K.H., and Kendall, W.L., 1987, Visibility bias in aerial surveys - A review of estimation procedures: Journal of Wildlife Management, v. 51, p. 502-510.

Samuel, M. D., Garton, E.O., Schlegel, M.W., and Carson, R.G., 1987, Visibility bias during aerial surveys of elk in northcentral Idaho: Journal of Wildlife Management, v. 51, p. $622-630$.

Samuel, M. D., and Pollock, K.H., 1981, Correction of visibility bias in aerial surveys where animals occur in groups: Journal of Wildlife Management, v. 45, p. 993-997.

Seber, G. A. F., 1982, The estimation of animal abundance and related parameters ( $2 \mathrm{~d}$ ed.): New York, MacMillian, $653 \mathrm{p}$.

Singer, F.J., and Zeigenfuss, L.C., comps., 2002, Ecological evaluation of the abundance and effects of elk herbivory in Rocky Mountain National Park, Colorado, 1994-1999: U.S. Geological Survey Open-File Report 2002-208, 268 p.

Skovlin, J.M., Zager, P., and Johnson, B.K, 2002, Elk habitat selection and evaluation, in Toweill, D.E., Thomas, J.W., and Metz, D.P., eds., North American elk-Ecology and management: Washington, D.C., Smithsonian Institution Press, p. 531-555.

Southwell, C., 1994, Evaluation of walked line transect counts for estimating macropod density: Journal of Wildlife Management, v. 58, p. $348-356$.

Steinhorst, R.K., and Samuel, M.D., 1989, Sightability adjustment methods for aerial surveys of wildlife populations. Biometrics, v. 45, p. 415-425.

Stevens, D.R., 1980, The deer and elk of Rocky Mountain National Park-A 10-year study: Estes Park, Colo., Rocky Mountain National Park, Park Report ROMO-N-13, 67 p.

Thomas, L., Buckland, S.T., Rexstad, E.A., Laake, J.L., Strindberg, S., Hedley, S.L., Bishop, J.R.B., Marques, T.A., and Burnham, K.P., 2010, Distance software-Design and analysis of distance sampling surveys for estimating population size: Journal of Applied Ecology, v. 47, p. 5-14. 
Trenkel, V.M., Buckland, S.T., McLean, C., and Elston, D.A., 1997, Evaluation of aerial line transect methodology for estimating red deer (Cervus elaphus) abundance in Scotland: Journal of Environmental Management, v. 50, p. $39-50$.

Unsworth, J.W., Leban, F.A., Leptich, D.J., Garton, E.O., and Zager, P., 1994, Aerial survey-User's manual (2d ed.): Boise, Idaho, Idaho Department of Fish and Game, 84 p.

White, G.C., 1996, NOREMARK - Population estimation from mark-resighting surveys: Wildlife Society Bulletin, v. 24 , p. $50-52$.

White, G.C., Bartmann, R.M., Carpenter, L.H., and Garrott, R.A., 1989, Evaluation of aerial line transects for estimating mule deer densities: Journal of Wildlife Management, v. 53, p. $625-635$.
Wong, C., 1996, Population size estimation using the modified Horvitz-Thompson estimator with estimated sighting probabilities: Fort Collins, Colo., Colorado State University, Ph.D. Dissertation, $131 \mathrm{p}$.

Zeigenfuss, L.C., Singer, F.J., D. Bowden, D., 1999, Vegetation responses to natural regulation of elk in Rocky Mountain National Park: Denver, Colo., U.S. Government Printing Office, Biological Science Report USGS/BRD/BSR-1999-0003, 23 p.

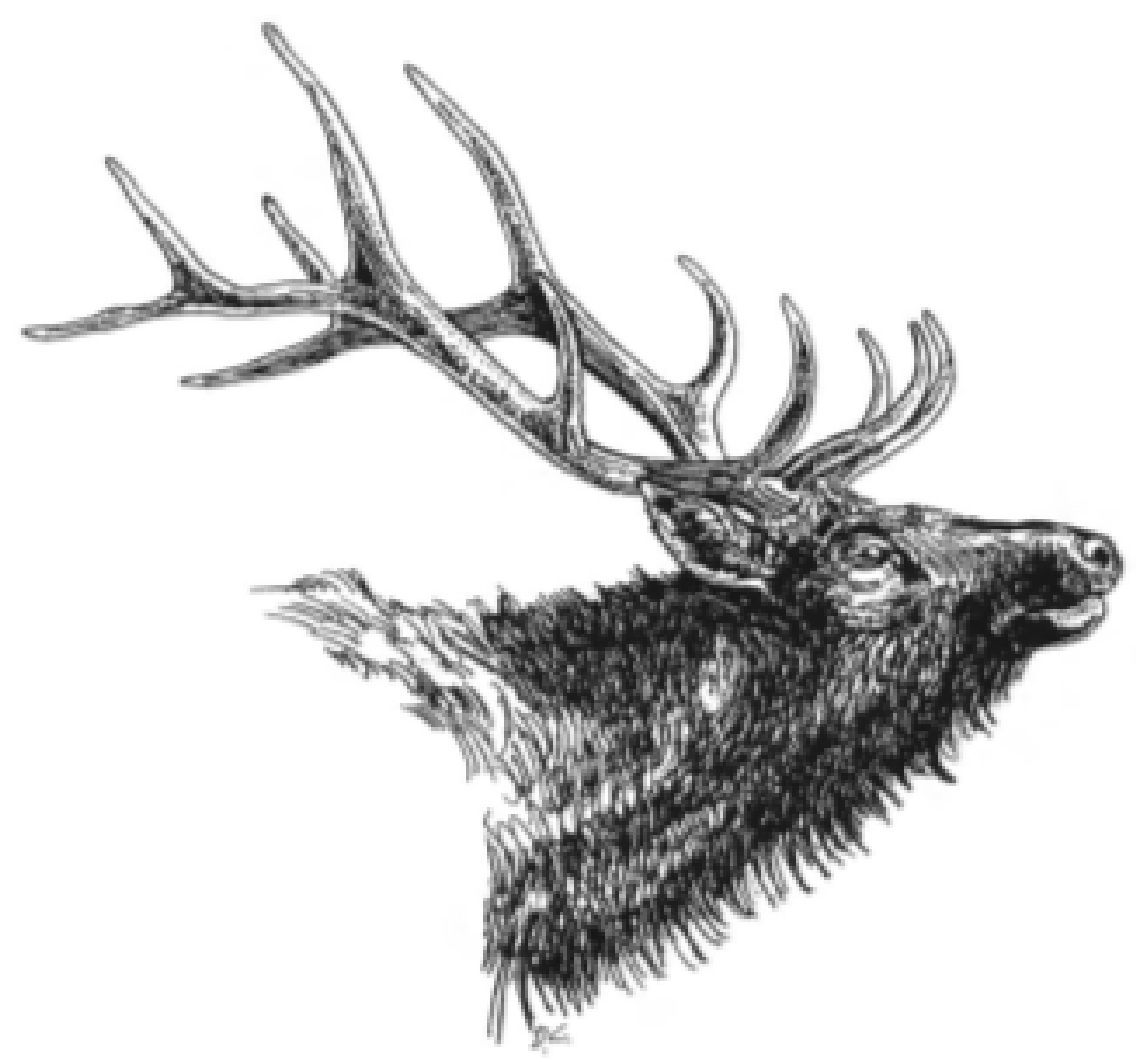

Publishing support provided by the Science Publishing Network, Denver Publishing Service Center

For more information concerning the research in this report, contact the Center Director, USGS Fort Collins Science Center

2150 Centre Ave., Bldg. C

Fort Collins, CO 80526-8118

(970) 226-9398

Or visit the Fort Collins Science Center website at

https://www.fort.usgs.gov/ 


\section{Appendix 1. Description of Aerial Survey Methods Considered for Elk Surveys in Rocky Mountain National Park, Colorado}

\section{Radio (Known-Fates) Mark-Recapture Method}

The mark-resight method using radio-marked animals is often considered the "gold standard" for population surveys (Seber, 1982; Bowden and Kufeld, 1995; White, 1996). The method is implemented by marking individual elk with radio collars. Surveys are then conducted by one group of observers, while another group independently locates each of the marked elk (or, more precisely, the groups containing these marked elk) utilizing radio telemetry, either from the ground or from the air. Subsequently, the two sets of locations are compared to determine which marked groups were seen and which were not seen by the aerial observers. These mark-resight data can then be analyzed in Program MARK using the known fates model structure. The major advantage of this approach is that sighting probabilities do not need to be homogeneous, because the marked groups have 100 percent sighting probability due to the radios. However, to meet model assumptions, the radios must be distributed randomly among all elk groups in the study area. In addition, to obtain precise estimates, either a large portion of the elk groups must be marked, or the survey must be conducted several times over a brief interval (short enough so that elk do not leave or enter the population over the course of the repeated surveys). This method requires that the radios be present and located each time a survey is done. The greatest obstacle to applying this method is the high cost and intrusiveness of placing radio collars on a sufficient sample of elk, especially given the requirement that they be randomly distributed across all elk present.

\section{Simultaneous Double-Observer Method}

The simultaneous double-observer method is another form of the broader methodology of mark-resight survey (Seber, 1982; Bowden and Kufeld, 1995; White, 1996). Specifically, the population is sampled simultaneously by two independent (typically aerial) observers and the numbers of elk seen by each observer and by both observers are used to estimate abundance (Cook and Jacobson, 1979; Seber, 1982; Pollock and Kendall, 1987; Bayliss and Yeomans, 1989; Graham and Bell, 1989; Daigle and others, 1995; Manly and others, 1996). The sample is obtained by having two observers record sightings in such a way that sightings of the same individual elk or groups can be determined concurrently or post hoc. Group size, location, and observation time are typically sufficient to determine whether the same group was detected by both observers. This method can easily be combined with a sampling of count units within the total area to be surveyed. The assumptions underlying this method are (1) the two observers are completely independentobservations by one cannot affect the other, (2) sighting probability varies only between the two observers and is not different for different animals or groups of animals, and (3) the population within a count unit remains relatively immobile during the duration of the survey so that animals neither leave nor enter the count unit or move so as to evade observation or be observed more than once. Advantages of this method include (1) no marked animals are needed and (2) a single survey can provide all of the data required for each population estimate. Sighting probability corrections are thus based on current observers and conditions.

\section{Distance Sampling Method}

Line-transect, or distance sampling, methodology uses distances from a transect line to observed animals or groups to correct for visibility bias that varies with distance from the observer (Burnham and Anderson, 1976; Buckland and others, 1993; Anderson and Southwell, 1995). Hundreds of applications of this technique have been published that cover a wide range of vertebrate and invertebrate animal species, as well as plants and other inanimate objects, in both terrestrial and marine ecosystems. Sampling can use varied observation platforms and vehicles, including manned and unmanned, powered and self-propelled, aerial, land surface, water surface, and underwater. The largest number of applications pertain to marine mammals and small terrestrial vertebrates, especially birds and mammals. Examples involving large terrestrial mammals include Gogan and others (1986), White and others (1989), Johnson and others (1991), Southwell (1994), and Trenkel and others (1997).

Line-transect surveys use a random or systematic sample of lines located within the study area. These lines do not need to be straight and, in fact, are often placed to follow natural contours such as elevation or shorelines. Surveys are conducted by following the selected lines and observing animals on and near the line. When animals are spotted, distances to these animals are measured and recorded, along with group size and animal activity. In aerial surveys, this can be done by leaving the line and going to the location where the animal was first observed and recording the location with a global positioning system receiver and data recorder. Distance can also be estimated without leaving the transect line by measuring sighting angle, altitude, and location. Three critical assumptions underlie this technique: (1) the measured distance from the observed animal to the transect line is estimated accurately, which implies that the exact location of both the 
observed animals and the transect line can be determined; (2) animals on or very near the line are sighted with certainty and those further from the line are sighted with smoothly decreasing probability; and (3) observed locations of animals are not systematically influenced by the approach of the survey team. In other words, detection occurs before any animal movement toward or away from the transect line.

Distance sampling theory is based on sampling with replacement, which has several important consequences. A positive consequence is that there is no requirement that the entire survey area be observed; a random sample of distances is all that is required, so groups may be counted multiple times but other groups are never approached closely enough to have any chance of being seen. However, a downside of this method is that large sample sizes are typically required to gain the same precision provided by other methods. This method is often the most efficient when the population of interest is large and dispersed over vast areas.

\section{Sightability Bias Correction Method}

The sightability bias correction method is a two-phase approach (Samuel and Pollock, 1981; Samuel and others, 1987; Steinhorst and Samuel, 1989; Unsworth and others, 1994; Bodie and others, 1995; Wong, 1996). During the first phase, a model of sighting probability as a function of various covariates is developed using surveys of known individuals or groups of animals. These can be animal groups under constant surveillance by ground observers or radio-marked groups. The model provides an estimate of the probability that a given animal or group is observed, given the covariates associated with each group. Typically, these covariates include group size, some measure of potentially concealing cover or habitat, weather and lighting conditions, and possibly observer location and experience. The model most often used is a logistic regression model of these covariates against the dichotomous variable, that is, seen versus not seen. Data for this model are obtained by observing (or failing to observe) a series of animals that are independently under observation by other observers. Once the model is developed, it is then applied to subsequent surveys to estimate population size by adjusting the number of observed animals to account for those that were unobserved. Survey areas can be subdivided into count units to facilitate counting, and these count units can be sampled to reduce survey effort, but at the cost of reduced precision.

Sightability models have been developed primarily for large mammals. The critical assumptions of the method are (1) the conditions measured during the model calibration remain the same when the model is applied - in other words, the sighting probability function does not change over time, observers, or locations; (2) animal movement during the duration of the survey does not cause animals to systematically leave or enter count units in response to the observer or to be counted more than once; (3) an adequate sample size is obtained for model calibration; (4) the known groups under independent observation during calibration are a random sample of all groups in the study area; (5) a logistic model fits the data well; (6) sighting probabilities are relatively large (greater than 30 percent) under all conditions so that no animal groups have very low probability of being sighted; and (7) all covariates are measured accurately, especially the size of each group.

\section{Hybrid Methods}

The above methods can be used in several combinations to produce hybrid methods. The distinct advantage of this approach is that any limitations of a single method can often be largely overcome by combining it with a complementary second method.

The theory to integrate the several techniques described above into a single methodology has been under development. This work was pioneered by Manly and others (1996) and Borchers and others (1998a, b) and is partially supported by software (Thomas and others, 2010). This method is a hybrid version of distance sampling that incorporates sighting covariates and a double-observer method. Under this approach, line transects are surveyed; however, covariates in addition to distance are recorded, and multiple observers are used to obtain independent simultaneous counts. Thus, in a single pass, a model that factors in sightability covariates and distance can be fitted and used to estimate population. In addition, this single dataset can be analyzed by several of the other methods by disregarding the supplemental data, so the hybrid method can be compared to the results of any of the single methods, all using the same dataset collected on a single survey.

The strength of this method is that multiple sources of data serve to offset the deficiencies inherent in each of the individual methods when used alone. For example, sightability bias correction models rely on a single calibration period and the implausible assumption that a fixed model is applicable in the future without further updating or ongoing validation. However, using a double-observer platform enables the calibration of the sightability model to be updated with new data from each survey. Another example of the complementary nature of the hybrid technique is the requirement in a simple double-observer survey for all groups to have similar sighting probabilities, which is never met in reality; some groups, due to their size or location, are inherently much more or less visible than others. However, use of sightability covariates helps to overcome these differences by modeling them explicitly; adding distance sampling can provide information to ameliorate this difficulty. Finally, the requirement in distance sampling that all groups be sighted on and near the transect line is not required when the probability of sighting within this first distance category can be estimated through double observer, sightability corrections, or both.

A simpler hybrid technique combines only the simultaneous double-observer method with sighting covariates. This approach avoids the need to meet the stringent conditions for distance sampling. The heterogeneity problems of a simple double-observer method can be addressed with the sighting 
covariates. The static nature of the sightability calibration method is overcome by the ongoing enhancement of the dataset with new sightability data from each survey. The theory for this approach is largely drawn from Huggins (1991). An extension of this approach can also incorporate radio-marked animals in addition to the simultaneous double-observer and sighting covariates. Incorporating this additional source of data helps to evaluate the effectiveness of the heterogeneity bias corrections by the sighting covariates and potentially provides the information to correct any residual bias. 


\section{Appendix 2. Discussion of Considerations for Aerial Work in Rocky Mountain National Park, Colorado}

For this study, we initially proposed to conduct surveys four times per winter over 2 years to accumulate sufficient data for fitting sightability models and to test methods, but more importantly, to observe and measure the patterns of elk population fluctuation in Rocky Mountain National Park (RMNP). It became clear that this would not be possible due to constraints on flight time from frequent high winds and poor visibility throughout the winter, with occasional 1-day windows of suitable flying weather. Suitable flight days were mostly timed directly after a large storm system had moved through the area the night before, and before winds usually picked up the next day (the survey day) by 1300-1400. In order to complete our surveys during this short window, there was a substantial "on-call" status all winter long required of research personnel (National Park Service resource management, National Park Service aviation safety team, observers from the U.S. Geological Survey, National Park Service, Colorado Parks and Wildlife, and others) and vendors (both fixed-wing and helicopter companies), which was not always feasible. Some cautions and considerations in conducting aerial missions in RMNP include:

1. Environmental factors

a. Wind and high elevation. Surveys were limited by high winds and severe winter conditions more than any other factor. The alpine tundra was the most difficult to access on most survey days. By early afternoon after we completed the core elk winter range, winds had usually picked up enough to preclude flying over the alpine tundra. We were able to survey the alpine tundra during only two of five surveys.

b. Stormy conditions. Precipitation, and especially low cloud cover or cloud ceiling, prevented aerial activity, especially fixed-wing aircraft activity. On occasion, a storm moved in after the survey had started and we were forced to cancel the survey before it was completed.

c. High mountainous and rugged terrain. This required aircraft to climb and descend often, sometimes approaching safety boundaries.

2. Sighting conditions

a. Difficult sighting conditions in low and patchy snow cover. Low heterogeneity in sighting conditions could not be matched to good flying conditions because contiguous snow cover and low wind rarely occur simultaneously.

\section{Elk behavior and habitat use}

a. Few observations obtained per survey. Most elk in RMNP during winter cluster into a few very large groups. Typically only 10-12 elk groups are observed per flight, in which each elk group constitutes one data point. Consequently, it takes many surveys to obtain a sample size sufficient for rigorous model development.

b. Undercounting of bull elk. In a study of elk in tree cover, cow elk were more than nine times more likely than bulls to be seen in helicopter surveys (McCorquodale, 2001). Bull elk are more likely to be undercounted during aerial surveys because they are segregated from cow/calf groups in winter, tend to be in higher elevation habitat, stay in the trees when aircraft fly over, and are in smaller groups or alone. Our models attempt to correct for these differences by taking vegetation and group size into account in predicting sighting probability, but the models may not fully address disparate detection between the sexes.

4. Logistics

a. Finding available vendors was a significant challenge to conducting aerial surveys, second only to wind. We had considerable difficulty finding qualified vendors. Personnel from Aviation Management Directorate informed us that there were almost no Lama helicopter models in the Federal fleet, and this specific helicopter is needed for high elevation flying in RMNP. Helicopter vendors are phasing out the Lama model due to difficulty in maintenance and finding parts, and it is being replaced by the A-Star. Although appropriate for high elevation rugged terrain, the A-Star has substantially decreased visibility with much smaller windows and solid/opaque surfaces (as opposed to clear) across the lower part of the aircraft. Finding fixed-wing vendors was also a challenge. Fixed-wing pilots typically had other, larger contracts with State agencies (for example, Colorado Parks and Wildlife or Wyoming Game and Fish Department) and these contracts were prioritized on good weather days and our project (which needed only 3-4 flights/year) received low priority. No replacement vendors were available within a reasonable distance. Aviation Management Directorate carding delays, as well as aircraft maintenance, also postponed flights. 
b. Helicopter pilots initially had difficulty following transect lines and underwent a steep learning curve during the study. Fixed-wing pilots could not always collect the needed covariates, such as group size, due to their flight altitude.

c. Scheduling a fixed-wing aircraft and pilot, an available Lama and pilot, a RMNP helicopter manager, and three observers usually from three different agencies, and obtaining a good-weather day to fly, required immeasurable patience and daunting efforts in coordination. To simultaneously select a day with good sighting conditions (that is, not patchy snow) proved nearly impossible. 


\section{Appendix 3. Instructional Protocols and Datasheets for Simultaneous Double-Observer Aerial Surveys in Rocky Mountain National Park, Colorado}

\section{Field Protocols for Simultaneous Double- Observer Aerial Elk Surveys}

The simultaneous double-observer method is a form of mark-resight abundance estimator in which the observations by the front seat observer are considered one independent survey (the "mark"), and the rear observer acts as a second independent survey (the "resight"). Therefore, no communication, visual or verbal, can occur between front and rear observers until after both observers have had adequate opportunity to detect independently each elk group. The front observer must wait until the elk group is completely aft of the aircraft to be sure the rear observer has an adequate chance to see the group before calling it out. If the pilot spots an elk group, the pilot can nonverbally identify it to the front observer, so that the rear observer(s) is not alerted. Usually a group is circled to obtain a better count or classification to age and sex. Once a group has been identified and the observers who saw it independently have recorded their observations, all crew members can participate in the count, record sighting covariates, and take digital photographs of the group for more careful recounting after the flight. The helicopter pilot gently pushes elk groups away from future transect lines to avoid recounting the same group.

A "group" is considered to be one or more individual animals that are close enough together so that spotting any part of the group leads to locating the entire group. When a group is spotted, observers record (1) the size of the group, (2) the vegetation type and percent canopy cover as described by Unsworth and others (1994), (3) whether the group was moving or not when first spotted, (4) which observers in the aircraft saw the group and their positions in the aircraft, (5) where the elk group was located relative to the aircraft (right, left, or centerline), (6) the percent snow cover in the patch where the group was first observed, (7) the time of the observation, (8) the presence and number of radio-collared elk in the group, and (9) the global positioning system location. A photo is taken of groups of more than 10 individuals to confirm or adjust aerial counts. Datasheets for helicopter surveys and fixed-wing surveys are provided in this instructional protocol. Several observers can record data to compare, or the datasheet can be split among observers so one records sighting covariates, another records elk numbers and classifications, and the third observer obtains a waypoint for each elk group. The helicopter should fly predetermined transect lines developed for Rocky Mountain National Park in this study (see figs. 4 and 5) so observers can remain focused on searching for elk groups.

The flight forms used for data collection are presented below. The abbreviations used in the forms are: ROMO, Rocky Mountain National Park; AGL, above ground level; $\mathrm{ft}$, foot; $\mathrm{mph}$, mile per hour; $\mathrm{km} / \mathrm{hr}$, kilometer per hour; $\mathrm{LF}$, left front; RF, right front; LR, left rear; RR, right rear; grp, group; no., number; hh, hour; mm, minute; GPS, global positioning system; wypt, waypoint; A/C, aircraft; obs, observers; veg, vegetation; $\mathrm{L}$, left of transect; $\mathrm{R}$, right of transect; C, centerline; B, both; A, active; N, not active; O, open; S, shrub; $\mathrm{T}$, tree. 


\section{Sample Datasheets}

ROMO Aerial Elk Survey Information

Date of Survey:

$\underline{\text { Observer } 1}$

Name Agency

E-mail Telephone

Observer 2

Name Agency

E-mail Telephone

Observer 3

Name Agency

E-mail Telephone

Pilot

Name Company

Office Address

E-mail Telephone

Aircraft

Type (helicopter/fixed wing)

Planned altitude AGL $\mathrm{ft}$

Planned air speed ___ statute $\mathrm{mph} /$ nautical $\mathrm{mph} / \mathrm{km} / \mathrm{hr}$ (circle one)

General comments: (conditions that might affect observer's ability to spot elk or the number counted. Examples: general weather, lighting, and sky conditions; description of sun, clouds, shadows, visibility, turbulence during flight, gusty conditions, etc. Include lighting condition changes during survey if possible ["started cloudy, became sunny in early afternoon"]). 
ROMO Aerial Elk Survey_HELICOPTER

(Start a new datasheet for each leg of flight; each time you takeoff)

Date:

Page of . Observer positions in aircraft (LF, RF, LR, RR; use initials):

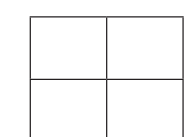

Survey segment start time: Segment End time:

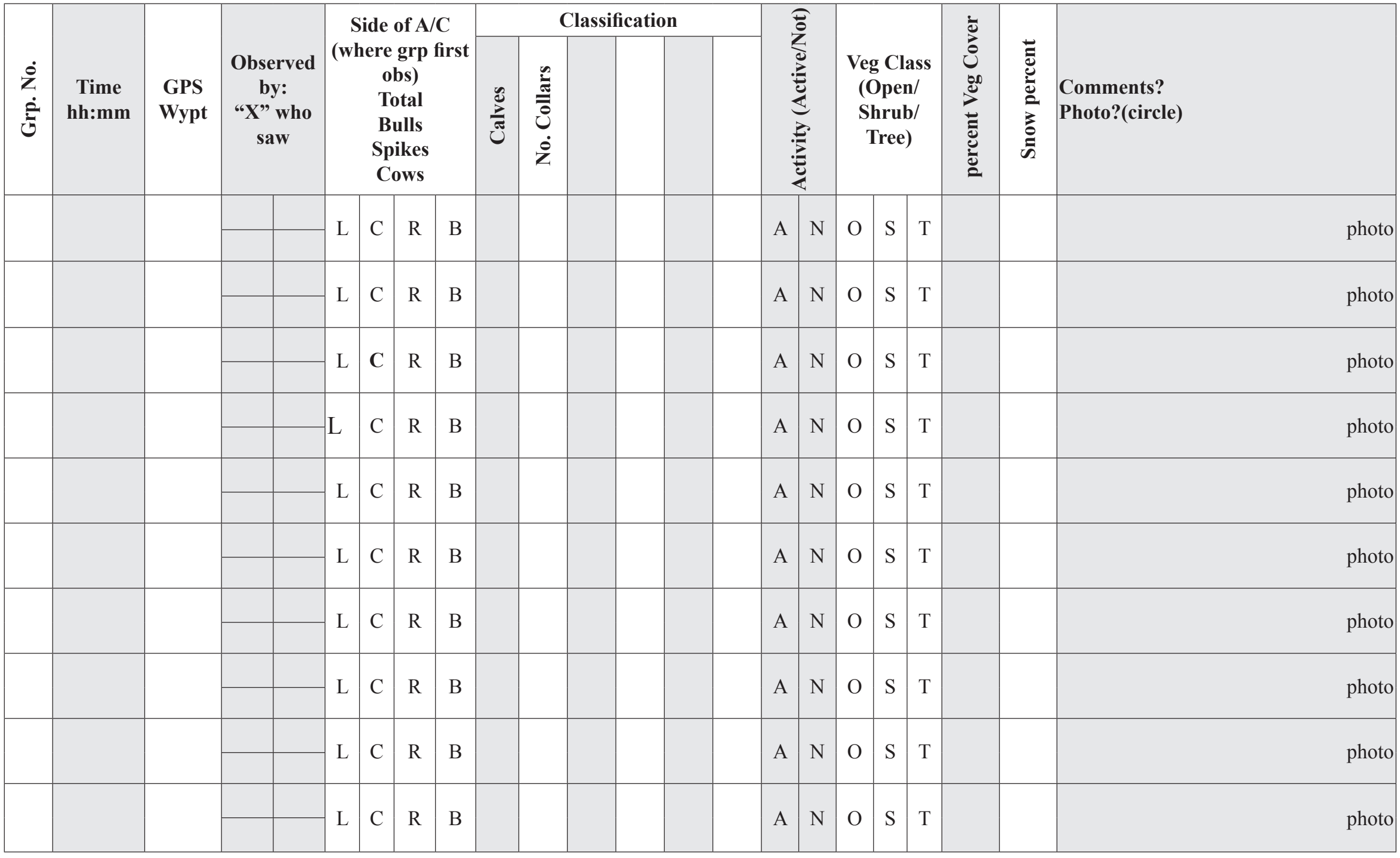


1. Use a new datasheet each time you start a new leg of the survey flight, so observer position is updated in the squares at the top, and it is clear that you stopped to refuel, for example. It's important that observer position on each segment of the survey is clear.

2. All observers should search for horses or burros with equal effort (not one recording while others search). Ok to divide datasheet between observers.

3. Use a reliable GPS unit to record each elk group location separately, and call out the waypoint to the other observers. The waypoint is the reference number for that group. It will also have the timestamp for each group.

\section{Codes:}

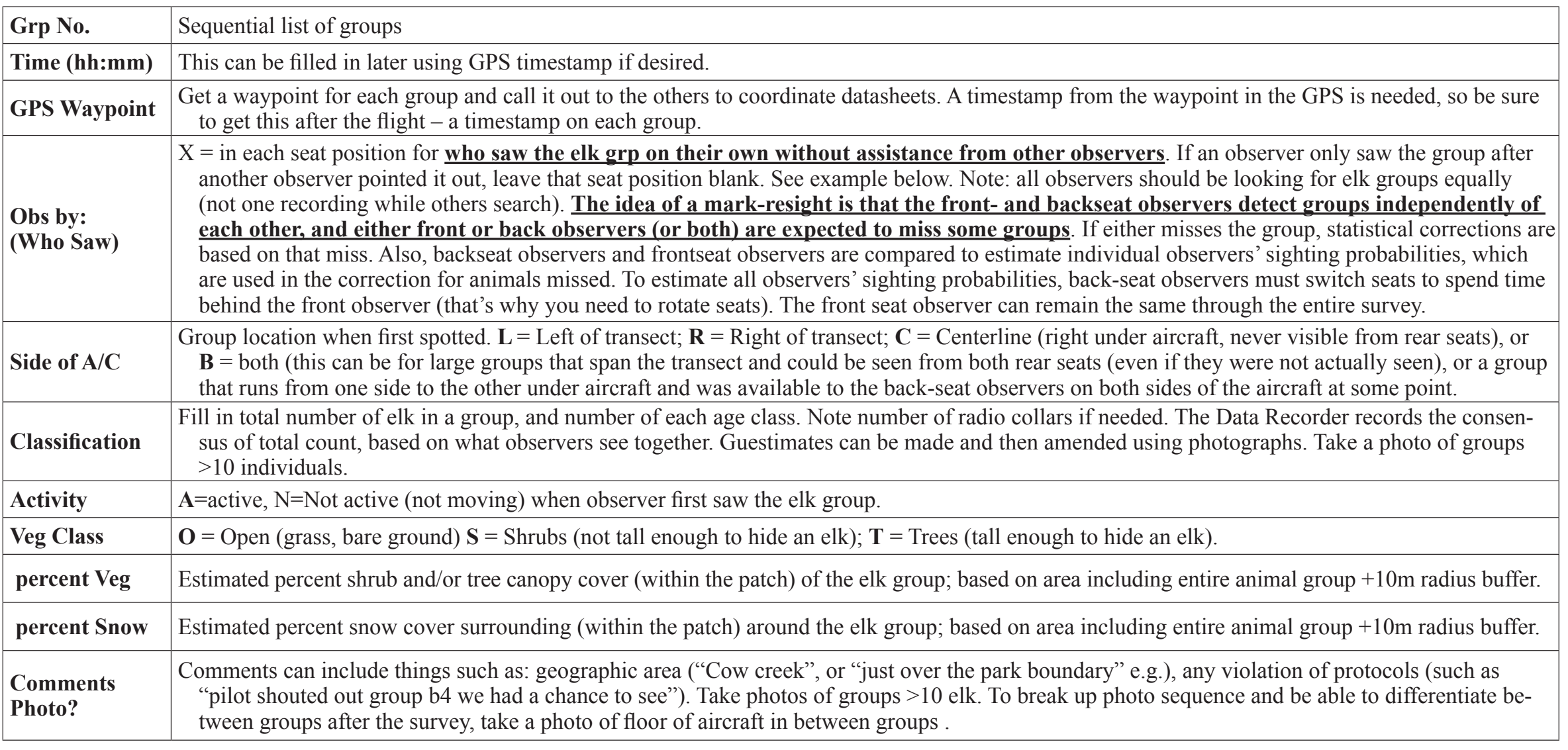

\section{Example: Front of aircraft}

\begin{tabular}{|c|l|}
\hline$X$ & \\
\hline$X$ & \\
\hline
\end{tabular}

\section{$\leftarrow$ Pilot seat}

(In this example, the two left side observers both saw the group independently, while neither pilot nor back-right observer saw the group) 


\section{ROMO Aerial Elk Survey Data Sheet_FIXED WING}

Date: ___ Observer(s) and Position in Aircraft:

\begin{tabular}{|c|c|c|c|c|c|c|c|c|c|c|c|c|}
\hline Grp. Number & Collar Frequency & Time hh:mm & $\begin{array}{l}\text { GPS Waypt } \\
\text { No. }\end{array}$ & $\begin{array}{l}\text { Total Count (small } \\
\text { Groups only) }\end{array}$ & & 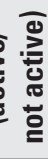 & & Cla & & 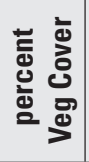 & 莺 & Comment \\
\hline 1 & & : & & & A & $\mathbf{N}$ & 0 & $\mathbf{S}$ & $\mathbf{T}$ & & & \\
\hline 2 & & : & & & A & $\mathbf{N}$ & 0 & $\mathbf{S}$ & $\mathbf{T}$ & & & \\
\hline 3 & & : & & & A & $\mathbf{N}$ & 0 & $\mathbf{S}$ & $\mathbf{T}$ & & & \\
\hline 4 & & : & & & A & $\mathbf{N}$ & 0 & $\mathbf{S}$ & $\mathbf{T}$ & & & \\
\hline 5 & & : & & & A & $\mathbf{N}$ & 0 & $\mathbf{S}$ & $\mathbf{T}$ & & & \\
\hline 6 & & : & & & A & $\mathbf{N}$ & 0 & $\mathbf{S}$ & $\mathbf{T}$ & & & \\
\hline 7 & & : & & & A & $\mathbf{N}$ & 0 & $\mathbf{S}$ & $\mathbf{T}$ & & & \\
\hline 8 & & : & & & A & $\mathbf{N}$ & 0 & S & $\mathbf{T}$ & & & \\
\hline 9 & & : & & & A & $\mathbf{N}$ & 0 & $\mathbf{S}$ & $\mathbf{T}$ & & & \\
\hline 10 & & : & & & A & $\mathbf{N}$ & 0 & $\mathbf{S}$ & $\mathbf{T}$ & & & \\
\hline
\end{tabular}




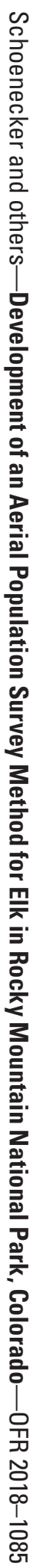

